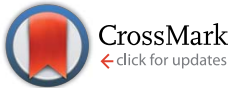

Cite this: RSC Adv., 2017, 7, 2682

Received 6th October 2016 Accepted 14th November 2016

DOI: $10.1039 / c 6 r a 24823 c$

www.rsc.org/advances

\title{
Synthesis, utility and medicinal importance of 1,2- \& 1,4-dihydropyridines
}

\begin{abstract}
Vivek K. Sharma ${ }^{a}$ and Sunil K. Singh*b
Dihydropyridine (DHP) is among the most beneficial scaffolds that have revolutionised pharmaceutical research with unprecedented biological properties. Over the years, metamorphosis of easily accessible 1,2- and 1,4-dihydropyridine (1,4-DHP) intermediates by synthetic chemists has generated several drug molecules and natural products such as alkaloids. The 1,4-dihydropyridine (1,4-DHP) moiety itself is the main fulcrum of several approved drugs. The present review aims to collate the literature of 1,2and the 1,4-DHPs relevant to synthetic and medicinal chemists. We will describe various methodologies that have been used for the synthesis of this class of compounds, including the strategies which can furnish enantiopure DHPs, either by asymmetric synthesis or by chiral resolution. We will also elaborate the significance of DHPs towards the synthesis of natural products of medicinal merit.
\end{abstract}

\section{Introduction}

Arthur Hantzsch added one of the most valuable scaffolds to the toolbox of medicinal chemists, reporting the synthesis of dihydropyridine (DHP) in 1882. Among five possible regioisomers only 1,2- and the 1,4-DHP (Fig. 1) have gained significant attention. The 1,4-DHP scaffold has served as a nucleus for several blockbuster drugs such as nifedipine and amlodipine. ${ }^{1}$ Close resemblance to nicotinamine adenine dinucleotide $(\mathrm{NADH})$ coenzyme, which has an important role in biological

${ }^{a}$ RNA Therapeutics Institute, University of Massachusetts Medical School, Worcester, MA 01605, USA

${ }^{b}$ Department of Chemistry, Kirori Mal College, University of Delhi, Delhi-110007, India. E-mail: chem.sunil@gmail.com

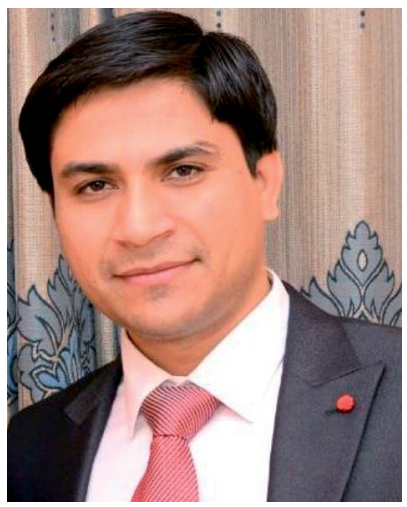

Vivek received his $P h D$ degree in Chemistry in 2014 from University of Delhi, India. Currently he is working as Postdoctoral Fellow at RNA Therapeutics Institute, University of Massachusetts Medical School, USA. His current research interests include development of low-cost microfluidic gene synthesis, to improve in vivo delivery of peptide nucleic acid (PNA), and study the effect of neutral linkage between conformationally locked nucleotides for gene silencing applications. oxidation-reduction reactions, has made the 1,4-DHP core even more lucrative. Perhaps less studied in the past, the potential of 1,2-dihydropyridines has recently been explored as a critical scaffold for the synthesis of alkaloids and other drugs. 1,2-DHPs are now popular as a precursor for the synthesis of the 2-azabicyclo[2.2.2] octanes (isoquinuclidines) ring system present in alkaloids, ibogaine and dioscorine. The anti-influenza drug, oseltamivir phosphate (Tamiflu), is also synthesised from 1,2DHP via an isoquinuclidine intermediate (Fig. 1). ${ }^{2}$

Recently, we reviewed reactions of 1,2- and the 1,4-dihydropyridines. ${ }^{3 a}$ The present manuscript aims to highlight the importance of 1,2- and the 1,4-dihydropyridines relevant to both synthetic and medicinal chemists. We will describe various methodologies that have been used for the synthesis of this class of compounds. We then focus on strategies which can

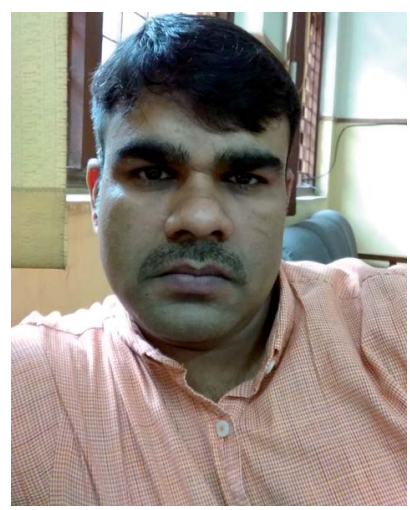

Sunil K. Singh has obtained his M.Sc and PhD in Chemistry from University of Delhi. He is currently working as Assistant Professor in Chemistry Department at Kirori Mal College (A constituent college), University of Delhi. His current research works include multicomponent synthesis and biocatalysis. He has 17 research publications in his credit. 


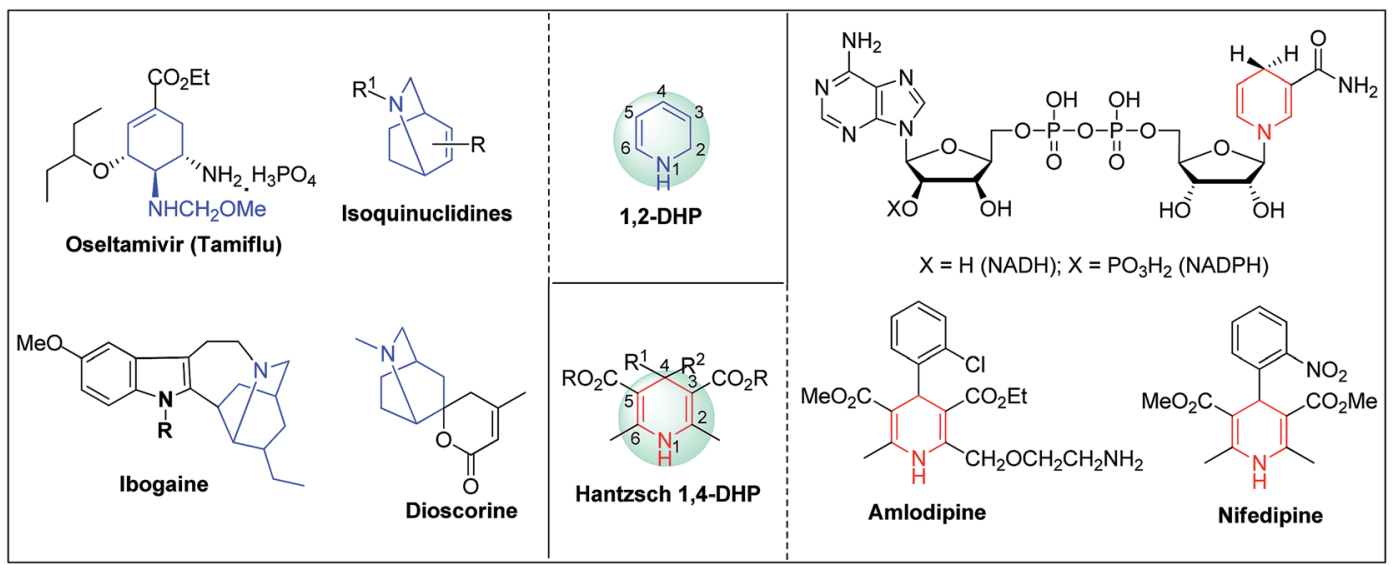

Fig. 1 Structures of 1,2-DHP, Hantzsch 1,4-DHP, NADH/NADPH and some medicinally important compounds/cores accessible from DHPs.

furnish enantiopure DHPs, either by asymmetric synthesis or by chiral resolution. We will also spotlight the utility of DHPs towards the synthesis of natural products of medicinal merit. In

$$
\begin{array}{r}
\text { Temperature } \\
\begin{array}{ccc}
\text { Organic Solvents, } \\
\text { THF, } 0-10^{\circ} \mathrm{C} & 60-65 \% & 40-35 \% \\
\hline \mathrm{CH}_{3} \mathrm{OH},-70^{\circ} \mathrm{C} & 86-88 \% & 2-4 \%
\end{array}
\end{array}
$$

Scheme 1 Synthesis of 1,2- and 1,4-dihydropyridines 1 and 2 by reduction of pyridine using $\mathrm{NaBH}_{4}$.

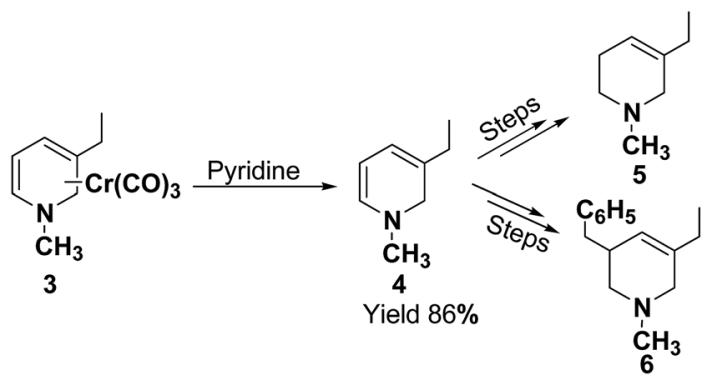

Scheme 2 Dihydropyridine 4 generated from precursor chromium complex 3 .
2002, Rodolfo Lavilla compiled the synthesis, reactivity, and applications of DHPs in medicinal chemistry. ${ }^{3 b}$

\section{Synthesis of dihydropyridines}

Substituted dihydropyridine are usually prepared either by the cyclization reactions (Hantzsch ring closure) or by reduction of pyridinium ions. The reviews by Eisner and Kuthan, ${ }^{3 c}$ and Stout and Meyers ${ }^{3 d}$ covers the chemistry of DHPs from early development till 1982. Beside these, R. Lavilla ${ }^{3 b}$ in 2002 and Silva, et $a l .^{3 e}$ in 2013 also compiled the literature for the synthesis of DHPs.

\subsection{Synthesis of 1,2-dihydropyridine}

In 1972, Fowler et $a .^{4}$ reported the synthesis of both $N$ carbomethoxy-1,2- and 1,4-dihydropyridine by treating a mixture of pyridine and sodium borohydride with methyl chloroformate in various organic solvents like, ether, glyme, THF, methanol and water. They observed that reaction in THF at $0{ }^{\circ} \mathrm{C}$ gave a mixture of dihydropyridines containing about $35-40 \%$ of 1,4-dihydropyridine along with the 1,2-dihydropyridine. However, the amount of 1,4-isomer can be reduced to $2-4 \%$ by performing the reaction in methanol at $-70{ }^{\circ} \mathrm{C}$ giving $1,2-\mathrm{DHP}$ in $86-88 \%$ yields (Scheme 1).

Kutney, et $a .^{5}$ have described the synthesis of novel and stable chromium complex of $N$-methyl-3-ethyl-1,2-
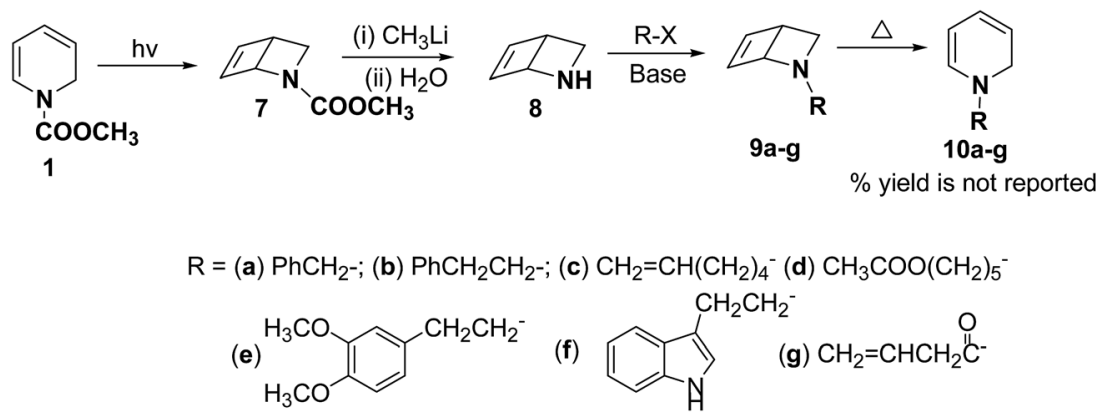

(c) $\mathrm{CH}_{2}=\mathrm{CH}\left(\mathrm{CH}_{2}\right)_{4}^{-}$(d) $\mathrm{CH}_{3} \mathrm{COO}\left(\mathrm{CH}_{2}\right)_{5}^{-}$

(f)<smiles>Clc1c[nH]c2ccccc12</smiles>

(g) $\mathrm{CH}_{2}=\mathrm{CHCH}_{2} \mathrm{C}^{-}$

Scheme 3 Synthesis of $N$-substituted 1,2-dihydropyridines $10 \mathrm{a}-\mathrm{g}$ 
dihydropyridine. This metal carbonyl complex 3 has been used for the synthesis of essentially pure $N$-methyl-3-ethyl-1,2dihydropyridine $\mathbf{4}$, which can be used as a precursor to synthesize a number of useful heterocyclic compounds such as 5 and 6 (Scheme 2).

Beeken, et $a l .{ }^{6}$ have developed a synthetic methodology for the synthesis of 1,2-dihydropyridines $\mathbf{1 0 a}-\mathbf{g}$ via 2-azabicyclo [2.2.0] hex-5-ene $\mathbf{8}$ as a synthetic equivalent. The amine $\mathbf{8}$ was conveniently synthesized by methyl lithium mediated hydrolysis of carbamate derivative of 1,2-dihydropyridine 7 which in turn was photochemically synthesized from compound $\mathbf{1}$. Alkylation and acylation of amine $\mathbf{8}$ has lead to the formation of 9a-g which were easily isolated. The alkylated/acylated analogues 9a-g were converted into the corresponding 1,2dihydropyridines $\mathbf{1 0 a}-\mathbf{g}$ under thermal heating condition (Scheme 3).

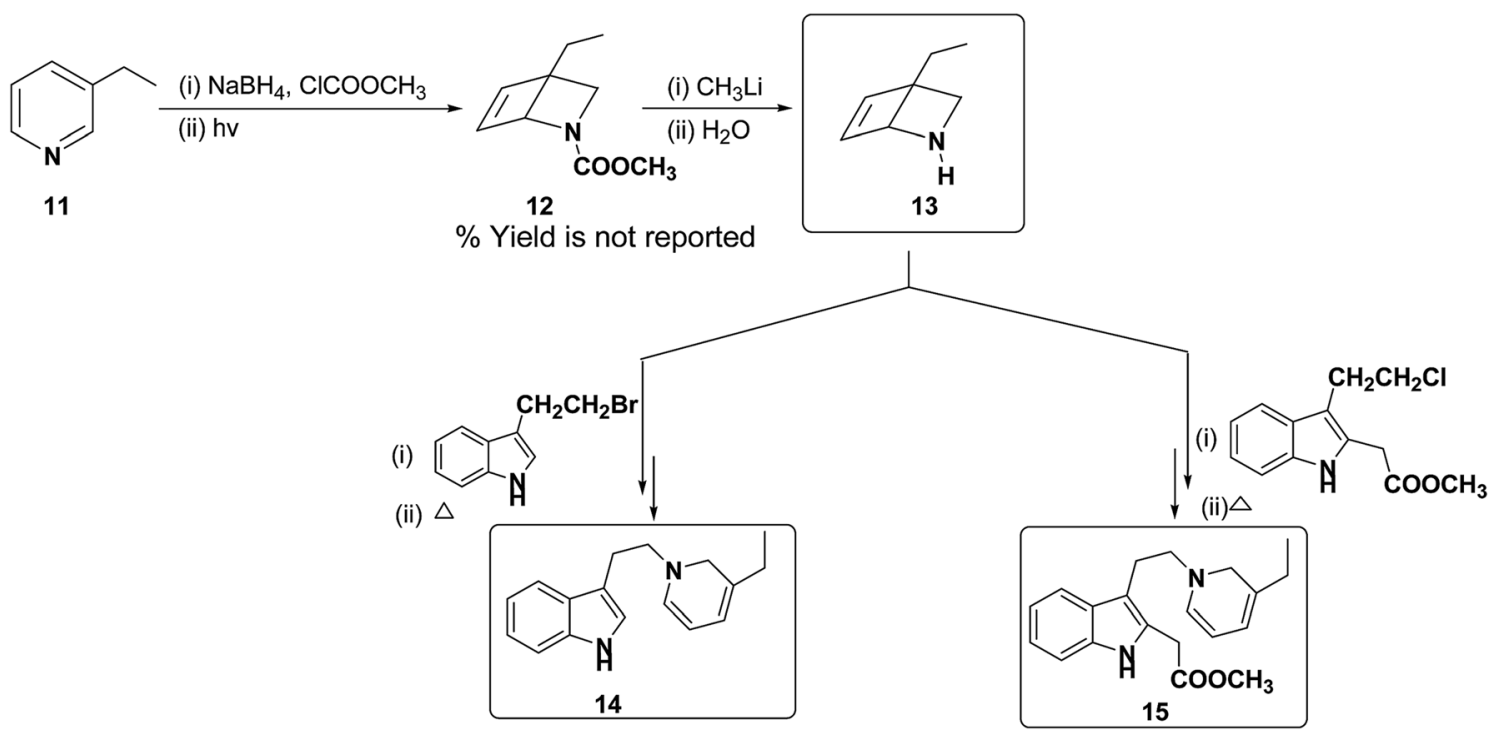

Scheme 4 Synthesis of 1,2-dihydropyridines 14 and 15 from 3-ethyl pyridine 11.

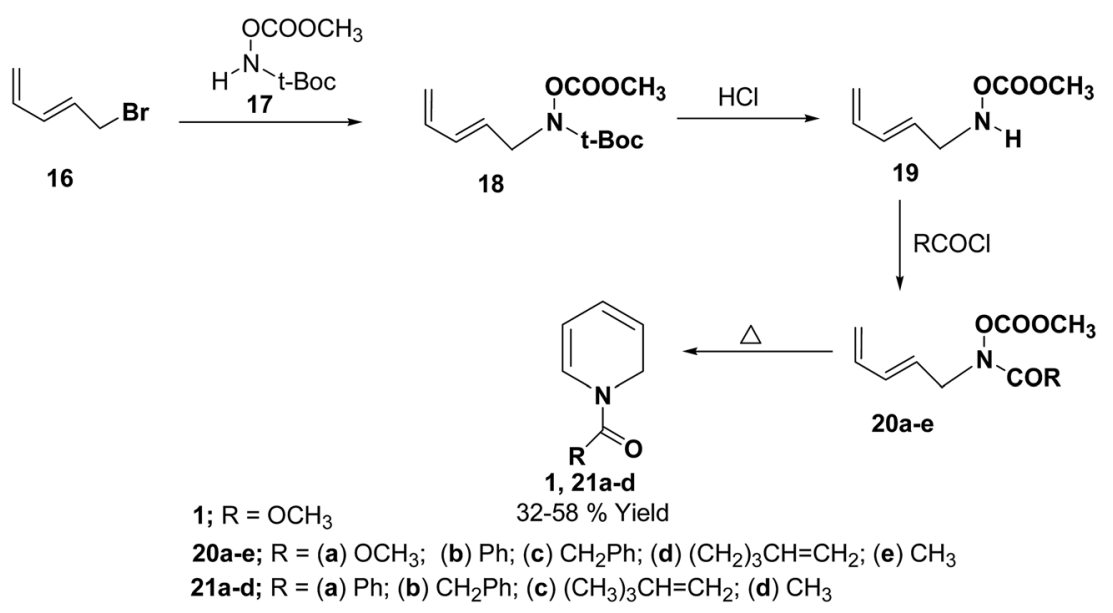

Scheme 5 Synthesis of 1,2-dihydropyridines 1, 21a- $d$ by thermal cyclisation of hydroxamic acid derivatives.

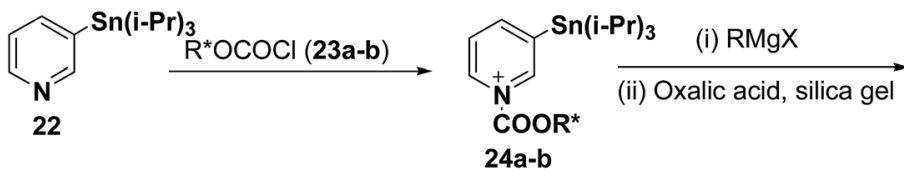

23a, 24a; $R^{*}=(-)-8-(4-$ phenoxyphenyl)menthol

23b, 24b; $R^{*}=(-)-8-$ phenyl-menthol

Scheme 6 Asymmetric synthesis of 1-acyl- $\alpha$-alkyl-1,2-dihydropyridines 25 and 26. 
Further, Fowler et al. have successfully prepared dihydropyridines 14 and 15 from 3-ethyl pyridine 11 (Scheme 4). 3Ethyl pyridine 11 was first converted into $N$-carboxymethyl amine 12 using $\mathrm{ClCOOCH}_{3}$ and sodium borohydride, which on hydrolysis yield amine 13. This method is significantly important as it can be applied to relatively more complex 1,2-DHP structures which may serve as an intermediate for the synthesis of alkaloids, e.g. compound $\mathbf{1 5}$ is an intermediate in a biomimetic synthesis of Strychnos alkaloids.

Fowler, et al. ${ }^{7}$ has synthesized the 1,2-dihydropytidines $\mathbf{1}$, $\mathbf{2 1 a}-\mathbf{d}$ by the thermal cyclisation of hydroxamic acid esters $\mathbf{2 0}$. Reaction of the hydroxamic acid ester 17 with 5-bromopenta1,3-diene 16 gave the compound 18. The removal of $t$-Boc protecting group from compound $\mathbf{1 8}$ followed by acylation with various acid chlorides gave the hydroxamic acid derivatives 20. Evaporation of these hydroxamic acid derivatives through a hot tube gave the 1,2-dihydropyridines 1, 21a-d as the only isolable products in 32 to $58 \%$ yields (Scheme 5 ).

2-Substituted-1,2-dihydropyridine analogues are useful intermediate for the synthesis of natural products such as piperidine, indolizidine, quinolizidine and cis-decahydroquinoline alkaloids. Comins, et al. ${ }^{8}$ have reported the asymmetric synthesis of 2-substituted-1,2-dihydropyridines 25 \& 26 from $N$-acyl pyridinium salt $\mathbf{2 4}$, which was synthesized via the addition of 3-(triisopropylstannyl)pyridine 22 to an enantiopure chloroformate 23a-b derived from (-)-8-(4-phenoxyphenyl)menthol or (-)-8-phenyl-menthol. The reaction of $N$ -

Table 1 Synthesis of 1-acyl-2-alkyl-1,2-dihydropyridines 25 and 26

\begin{tabular}{llllll}
\hline Entry & R*OCOCl & RMgX & Product & Yield\% & de \\
\hline 1 & 23a & $n$-PrMgCl & 25a & 72 & 82 \\
2 & 23b & $n$-PrMgCl & 25b & 81 & 78 \\
3 & 23a & $n$ - HexMgCl $^{*}$ 25c & 81 & 91 \\
4 & 23a & PhCH ${ }_{2} \mathrm{MgCl}$ & $\mathbf{2 5 d}$ & 58 & 76 \\
5 & 23a & VinylMgBr & $\mathbf{2 5 e}$ & 71 & 90 \\
6 & 23a & PhMgCl & $\mathbf{2 5 f}$ & 85 & 89 \\
7 & 23b & PhMgCl & $\mathbf{2 5 g}$ & 87 & 84 \\
8 & 23a & $p$-MePhMgBr & $\mathbf{2 5 h}$ & 86 & 92
\end{tabular}

acyl pyridinium salt $\mathbf{2 4}$ with different Grignard reagents followed by treatment of the reaction mixture with silica gel containing oxalic acid provided chiral 1,2-dihydropyridines 25 and 26 (Scheme 6, Table 1).

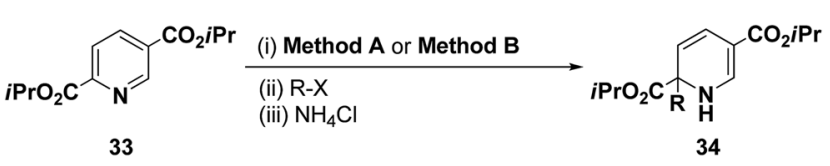

Method A: $\mathrm{Na}$ ( 3.5 equiv), $\mathrm{NH}_{3} / \mathrm{THF},-78^{\circ} \mathrm{C}$

Method B: $\mathrm{Na}$ ( 3.5 equiv), naphthalene (5 equiv), THF, $-78^{\circ} \mathrm{C}$

Scheme 8 Reduction of electron deficient pyridine 33: preparation of 1,2-dihydropyridines 34 .

Table 2 Reduction of pyridine 33 by using method A or B and their alkylation $^{a}$

\begin{tabular}{lllll}
\hline Entry & R-X & R & Method & Yield (\%) \\
\hline 1 & MeI & Me & A & 99 \\
2 & MeI & Me & B & 86 \\
3 & EtI & Et & A & 98 \\
4 & EtI & Et & B & 78 \\
5 & iBuI & iBu & A & 93
\end{tabular}

$6 \quad$ Epibromohydrin

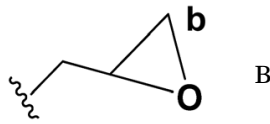

84

$\begin{array}{lllll}7 & \text { Allyl-Br } & \text { Allyl }^{\mathrm{c}} & \text { A } & 90 \\ 8 & \mathrm{I}\left(\mathrm{CH}_{2}\right)_{3} \mathrm{Cl} & \left(\mathrm{CH}_{2}\right)_{3} \mathrm{Cl} & \text { A } & 96 \\ 9 & \mathrm{I}\left(\mathrm{CH}_{2}\right)_{3} \mathrm{Cl} & \left(\mathrm{CH}_{2}\right)_{3} \mathrm{Cl} & \text { B } & 96 \\ 10 & \mathrm{I}\left(\mathrm{CH}_{2}\right)_{4} \mathrm{Cl} & \left(\mathrm{CH}_{2}\right)_{4} \mathrm{Cl} & \text { A } & 99 \\ 11 & \mathrm{I}\left(\mathrm{CH}_{2}\right)_{4} \mathrm{Cl} & \left(\mathrm{CH}_{2}\right)_{4} \mathrm{Cl} & \mathrm{B} & 91 \\ 12 & \mathrm{I}\left(\mathrm{CH}_{2}\right)_{5} \mathrm{Cl} & \left(\mathrm{CH}_{2}\right)_{5} \mathrm{Cl} & \text { A } & 97 \\ 13 & \mathrm{I}\left(\mathrm{CH}_{2}\right)_{5} \mathrm{Cl} & \left(\mathrm{CH}_{2}\right)_{5} \mathrm{Cl} & \text { B } & 94\end{array}$

${ }^{a}$ Method A: Na (3.5 equiv.), $\mathrm{NH}_{3} / \mathrm{THF},-78{ }^{\circ} \mathrm{C}$, then $\mathrm{R}-\mathrm{X}$ ( 3.5 equiv.), then $\mathrm{NH}_{4} \mathrm{Cl}$ after 5-30 s (time delay depends upon the electrophile). Method B: Na (3.5 equiv.), naphthalene (5 equiv.), THF, $-78{ }^{\circ} \mathrm{C}$, then $\mathrm{R}-\mathrm{X}$ (3.5 equiv.), then $\mathrm{NH}_{4} \mathrm{Cl}$ after 5-30 s (time delay depends upon the electrophile). $\mathrm{b}=$ formed as a mixture of diastereomers. $\mathrm{c}=$ this compound will aromatize in approximately $24 \mathrm{~h}$ at room temperature and should be stored in the freezer.

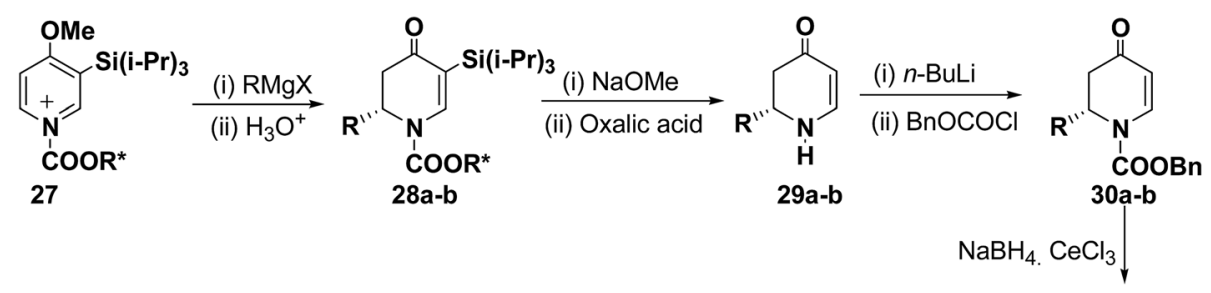

\footnotetext{
$\mathrm{R}^{*}-(-)-8-$ phenylmethyl a; $\mathrm{R}=p-\mathrm{MePh}$ b; $\mathrm{R}=c-\mathrm{Hex}$
}

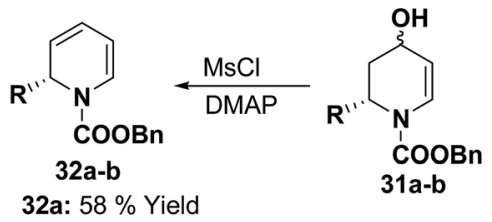


The presence of the chiral auxiliary in $\mathbf{2 5}$ may find application in the several transformations. Another asymmetric synthesis was developed for the synthesis of 1,2-dihydropyridines as shown in Scheme 7. The chiral salt 27 prepared in situ from 4-methoxy-3-

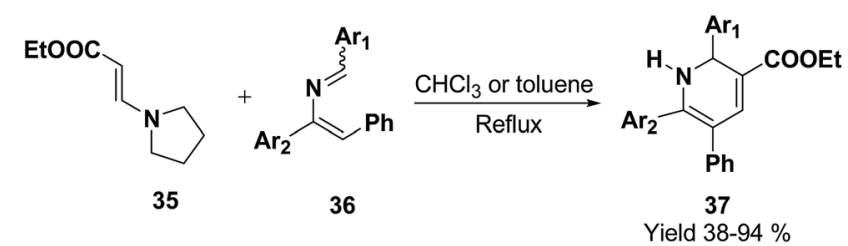

Scheme 9 Regioselective synthesis of 1,2-dihydropyridine.<smiles>O=C1C=C(NC(c2ccccc2)C(Oc2ccccc2)c2ccccc2)CCC1</smiles>

38
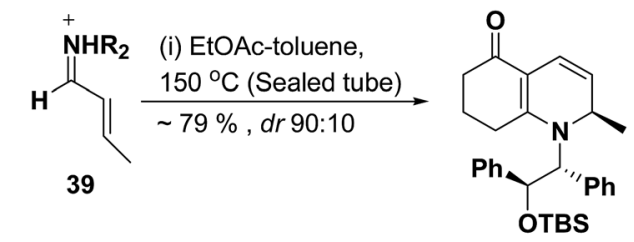

40 $80 \%$ Yield
Scheme 10 1,2-Dihydropyridine via [3 + 3] cycloaddition reaction.

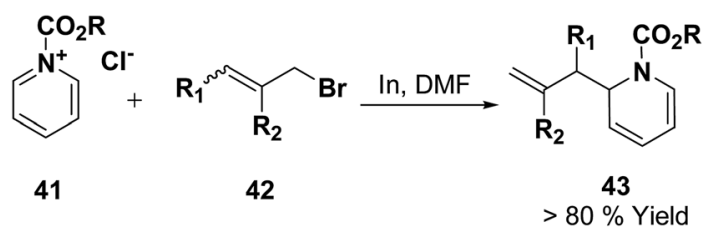

Scheme 11 Indium catalysed synthesis of 1,2-dihydropyridine.

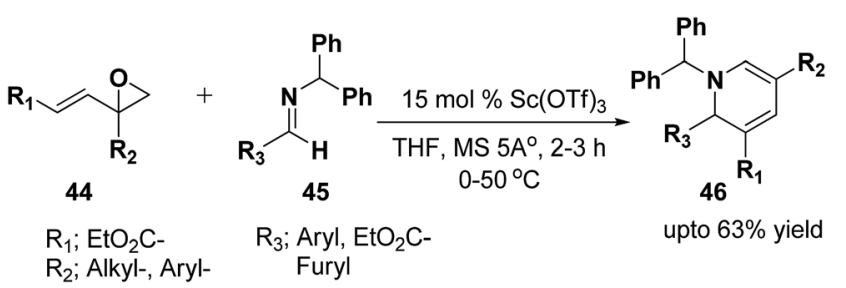

Scheme 12 Vinylogous imino-aldol reaction with vinyloxiranes: synthesis if 1,2-dihydropyridines. (triisopropylsilyl)pyridine and (-)-8-phenylmethyl chloroformate, was treated with Grignard reagent ( $\mathrm{RMgX})$ to give tetrahydropyridone 28a-b in high yield and high diastereomeric excess (de). The chiral auxiliary and the triisopropyl silyl groups were removed from purified diastereomers $\mathbf{2 8}$ with sodium methoxide/methanol and oxalic acid to give enantiopure dihydropyridones 29a (88\% yield) and $29 b$ ( $81 \%$ yield) via one pot reaction. Deprotonation of 29 with $n$-BuLi and addition of benzyl chloroformate provided 30 in almost quantitative yield. Reduction of $\mathbf{3 0}$ to alcohols and subsequent dehydration gave the desired enantiomerically pure 1(benzyloxycarbonyl)-1,2-dihydropyridine 32a and 32b in 58 and $74 \%$ yields, respectively (Scheme 7 ).

Donohoe, et $a l .{ }^{9}$ has used Birch conditions or sodium naphthalene in THF for the partial reduction of electron deficient pyridines for the synthesis of 1,2-dihydropyridines 34 . Reductive alkylation of electron deficient pyridine diester $\mathbf{3 3}$ under Birch type conditions (Scheme 8, method A, quenching the reaction with an electrophile followed by a proton source) gave excellent yield of the corresponding monoalkylated dihydropyridine 34 . The partial reduction using sodium and naphthalene in THF (Scheme 8, method B) was also accomplished, thus avoiding the use of liquid ammonia. Moreover, both sets of reducing conditions were compatible with a range of electrophiles (Table 2).

Palacios, et $a .^{10}$ has reported the synthesis of 1,2-dihydropyridine 37 using enamines 35 and 2-azadienes 36 (readily prepared by aza-Wittig reactions). The compounds and 36 under reflux in toluene form a broad variety of substituted dihydropyridines 37 in a regiospecific manner (Scheme 9).

Vinylogous amides 38 undergo [3+3] cycloaddition reaction with $\alpha, \beta$-unsaturated iminium ions 39 to yield 1,2-dihydropyridines 40. Intramolecular and stereoselective versions of this process have been successfully developed (Scheme 10). ${ }^{\mathbf{1 1}}$

Loh, et al. ${ }^{12}$ has reported the indium-promoted allylations of $N$-acetylpyridinium salt 41 with allyl bromide 42 in DMF, to furnish 1,2-dihydropyridines $\mathbf{4 3}$ regioselectively in good yields (Scheme 11).

Brunner, et $a l .{ }^{13}$ has synthesized the functionalized 1,2dihydropyridine in moderate to good yield by using vinyloxiranes as dienolates in imino-aldol reactions. Under the optimized reaction condition the reaction of vinylepoxide $\mathbf{4 4}$ (1.5 equiv.) with benzhydril protected aldimine 45 (1.0 equiv.) in the presence of catalytic amount of $\mathrm{Sc}(\mathrm{OTf})_{3}(15.0 \mathrm{mmol})$ lead to the formation of stable 1,2-dihydropyridine 46 in upto 63\% yield (Scheme 12). Further it has been illustrated by the author

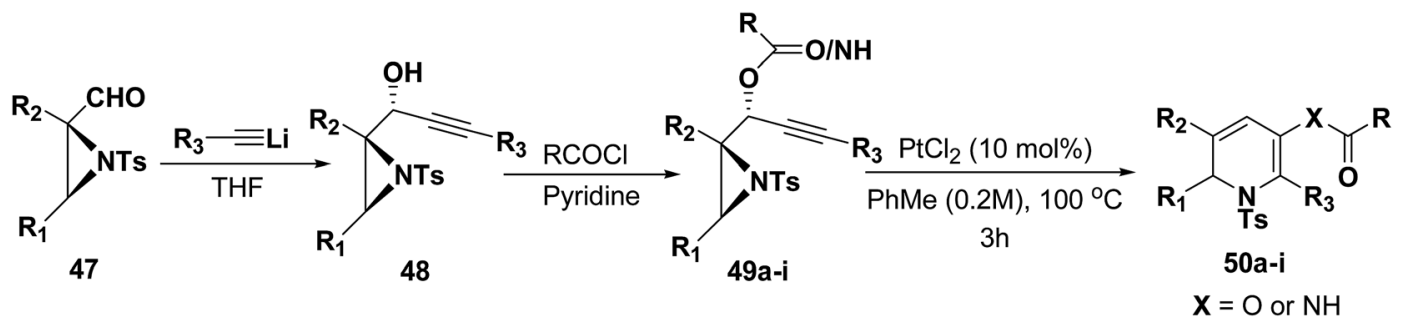

Scheme $13 \mathrm{Pt}(॥)$ catalyzed synthesis of 1,2-dihydropyridines. 
that the reaction proceeds via the vinylogous imino-aldol type reaction.

Motamed, et al. ${ }^{14}$ has reported the first $\mathrm{Pt}(\mathrm{II})$ catalyzed cycloisomerisation of aziridinyl propargylic esters $49 \mathbf{a}-\mathbf{i}$ to afford 1,2-dihydropyridines 50a-i (Scheme 13). The aziridinyl propargylic ester substrates (Table 3 ) were prepared by acylation of the corresponding aziridine propargylic alcohols 48, which were synthesized from aziridinyl aldehyde 47 via a highly diastereoselective ( $\mathrm{dr}>95 \%$ ) 1,2-addition of the corresponding alkyllithium or Grignard reagent. The aziridinyl propargylic esters 49a-i on cycloisomerisation using $\mathrm{Pt}(\mathrm{II})$ catalysis $(10$ $\mathrm{mol} \%$ of $\mathrm{PtCl}_{2}, 0.2 \mathrm{M}$ in toluene, $100{ }^{\circ} \mathrm{C}, 3 \mathrm{~h}$ ) afforded the corresponding 1,2-DHP products $\mathbf{5 0 a - i}$ in moderate to good yields (Table 3).

To explore the scope of the substrates that participate in the reaction, other substituents at the aziridine nitrogen were explored. The $N$-acyl substrates $\mathbf{4 9 j}-\mathbf{m}$ (Scheme 14) were subjected to the $\mathrm{Pt}$ (II) catalyzed reaction to afford the 1,2-dihy-

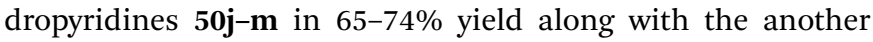
heterocycle $\mathbf{5 1 a - d}$ as by product, which were not isolated.

Hodgson, et $a .^{15}$ have developed a new methodology of radical deoxygenation process on 3-azatricyclo[2.2.1.0 $\left.0^{2,6}\right]$ heptan-5-ols 53 using tributyltin hydride to afford the 1,2dihydropyridines. 3-Azatricyclo[2.2.1.0 $\left.{ }^{2,6}\right]$ heptan-5-ols $\mathbf{5 4 a -}$ b were synthesized from the corresponding epoxide 52 (readily available from cycloaddition of the $N$-Boc pyrrole and tosyl ethyne, followed by the epoxidation of the resulting bicyclic diene), which on radical deoxygenation (via the xanthate) using $\mathrm{Bu}_{3} \mathrm{SnH}$ (2.0 equiv.) gave the 1,2-dihydropyridines 54a-b in 37 and $10 \%$ yields, respectively (Scheme 15 ).

Wan, et al. ${ }^{16}$ have reported the three component sequential reaction enaminones 55, $\alpha, \beta$-unsaturated aldehydes $56 \mathbf{a}-\mathbf{b}$ and amines $\mathbf{5 7 a - k}$ to afford 1,2-dihydropyridines 58 in highly regioselective manner. This novel regioselectivity has been

Table 3 Pt(II)-Catalyzed synthesis of 1,2-dihydropyridines ${ }^{a}$

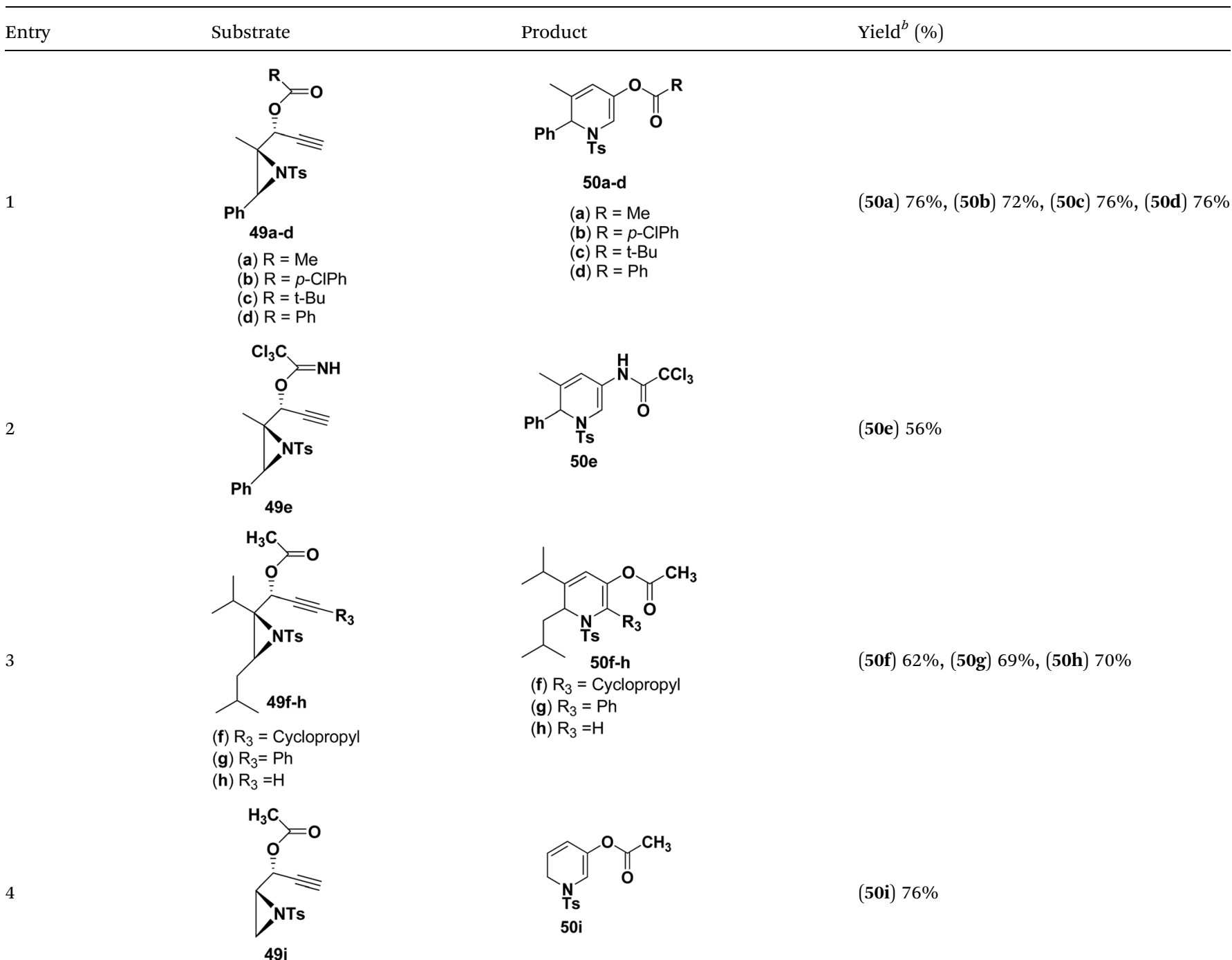

${ }^{a}$ Standard conditions: $10 \mathrm{~mol} \%$ of $\mathrm{PtCl}_{2}, 0.2 \mathrm{M}$ in toluene at $100{ }^{\circ} \mathrm{C}$ over $3 \mathrm{~h} .{ }^{b}$ Isolated yields after column chromatography. 


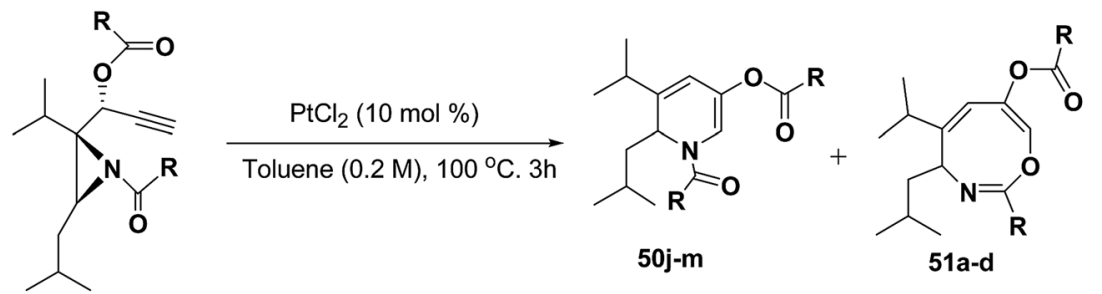

49j-m

\begin{tabular}{clc}
\hline Entry & Substrate $\mathbf{4 9}$ & \% Yield of $\mathbf{5 0}$ \\
\hline 1 & (j) $\mathrm{R}=\mathrm{Me}$ & 71 \\
2 & (k) $\mathrm{R}=\mathrm{Ph}$ & 74 \\
3 & (I) $\mathrm{R}=p$-Tol & 69 \\
4 & (m) $\mathrm{R}=p$-CIPh & 65 \\
\hline
\end{tabular}

Scheme $14 \mathrm{Pt}(॥)$-Catalyzed cycloisomerization of acylated aziridines substrates to 1,2-dihydropyridines.

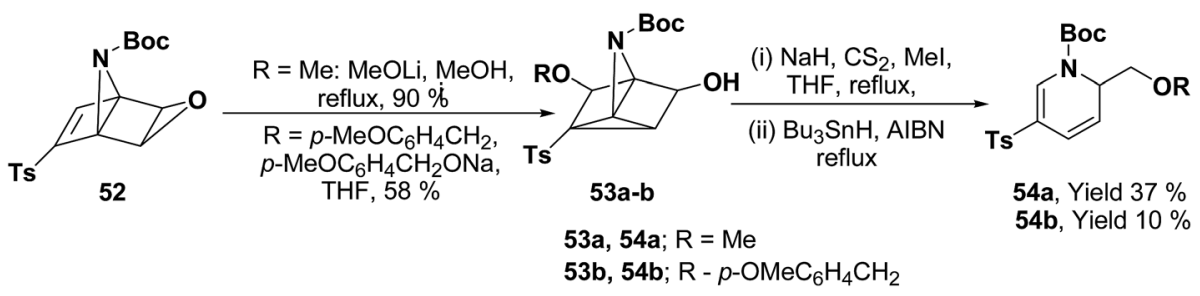

Scheme $15 \mathrm{Bu}_{3} \mathrm{SnH}$ catalyzed radical deoxygenation on xanthate: synthesis of 1,2-dihydropyridines.

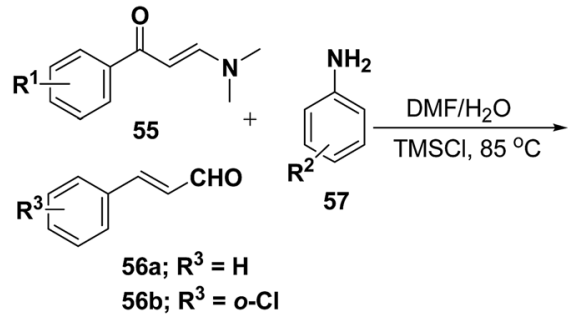

$56 \mathrm{~b} ; \mathrm{R}^{3}=\mathrm{o}-\mathrm{C}$<smiles>[R][R]1ccc(C2C=CC(C(=O)c3ccccc3)=CN2c2ccccc2)cc1</smiles>

58

When $R^{2}$ was bulky or strong electron withdrawing group<smiles>[R]c1cccc(N2C=CC(c3ccccc3)C(C(=O)c3cc[nH]c3)=C2)c1</smiles>

$\%$ yield of $\mathbf{5 8} \&$ $\mathbf{5 9}$ is reported in Table 4

Scheme 16 Regioselective synthesis of 1,2-dihydropyridines.

Table 4 Regioselective synthesis of 1,2-DHPs and 1,4-DHPs ${ }^{a}$

\begin{tabular}{|c|c|c|c|c|c|}
\hline Entry & $\mathrm{R}^{1}$ & $\mathrm{R}^{3}$ & $\mathrm{R}^{2}(57 \mathrm{a}-\mathrm{k})$ & $\%$ yield $^{b}$ of $\mathbf{5 8}$ & $\%$ yield $^{b}$ of 59 \\
\hline 1 & $\mathrm{H}$ & $\mathrm{H}$ & (57a) $p-\mathrm{NO}_{2}$ & (58a) 63 & nd \\
\hline 2 & $p-\mathrm{OCH}_{3}$ & $\mathrm{H}$ & (57a) $p-\mathrm{NO}_{2}$ & $(58 b) 14$ & (59c) 53 \\
\hline 4 & $p-\mathrm{OCH}_{3}$ & $\mathrm{H}$ & $(57 \mathbf{b}) o-\mathrm{F}$ & (58d) nd & (59d) 52 \\
\hline 5 & $\mathrm{H}$ & $\mathrm{H}$ & $(57 \mathrm{c}) o-\mathrm{Cl}$ & $(58 e) 59$ & (59e) nd \\
\hline 6 & $o-\mathrm{Cl}$ & $o-\mathrm{Cl}$ & (57d) $\mathrm{H}$ & (58f) 52 & (59f) nd \\
\hline 9 & $\mathrm{H}$ & $\mathrm{H}$ & $(57 \mathrm{~d}) o-\mathrm{I}$ & (58i) 27 & (59i) 51 \\
\hline 10 & $\mathrm{H}$ & $\mathrm{H}$ & $(57 \mathrm{~g}) o-\mathrm{CH}_{3}$ & $(58 \mathbf{j})$ nd & (59j) 65 \\
\hline 11 & $\mathrm{H}$ & $\mathrm{H}$ & (57h) 2,4,6-trimethyl & $(\mathbf{5 8 k})<10$ & $(59 k) 51$ \\
\hline
\end{tabular}

${ }^{a}$ General conditions: $0.3 \mathrm{mmol}$ of enaminones, $0.35 \mathrm{mmol}$ of aldehyde, $0.3 \mathrm{mmol}$ of amine, $0.3 \mathrm{mmol}$ of TMSCl mixed in $1 \mathrm{~mL}$ of solvents $(0.5 \mathrm{~mL}$ $\mathrm{H}_{2} \mathrm{O}+0.5 \mathrm{~mL}$ of DMF), stirred at $85{ }^{\circ} \mathrm{C}$ for $10 \mathrm{~h} .{ }^{b}$ Isolated yield based on the corresponding enaminone. ${ }^{c}$ nd $=$ not determined. 


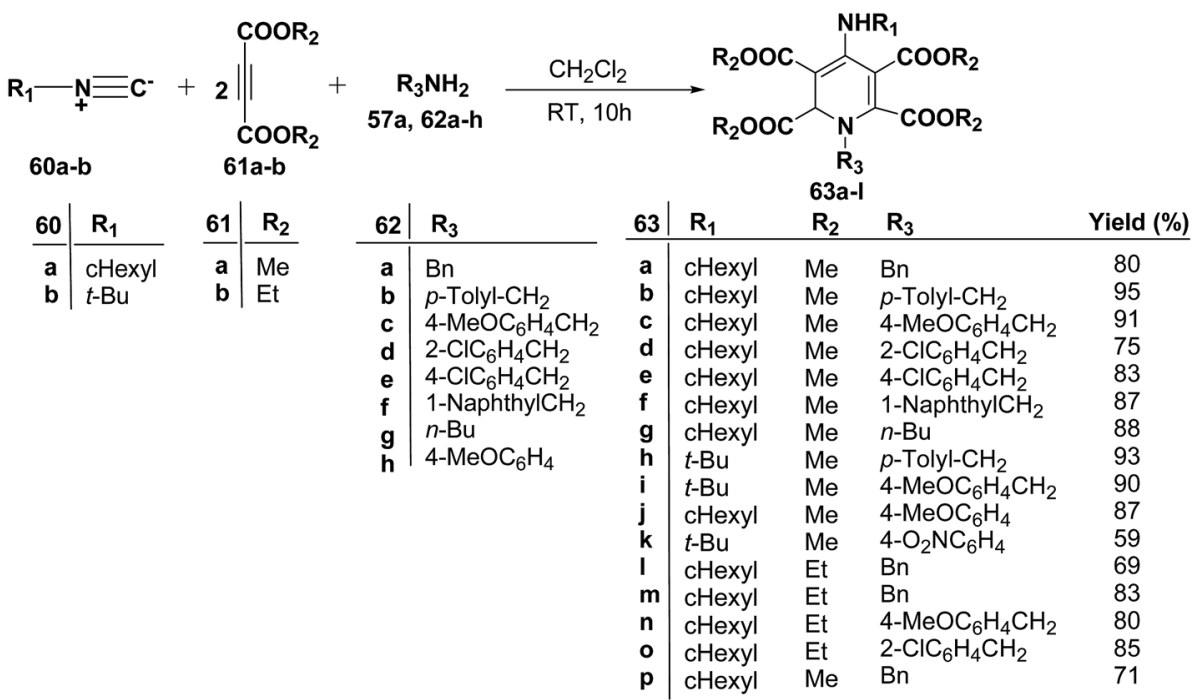

Scheme 17 Three component one-pot synthesis of functionalized 1,2-dihydropyridines 63a-l.

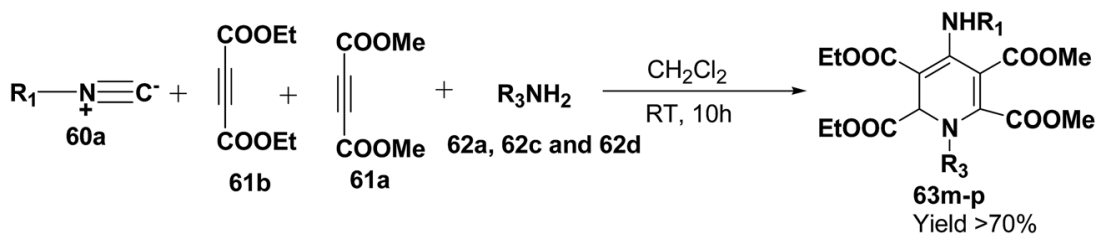

Scheme 18 Four component one-pot synthesis of functionalized 1,2-dihydropyridines $63 \mathrm{~m}-\mathrm{p}$.

assigned to both steric and electronic effects originating from the amine partner (Scheme 16).

To examine the factors contributing to the selectivity, a series of reactions by taking $p$-nitroaniline and ortho-substituted anilines, have been carried out with enaminones and $\alpha, \beta$ unsaturated aldehydes. The results are highlighted in Table 4 . As shown in Table 4 both 1,2-DHPs 58 and/or 1,4-DHPs 59 could be furnished depending on the properties of the substituent on phenyl ring of the anilines. $p$-Nitroaniline mainly offered 1,2DHPs 58 as a major product, while with different ortho-anilines indicate that the regioselectivity was affected by both the size and the electronic profiles of the ortho groups. The reaction of $o$ haloanilines, fluoro- and bromoaniline gave 1,4-DHP 59c, 59d and $59 \mathrm{~h}$ as the major product (entries 3,4 , and 8), while $o$ chloroaniline gave 1,2-DHP 58e, $\mathbf{5 8 f}$ and $\mathbf{5 8 g}$ as the only isolated
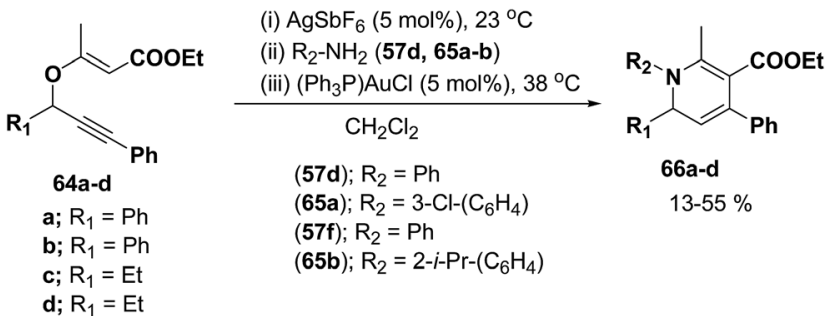

Scheme 19 Synthesis of 1,2-dihydropyridines 66a-d from propargyl ethers. product (entries 5-7). Integrating the 1,2- and/or 1,4-DHP furnished in the 2-iodoaniline, 2-methylaniline, and 2,4,6-trimethylaniline entries (entries 9-11), it is evident that the bulky ortho group is important, but not the only inducing factor for 1,2-DHP formation. Further it was observed that the sequence of adding the reactants did not make a visible difference in the regioselectivity of the reactions.

Yavari, et al. ${ }^{17}$ has reported one pot synthesis of highly functionalized 1,2-dihydropyridines from alkyl isocyanide $\mathbf{6 0 a - b}$,

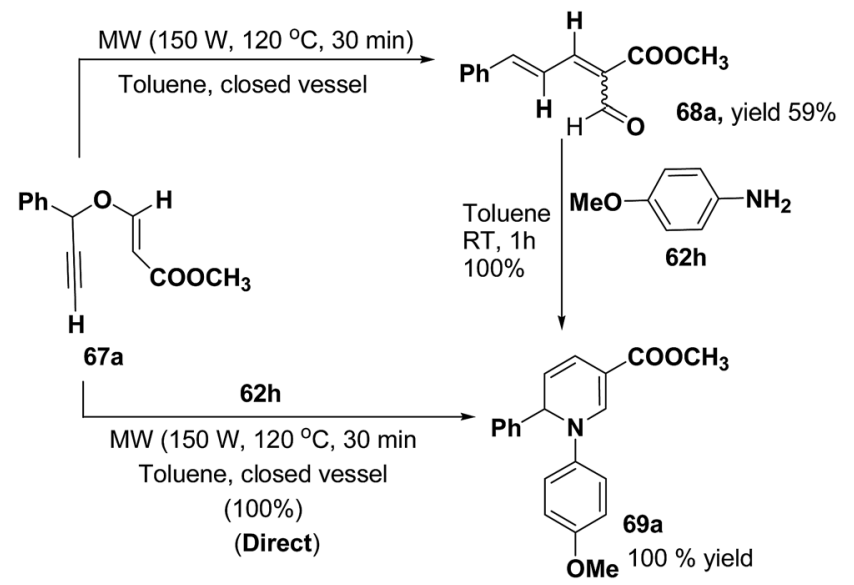

Scheme 20 Two step versus domino reaction: synthesis of 1,2-dihydropyridine 69 a. 
Table 5 Domino synthesis of 1,2-dihydropyridines $69 a-q$ from propargyl enol ethers 67 and primary amines ${ }^{a}$

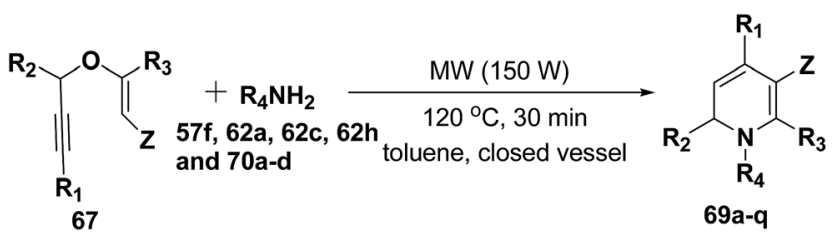

\begin{tabular}{|c|c|c|c|c|c|c|c|}
\hline Entry & $\mathrm{R}_{1}$ & $\mathrm{R}_{2}$ & $\mathrm{R}_{3}$ & 67 & $\mathrm{R}_{4} \mathrm{NH}_{2}$ & 69 & Yield (\%) \\
\hline 1 & $\mathrm{H}$ & $\mathrm{Ph}$ & $\mathrm{H}$ & $\mathbf{a}$ & $p \mathrm{MeOC}_{6} \mathrm{H}_{4}(\mathbf{6 2 h})$ & $\mathbf{a}$ & 100 \\
\hline 2 & $\mathrm{H}$ & $\mathrm{H}$ & $\mathrm{H}$ & b & $p \mathrm{MeOC}_{6} \mathrm{H}_{4}(\mathbf{6 2 h})$ & b & $51^{b}$ \\
\hline 3 & $\mathrm{H}$ & $\mathrm{Me}$ & $\mathrm{H}$ & c & $p \mathrm{MeOC}_{6} \mathrm{H}_{4}(\mathbf{6 2 h})$ & c & 87 \\
\hline 4 & $\mathrm{~h}$ & $n$ Pent & $\mathrm{H}$ & d & $p \mathrm{MeOC}_{6} \mathrm{H}_{4}(\mathbf{6 2 h})$ & d & 71 \\
\hline 5 & $\mathrm{Ph}$ & $\mathrm{Ph}$ & $\mathrm{H}$ & $\mathbf{e}$ & $p \mathrm{MeOC}_{6} \mathrm{H}_{4}(62 \mathrm{~h})$ & e & 95 \\
\hline 6 & $c \mathrm{Hex}$ & $\mathrm{Ph}$ & $\mathrm{H}$ & f & $p \mathrm{MeOC}_{6} \mathrm{H}_{4}(\mathbf{6 2 h})$ & f & 55 \\
\hline 7 & $\mathrm{H}$ & $\mathrm{Ph}$ & $\mathrm{Me}$ & $\mathrm{g}$ & $p \mathrm{MeOC}_{6} \mathrm{H}_{4}(\mathbf{6 2 h})$ & $\mathrm{g}$ & $24^{c}$ \\
\hline 8 & $\mathrm{H}$ & $\mathrm{Me}$ & $\mathrm{Me}$ & h & $p \mathrm{MeOC}_{6} \mathrm{H}_{4}(\mathbf{6 2 h})$ & h & $17^{c}$ \\
\hline 9 & $\mathrm{H}$ & $\mathrm{Ph}$ & $\mathrm{H}$ & i & $p \mathrm{MeOC}_{6} \mathrm{H}_{4}(\mathbf{6 2 h})$ & i & $80^{d}$ \\
\hline 10 & $\mathrm{H}$ & $\mathrm{Ph}$ & $\mathrm{H}$ & $\mathbf{a}$ & $\mathrm{Bn}(62 \mathrm{a})$ & $\mathbf{j}$ & 83 \\
\hline 11 & $\mathrm{H}$ & $\mathrm{Ph}$ & $\mathrm{H}$ & $\mathbf{a}$ & Allyl (70a) & $\mathbf{k}$ & 72 \\
\hline 12 & $\mathrm{H}$ & $\mathrm{Ph}$ & $\mathrm{H}$ & $\mathbf{a}$ & $\mathrm{Ad}^{e}(70 \mathrm{~b})$ & 1 & 87 \\
\hline 13 & $\mathrm{H}$ & $\mathrm{Ph}$ & $\mathrm{H}$ & a & $(S) \mathrm{PhCHMe} \mathrm{(70c)}$ & $\mathbf{m}$ & $83^{f}$ \\
\hline 14 & $\mathrm{H}$ & $\mathrm{Ph}$ & $\mathrm{H}$ & a & $\mathrm{PMB}^{g}(62 \mathrm{c})$ & $\mathbf{n}$ & 78 \\
\hline 15 & $\mathrm{H}$ & $\mathrm{Ph}$ & $\mathrm{H}$ & $\mathbf{a}$ & $\mathrm{Ph}(\mathbf{5 7 f})$ & $\mathbf{o}$ & 93 \\
\hline 16 & $\mathrm{H}$ & $\mathrm{Ph}$ & $\mathrm{H}$ & $\mathbf{a}$ & $4-\mathrm{Cl}-\mathrm{C}_{6} \mathrm{H}_{4}(70 \mathrm{~d})$ & $\mathbf{p}$ & 88 \\
\hline 17 & $\mathrm{H}$ & $\mathrm{Ph}$ & $\mathrm{H}$ & $\mathbf{a}$ & $p \mathrm{MeOC}_{6} \mathrm{H}_{4}(62 \mathrm{~h})$ & q & $100^{h}$ \\
\hline
\end{tabular}

${ }^{a}$ Propargyl vinyl ether 67 (1.0 equiv.), primary amine $62 \mathrm{~h}$ (1.1 equiv.) in toluene $(5 \mathrm{~mL}) . \mathrm{Z}=\mathrm{CO}_{2} \mathrm{CH}_{3} .{ }^{b} 300 \mathrm{~W}, 150{ }^{\circ} \mathrm{C}, 2 \mathrm{~h}^{c}{ }^{c} 300 \mathrm{~W}, 150{ }^{\circ} \mathrm{C}, 3 \mathrm{~h}, \mathrm{Z}$ $=\mathrm{CO}_{2} \mathrm{CH}_{2} \mathrm{CH}_{3} .{ }^{d} \mathrm{Z}=\mathrm{SO}_{2}$ Tol. ${ }^{e} \mathrm{Ad}=$ adamantyl. ${ }^{f} 50 \%$ de. ${ }^{g} \mathrm{PMB}=p$ methoxybenzyl. ${ }^{h}(R)$-1-Phenylprop-2-yn-1-ol was used to prepare enantiopure $(R)-69 \mathbf{q}$; product $69 \mathbf{q}$ obtained as a racemic mixture.

Table 6 Optimization of reaction conditions ${ }^{a}$

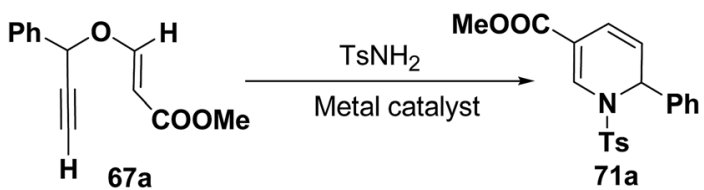

\begin{tabular}{|c|c|c|c|c|}
\hline Entry & Catalyst (mol\%) & Solution & $\mathrm{TsNH}_{2}(\mathrm{~mol} \%)$ & Yield (\%) \\
\hline 1 & $\mathrm{AuCl}_{3}$ & DCM & 200 & $\mathrm{NR}^{b}$ \\
\hline 2 & $\mathrm{PPh}_{3} \mathrm{AuCl} / \mathrm{AgOTf}$ & DCM & 200 & $\mathrm{NR}^{b}$ \\
\hline 3 & $\mathrm{PPh}_{3} \mathrm{AuCl} / \mathrm{AgBF}_{4}$ & DCM & 200 & 84 \\
\hline 4 & $\mathrm{PPh}_{3} \mathrm{AuCl} / \mathrm{AgSbF}_{6}$ & DCM & 200 & 92 \\
\hline 5 & $\mathrm{PPh}_{3} \mathrm{AuCl}$ & DCM & 200 & $\mathrm{NR}^{b}$ \\
\hline 6 & $\mathrm{AgSbF}_{6}$ & DCM & 200 & $\mathrm{NR}^{b}$ \\
\hline 7 & $\mathrm{PdCl}_{2}(\mathrm{CN})_{2}$ & DCM & 200 & $\mathrm{NR}^{b}$ \\
\hline 8 & $\mathrm{PtCl}_{2}$ & DCM & 200 & $\mathrm{NR}^{b}$ \\
\hline 9 & $\mathrm{PPh}_{3} \mathrm{AuCl} / \mathrm{AgSbF}_{6}$ & Toluene & 200 & Trace $^{c}$ \\
\hline 10 & $\mathrm{PPh}_{3} \mathrm{AuCl} / \mathrm{AgSbF}_{6}$ & $\mathrm{CH}_{3} \mathrm{CN}$ & 200 & $\mathrm{NR}^{b}$ \\
\hline 11 & $\mathrm{PPh}_{3} \mathrm{AuCl} / \mathrm{AgSbF}_{6}$ & DCE & 200 & 77 \\
\hline 12 & $\mathrm{PPh}_{3} \mathrm{AuCl} / \mathrm{AgSbF}_{6}$ & DCM & 120 & 80 \\
\hline
\end{tabular}

${ }^{a}$ Reactions were conducted with $0.4 \mathrm{mmol}$ of $1 \mathrm{a}$ in $3 \mathrm{~mL}$ of solvent at room temperature. ${ }^{b}$ No reaction. ${ }^{c}$ Most of the material decomposed. acetylenic esters 61a-b and primary alkylamine (62a-i). The reaction of alkyl isocyanides $\mathbf{6 0 a}-\mathbf{b}$, dimethyl acetylenedicarboxylate (61a), and primary amines $57 \mathbf{a}, \mathbf{6 2} \mathbf{a}-\mathbf{h}$, proceeded smoothly in $\mathrm{CH}_{2} \mathrm{Cl}_{2}$ at room temperature and produced tetramethyl 4(alkylamino)-1-alkyl(aryl)-1,2-dihydropyridine-2,3,5,6-tetracarboxylates 63a-k in good yields after purification (Scheme 17). Similarly, taking two equivalent of diethyl acetylenedicarboxylate $61 \mathrm{~b}$ in above reaction gives 631 in $69 \%$ yield. A wide range of structurally varied primary amines were employed in this cyclocondensation reaction. Addition of a solution of equimolar amounts of primary amine 62a, 62c \& 62d and 61a to a $1: 1$ mixture of cyclohexyl isocyanide (60a), and diethyl acetylenedicarboxylate $(\mathbf{6 1 b})$ in $\mathrm{CH}_{2} \mathrm{Cl}_{2}$ at $\mathrm{rt}$, produced 5,6-diethyl 2,3-

Table 7 Tandem synthesis of 1,2-dihydropyridines from propargyl vinyl ethers and $\mathrm{TsNH}_{2}{ }^{a}$

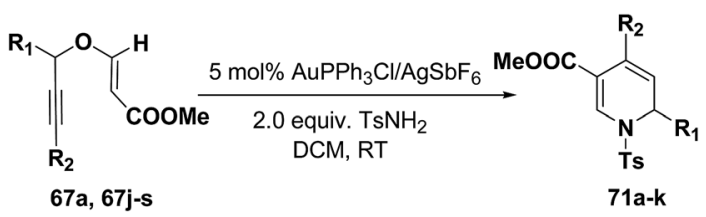

\begin{tabular}{|c|c|c|c|c|c|}
\hline Entry & $\mathrm{R}_{1}$ & $\mathrm{R}_{2}$ & 67 & Product & Yield $^{b}(\%)$ \\
\hline 1 & $\mathrm{C}_{6} \mathrm{H}_{5}$ & $\mathrm{H}$ & $67 a$ & $71 \mathrm{a}$ & 92 \\
\hline 2 & 2-Me- $\mathrm{C}_{6} \mathrm{H}_{4}$ & $\mathrm{H}$ & $67 j$ & $71 b$ & 90 \\
\hline 3 & $4-\mathrm{Me}-\mathrm{C}_{6} \mathrm{H}_{4}$ & $\mathrm{H}$ & $67 k$ & $71 \mathrm{c}$ & 91 \\
\hline 4 & 3-Me- $\mathrm{C}_{6} \mathrm{H}_{4}$ & $\mathrm{H}$ & 671 & $71 d$ & 80 \\
\hline 5 & $3,4-\mathrm{Di}-\mathrm{Me}-\mathrm{C}_{6} \mathrm{H}_{3}$ & $\mathrm{H}$ & $67 m$ & $71 \mathrm{e}$ & 78 \\
\hline 6 & $2-\mathrm{MeO}-\mathrm{C}_{6} \mathrm{H}_{4}$ & $\mathrm{H}$ & $67 n$ & $71 \mathrm{f}$ & 89 \\
\hline 7 & $4-\mathrm{CI}-\mathrm{C}_{6} \mathrm{H}_{4}$ & $\mathrm{H}$ & 670 & $71 \mathrm{~g}$ & 85 \\
\hline 8 & $2-\mathrm{CI}-\mathrm{C}_{6} \mathrm{H}_{4}$ & $\mathrm{H}$ & $67 p$ & $71 \mathrm{~h}$ & 84 \\
\hline 9 & 2-Naphthyl & $\mathrm{H}$ & $67 q$ & $71 \mathrm{i}$ & 88 \\
\hline 10 & $n$-Hexyl & $\mathrm{H}$ & $67 r$ & $71 \mathbf{j}$ & 82 \\
\hline 11 & $\mathrm{C}_{6} \mathrm{H}_{5}$ & $n$-Pentyl & $67 \mathrm{~s}$ & $71 \mathrm{k}$ & 60 \\
\hline
\end{tabular}

${ }^{a}$ Reactions were conducted with $0.4 \mathrm{mmol}$ of $67 \mathrm{in} 3 \mathrm{~mL}$ of solvent. ${ }^{b}$ Isolated yield after column chromatography.

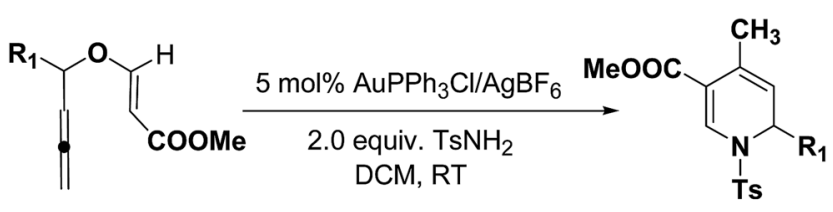

72a-h

73a-h

\begin{tabular}{lcc}
\hline $\mathbf{R}_{\mathbf{1}}$ & Product & Yield (\%) \\
\hline $\mathrm{C}_{6} \mathrm{H}_{5}$ & $\mathbf{7 3 a}$ & 69 \\
$2-\mathrm{Me}-\mathrm{C}_{6} \mathrm{H}_{4}$ & $\mathbf{7 3 b}$ & 67 \\
$4-\mathrm{Me}-\mathrm{C}_{6} \mathrm{H}_{4}$ & $\mathbf{7 3 c}$ & 65 \\
$3-\mathrm{Me}-\mathrm{C}_{6} \mathrm{H}_{4}$ & $\mathbf{7 3 d}$ & 56 \\
$4-\mathrm{Cl}-\mathrm{C}_{6} \mathrm{H}_{4}$ & $\mathbf{7 3 e}$ & 55 \\
$4-\mathrm{Br}-\mathrm{C}_{6} \mathrm{H}_{4}$ & $\mathbf{7 3 f}$ & 48 \\
2-naphthyl & $\mathbf{7 3 g}$ & 62 \\
n-hexyl & $\mathbf{7 3 h}$ & NR \\
\hline
\end{tabular}

Scheme 21 Tandem synthesis of 1,2-dihydropyridines 73a-h from allenic vinyl ethers and $\mathrm{TsNH}_{2}$. 
dimethyl 4-(cyclohexylamino)-1-(arylmethyl)-1,2-dihydropyridine2,3,5,6-tetracarboxylates 63m-o which contain two different ester groups (Scheme 18). Similarly reaction of $62 \mathbf{a}$ and $61 \mathbf{b}$ in a $1: 1$

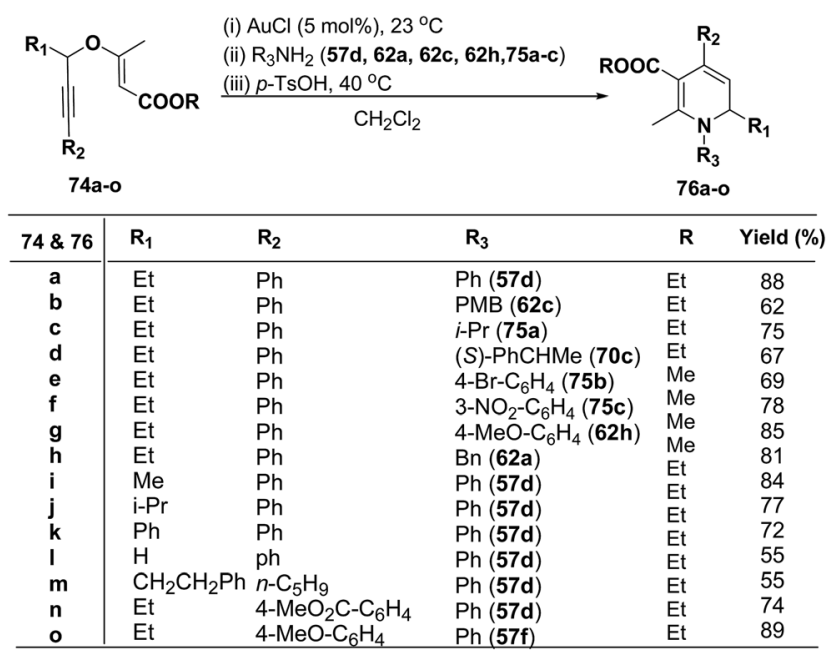

mixture of 60a \& 61a yields 63p. The formation of a single product when two different acetylenic esters are used is presumably controlled by the sequence in which the reaction is carried out.

Binder and Kirsch et al. ${ }^{18}$ has synthesized 1,2-dihydropyridines 66a-d from propargyl vinyl ethers 64a-d through a sequence of propargyl-Claisen rearrangement, condensation, and heterocyclization (Scheme 19). The scope of this protocol was quite limited, only four examples of 1,2-dihydropyridines with low to moderate yields are known.

Tejedor, et al. ${ }^{19}$ has developed a convenient domino access to substituted alkyl 1,2-dihydropyridine-3-carboxylates from propargyl enol ethers and primary amine. After some experimental work, it has been found that microwave irradiation of a solution of $67 \mathrm{a}$ in toluene $\left(150 \mathrm{~W}, 120^{\circ} \mathrm{C}, 30 \mathrm{~min}\right)$ afforded the corresponding dienal $\mathbf{6 8 a}$, which could be isolated as a mixture of $E / Z(1: 1)$ isomers in $59 \%$ yield after flashchromatographic purification (Scheme 20). Subsequent treatment of dienal $68 \mathrm{a}$ with $p$-anisidine $(\mathbf{6 2 h} ; 1.0$ equiv.) at room temperature in toluene for $1 \mathrm{~h}$ afforded 1,2-dihydropyridine 69a in quantitative yield. The direct microwave irradiation of 67a with $62 \mathrm{~h}$ in toluene $\left(150 \mathrm{~W}, 120{ }^{\circ} \mathrm{C}, 30 \mathrm{~min}\right)$ afforded the

Scheme 22 The conversion of 74a-o in 1,2-dihydropyridines 76a-o.

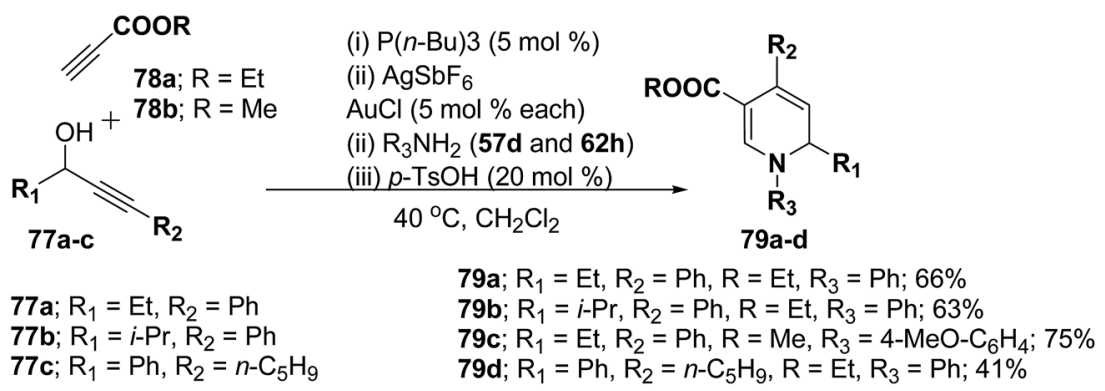

Scheme 23 One pot synthesis of 1,2-dihydropyridines 79a-d starting from propargylic alcohols 77a-c.

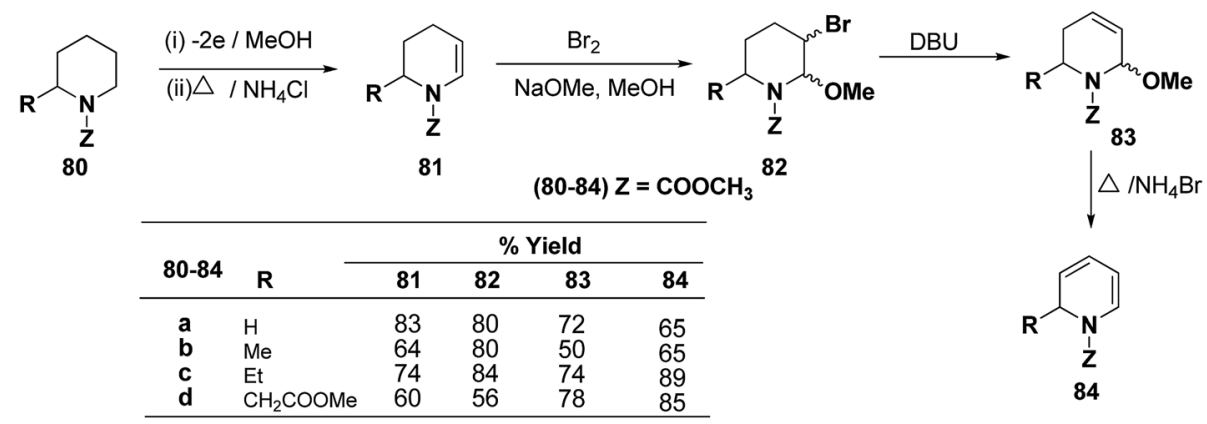

Scheme 24 Electrochemical synthesis of 1,2-dihydropyridines 84a-d.

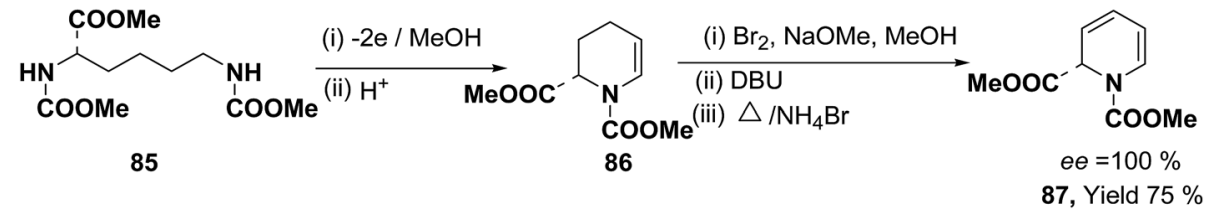

Scheme 25 Electrochemical synthesis of enantiomerically pure 1,2-dihydropyridine 87. 
corresponding 1,2-dihydropyridine 69a in almost quantitative yield.

After the development of one step domino process the scope of this reaction has been extended with regard to the propargylic component and amine (Table 5). In general, the reaction presented a broad spectrum for the amine although aromatic amines gave better yields than aliphatic amines (compare entries 1, 15 and 16 with entries 10-14). The effect of diastereo induction by the amine component was studied with the chiral amine 70c, which in turn yields chiral 1,2-dihydropyridine 69m with a significant $50 \%$ de (entry 13 ).

Wei, et al. ${ }^{20}$ has reported the synthesis of 1,2-dihydropyridines from propargyl vinyl ethers and allenic vinyl ethers by gold-catalyzed Claisen rearrangement and $6 \pi$-azaelectrocyclization. No reaction occurred with $\mathrm{AuCl}_{3}$ or AuPPh 3 Cl/AgOTf (5 mol\% each) in $\mathrm{CH}_{2} \mathrm{Cl}_{2}$ at room temperature (entries 1 and 2, Table 6). 1,2-Dihydropyridine was obtained in $84 \%$ yield when $\mathrm{AuPPh}_{3} \mathrm{Cl} / \mathrm{AgBF}_{4}(5 \mathrm{~mol} \%)$ was used (entry 3 ). It was interesting result that $92 \%$ yield was realized by using $\mathrm{AuPPh}_{3} \mathrm{Cl} / \mathrm{AgSbF}_{6}(5 \mathrm{~mol} \%)$ at room temperature (entry 4). Ag(I) could serve to abstract the chloride from $\mathrm{AuPPh}_{3} \mathrm{Cl}$ to form a more electrophilic catalyst. On the contrary, when $\mathrm{Au}\left(\mathrm{PPh}_{3}\right) \mathrm{Cl}$ or $\mathrm{AgSbF}_{6}$ was used alone (entries 5 and 6), the tandem reaction did not take place at all. On the other hand, other transition metal catalysts such as $\mathrm{PtCl}_{2}$ or $\mathrm{PdCl}_{2}(\mathrm{CN})_{2}$ did not promote any transformation (entries 7 and $8)$. The investigation on the solvent effect showed that the best choice of the solvent was $\mathrm{CH}_{2} \mathrm{Cl}_{2}$ (entries 9-11). However, the yield decreased when the amount of $\mathrm{TsNH}_{2}$ was reduced from 2.0 to 1.2 equivalents (entry 12). Thus the use of $5 \mathrm{~mol} \%$ of $\mathrm{AuPPh}_{3} \mathrm{Cl} / \mathrm{AgSbF}$, with 2.0 equivalents of $\mathrm{TsNH}_{2}$ in $\mathrm{CH}_{2} \mathrm{Cl}_{2}$ at room temperature constituted the optimal reaction conditions.

The scope of the reaction has been explored in gold catalysed tandem reaction by studying a wide variety of substrates (Table

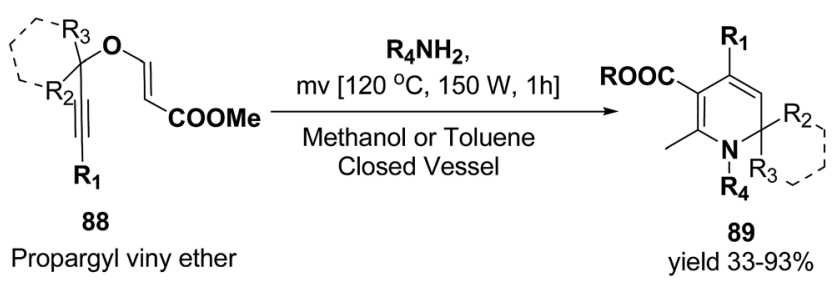

Scheme 26 Microwave-assisted domino synthesis of 1,2-dihydropyridines 89 from propargyl vinyl ether 88 .

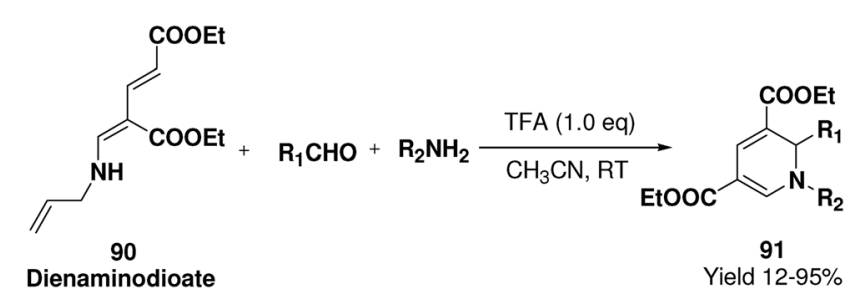

Scheme 27 Cascade synthesis of 1,2-dihydropyridine 91 by variation of aldehydes and amines.
7). Substrates containing electron-rich or electron-deficient aryl groups at the propargylic position gave good to excellent yields of desired 1,2-dihydropyridines (entries 2-9).

The scope of this reaction has been extended by Wei, et al. on allenic vinyl ethers $\mathbf{7 2 a}-\mathbf{h}$ and it has been found that $5 \mathrm{~mol} \%$ $\mathrm{AuPPh}_{3} \mathrm{Cl} / \mathrm{AgBF}_{4}$ in presence of 2.0 equiv. $\mathrm{TsNH}_{2}$ gave the moderate to good yield of diversified 1,2-dihydropyridines 73ah (Scheme 21).

1,2-Dihydropyridines $\mathbf{7 6 a - 0}$ were synthesized in good to excellent yields by using a standardized protocol of Kirsch

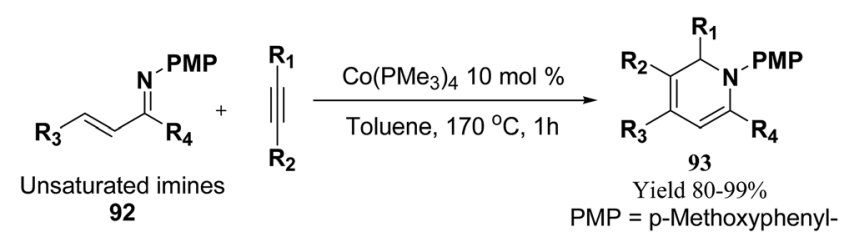

Scheme 28 Annulation reaction between unsaturated imines and alkynes for the formation of 1,2-dihydropyridines 93 .

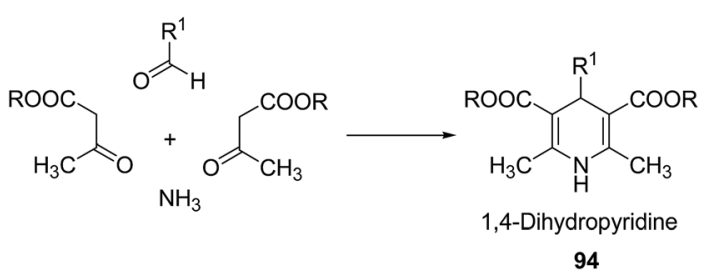

Scheme 29 Hantzsch dihydropyridine synthesis.

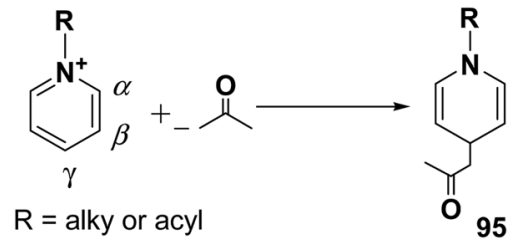

Scheme 30 An example of Kröhnke procedure

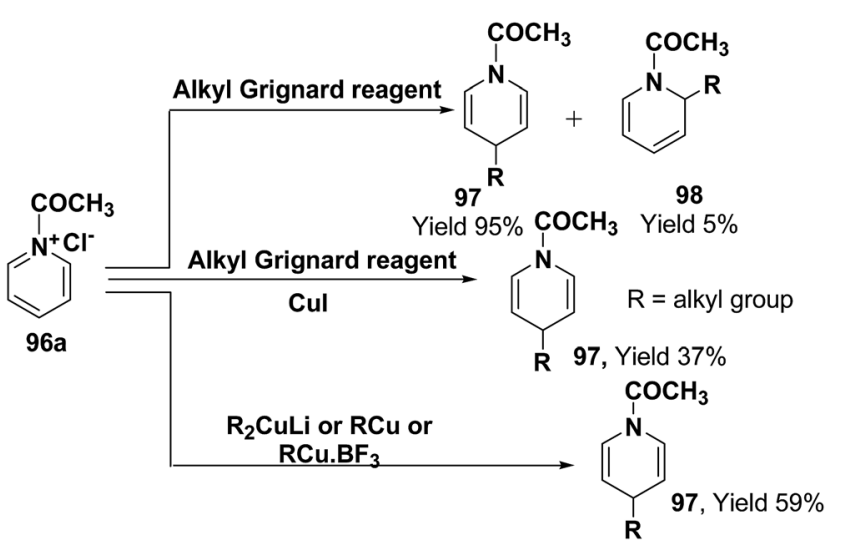

Scheme 31 Grignard and organocopper reagents catalyzed exclusive synthesis of 1,4-dihydropyridine 97. 
et $a .^{21}$ with internal alkynes $74 a-0$ and used a sequential addition of reagents and catalysts to obtain reproducibly high yields [(i) AuCl (5 mol\%), $23{ }^{\circ} \mathrm{C}$; (ii) $\mathrm{R}_{3} \mathrm{NH}_{2}$ (57d, 62a, 62c, 62h and 75a-c); (iii) $p$-TsOH (20 mol\%), $40{ }^{\circ} \mathrm{C}, \mathrm{CH}_{2} \mathrm{Cl}_{2}$ ] (Scheme 22). The formation of 1,2-dihydropyridines 76a-o tolerated substitution of $R_{1}$ and $R_{2}$ with both aryl and alkyl groups (Scheme 22). Compound $\mathbf{7 6 1}$ bearing no substituent in the 2-position $\left(R_{1}=\mathrm{H}\right)$ was obtained in only moderate yield.

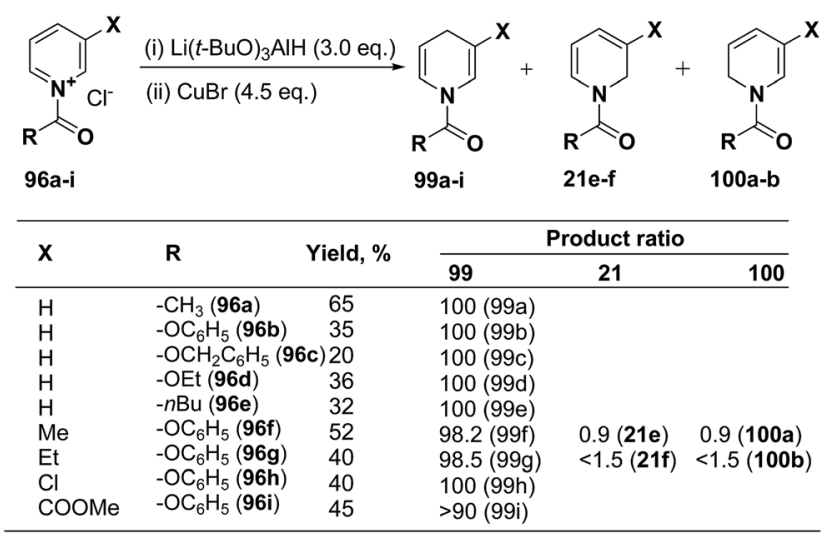

Scheme 32 Comins copper hydride catalyzed regioselective synthesis of 1,4-dihydropyridines $99 a-i$.
Further this one-pot procedure is extended by an additional step that is the formation of the propargyl vinyl ethers. When propargylic alcohols $77 \mathrm{a}-\mathrm{c}$ were reacted with 1.0 equiv. of ethyl propiolate $78 \mathrm{a} / \mathrm{methyl}$ propiolate $78 \mathrm{~b}$ and $5 \mathrm{~mol} \%$ of $\mathrm{P}(n-\mathrm{Bu})_{3}$, the Michael-addition remained an efficient process. Subsequent addition of both AuCl and $\mathrm{AgSbF}_{6}$ (5 mol\% each) furnished the allenylcarbonyl compounds. Notably, only the use of both catalysts together provided good and reproducible results; neither one was able to catalyze the reaction on its own. The sequence was terminated by condensation with 1.5 equiv. of an amine and 0.2 equiv. of $p$-TsOH at $40{ }^{\circ} \mathrm{C}$ for $15 \mathrm{~h}$ to give the desired products in good yields (Scheme 23). It is of particular note that this onepot procedure presents the possibility to access 1,2-dihydropyridines 79a-d even in cases when the required propargyl vinyl ether is not accessible due to poor stability.

Shono, et $a .^{22}$ have developed a convenient and regioselective method for the synthesis of 1,2-dihydropyridines, especially those possessing substituents at certain positions of the pyridine nucleus. 2-Substituted 1-(methoxycarbonyl)-1,2-dihydropyridines have been synthesized from piperidines electrochemically (Scheme 24).

Optically active 1,2-dihydropyridine 87 has been synthesized starting from L-lysine derivative $\mathbf{8 5}$ by electrochemically in two steps via the synthesis of tetrahydropyridine 86 in $75 \%$ yield, ee $\sim 100 \%$ (Scheme 25).<smiles>N#CC1=C(N)OC=C(C=O)C1c1ccccc1</smiles>
101
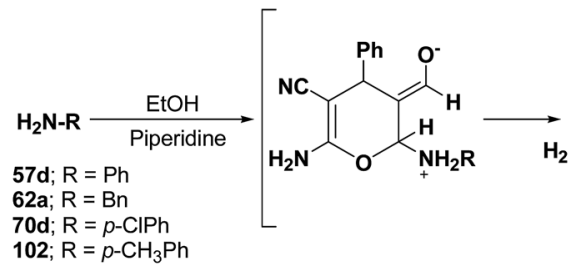<smiles>[R]N/C=C(/CO)C(c1ccccc1)C(C(N)=O)C(C#N)CCCC</smiles>

$103 a ; R=P h$
$103 b ; R=B n$ $103 \mathrm{~b} ; \mathrm{R}=\mathrm{Bn}$
$103 \mathrm{c} ; \mathrm{R}=p-\mathrm{CIPh}$ 103d; $\mathrm{R}=p-\mathrm{CH}_{3} \mathrm{Ph}$<smiles>[R]N1C=C(C=O)C(c2ccccc2)C(C(N)=O)=C1N</smiles>

103a-d $30-51 \%$ Yield

Scheme 33 Synthesis of 1,4-dihydropyridines 103a-d from 2-amino-5-formyl-4H-pyran 101.

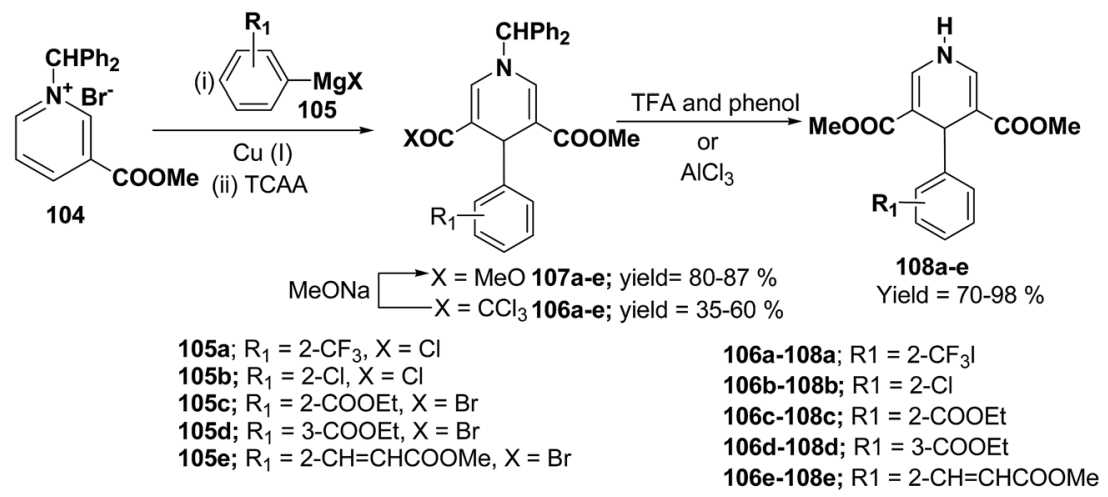

Scheme 34 Synthesis of 4-functionalized 3,5-diacyl-4-aryl-1,4-dihydropyridines 108a-e. 
Tejedor, et al. ${ }^{23}$ has developed a general and practical metalfree protocol for the synthesis of 1,2-dihydropyridines (Scheme 26) with variety of structural/functional diversity at the ring and featuring mono, double, or spiro substitution at the $\mathrm{sp}^{3}$ hybridized carbon position. The protocol contains a microwaveassisted domino reaction of propargyl vinyl ether $\mathbf{8 8}$ (secondary or tertiary) and a primary amine (aliphatic or aromatic) in toluene or methanol.

Challa, et al. ${ }^{24}$ has developed a convenient synthesis of 1,2dihydropyridine (91) from dienaminodioate $\mathbf{9 0}$ and an imine (generated in situ) mediated by $\mathrm{CF}_{3} \mathrm{COOH}$ in a one-pot cascade synthesis. The advantages associated with this transformation include conditions that are metal-free, room temperature,

Table 8 Optimizing the reaction conditions ${ }^{a}$

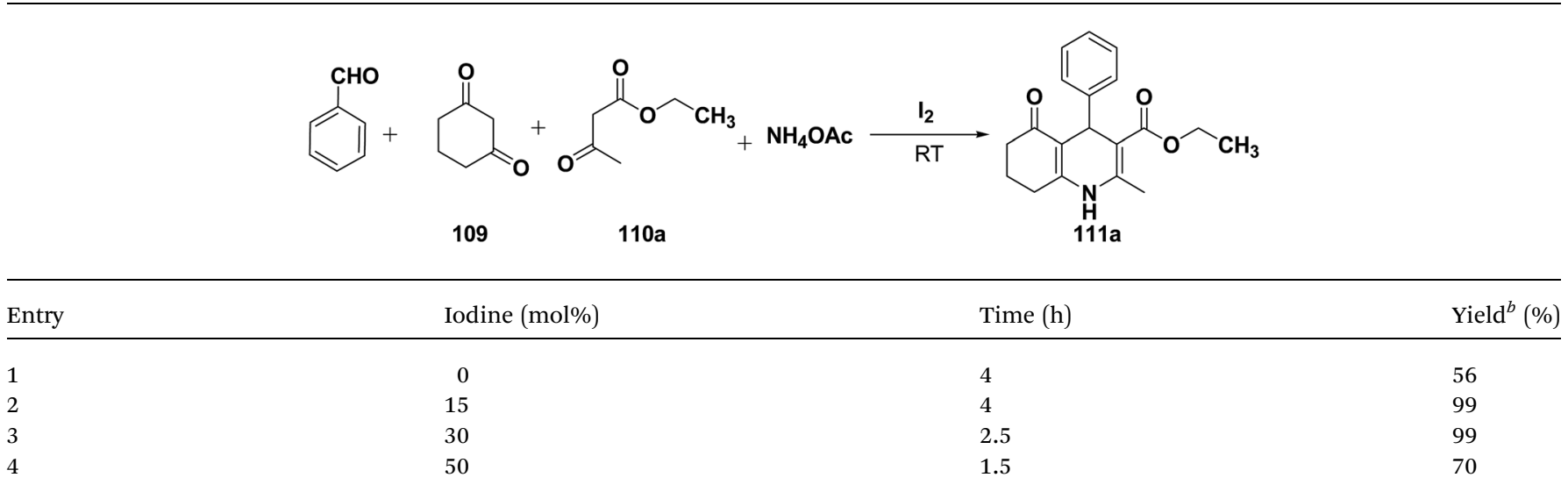

${ }^{a}$ Benzaldehyde : 1,3-cyclohexanedione : ethyl acetoacetate : ammonium acetate $(1: 1: 1: 1) .{ }^{b}$ Crude isolated yield.

Table 9 lodine catalyzed synthesis of 1,4-dihydropyridine derivatives through Hantzsch reaction

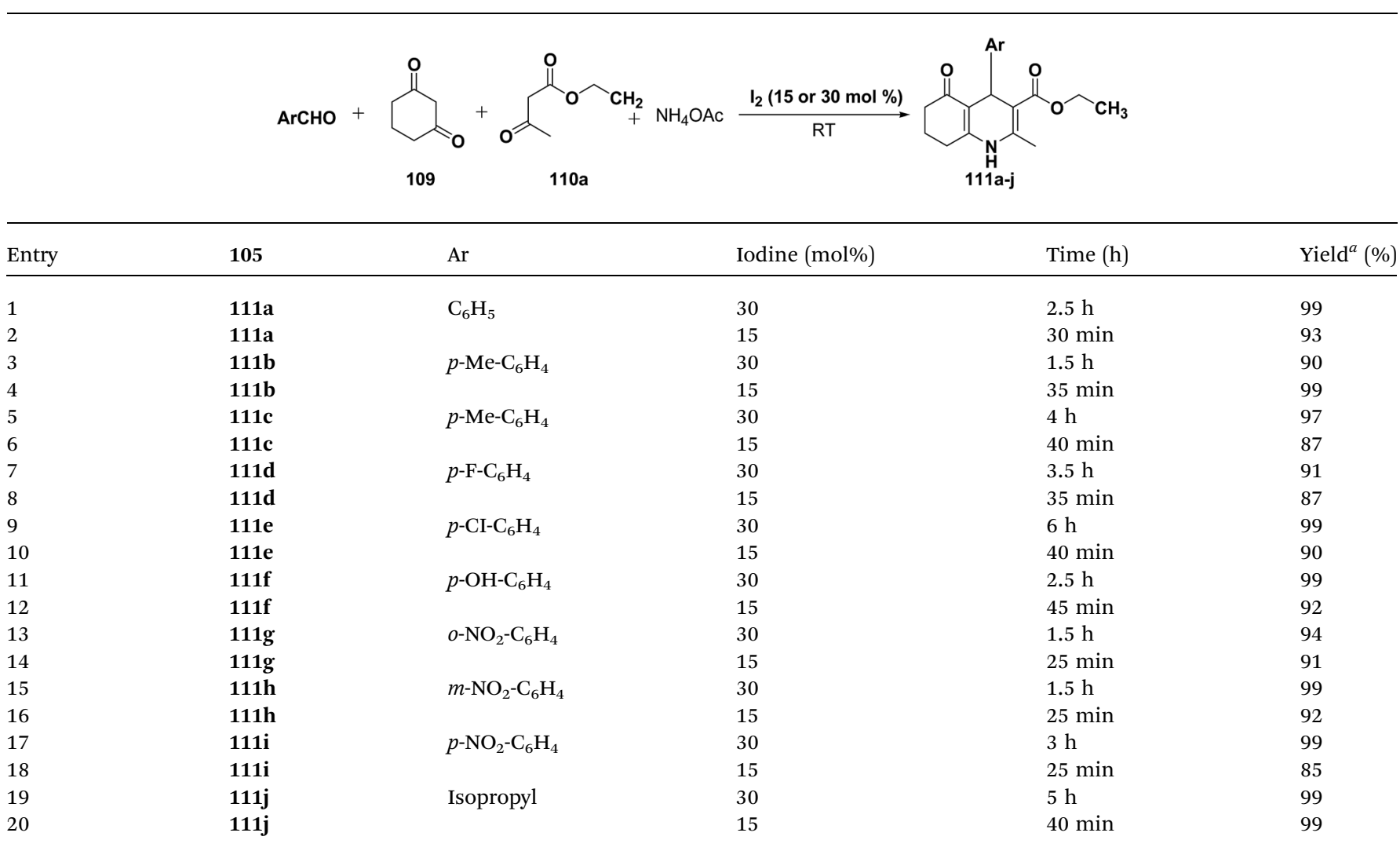

${ }^{a}$ Crude isolated yield. 
undistilled solvent, and expeditious in excellent yields. Out of the several acid catalyst used for the optimisation of the reaction condition trifluoroacetic acid was found to me excellent, which yield 1,2-dihydropyridine in excellent yield (Scheme 27). The substrate scope has been demonstrated with various aromatic, heteroaromatic, unsaturated aldehydes, and anilines, benzylic amines in impressive yields.

Fallon, et al. ${ }^{25}$ has developed a convenient one-pot synthesis of highly substituted 1,2-dihydropyridines $\mathbf{9 3}$ from unsaturated imines 92 and alkynes via $\mathrm{C}-\mathrm{H}$ activation/6 $\pi$-electrocyclisation pathway (Scheme 28). The reaction proceeds with high regioselectivity, and the author has disclosed the first example of isolated 1,2-dihydropyridines lacking substitution at 2 position. A low valent cobalt complex without reducing agents or additives provides $\mathrm{C}-\mathrm{H}$ activation.

\subsection{Synthesis of 1,4-dihydropyridines}

Over the years many outstanding discoveries have been made in the field of drug development and research with multifaceted

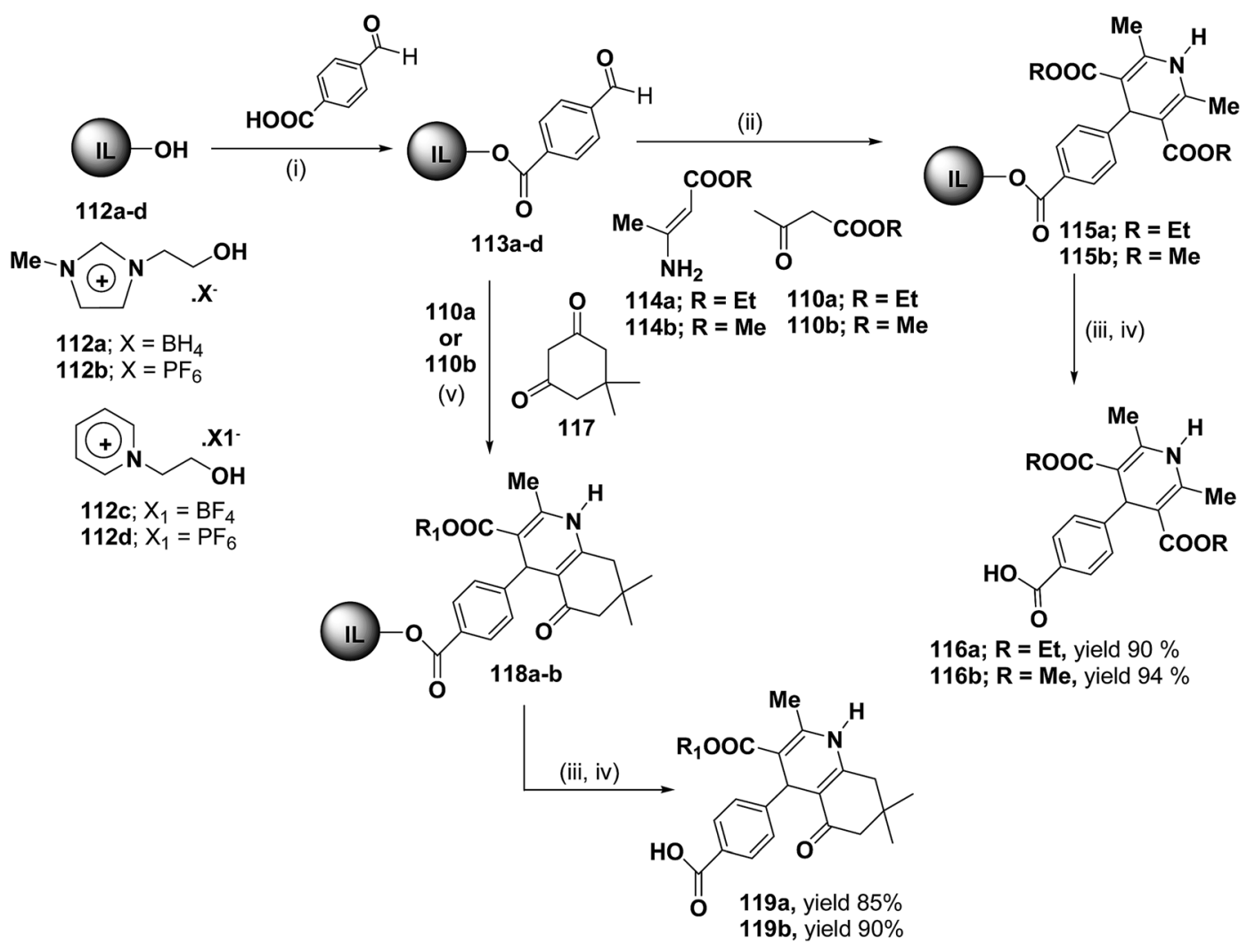

Scheme 35 Ionic liquid supported synthesis of 1,4-DHPs. Reagents and conditions (i) DCC (1.0 equiv.), DMAP (5\%), dry MeCN, rt, 24 h; (ii) method A: 110 (1.0 equiv.), 114 (1.0 equiv.), mw: $120^{\circ} \mathrm{C}$ (power level: $50 \%, 150$ W), 10 min or method B: 110 (2.0 equiv.), $\mathrm{NH}_{4} \mathrm{OAc}\left(2.0\right.$ equiv.), mw: $120{ }^{\circ} \mathrm{C}$ (power level: 50\%, 150 W); (iii) MeONa 30\%, MeOH, reflux, 18 h; (iv) LiOH 60\%, THF, rt, 20 h then 3 M HCl; (v) 110 (1.0 equiv.), 117 (1.0 equiv.), $\mathrm{NH}_{4} \mathrm{OAc}$ (2.0 equiv.), mw: $120{ }^{\circ} \mathrm{C}$ (power level: 50\%, $150 \mathrm{~W}$ ).

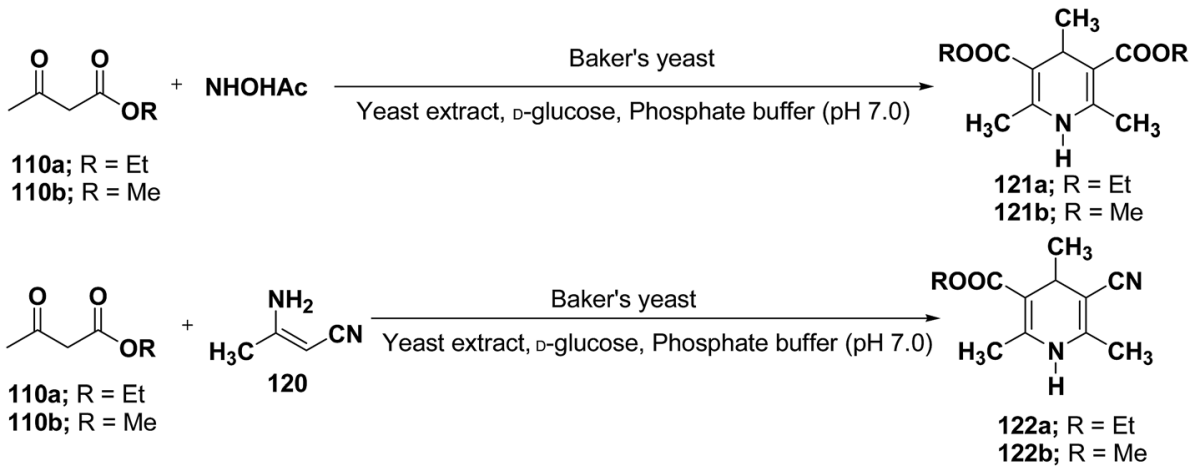

Yield of 121-122 are 46-70\% 


.

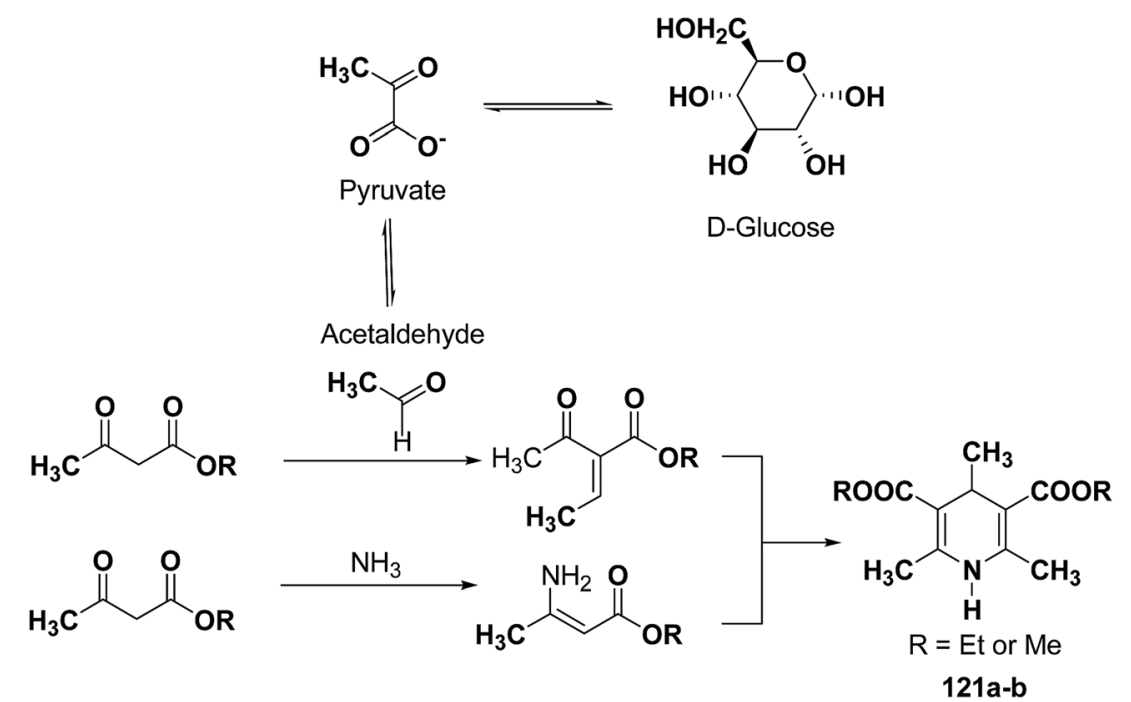

Scheme 37 Proposed mechanism for the baker's yeast catalysed synthesis of 1-4-DHPs.

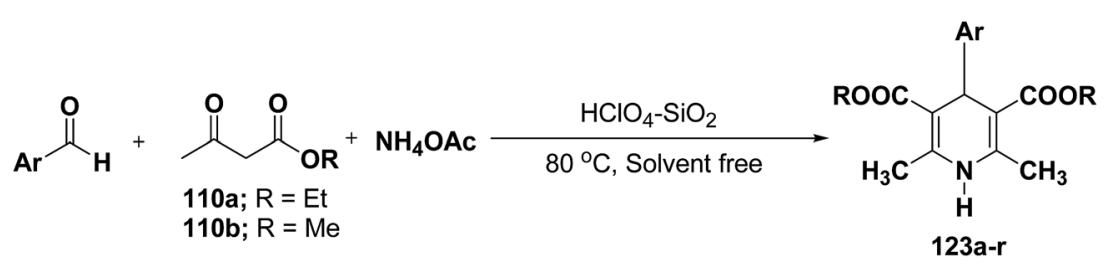

Scheme 38 Heterogeneous catalyst $\left(\mathrm{HClO}_{4}-\mathrm{SiO}_{2}\right)$ catalyzed synthesis 1,4-DHPs 123.

drugs having great potential. 1,4-Dihydropyridine is one such privileged structure which has revolutionized the pharmaceutical industry. It is a well explored scaffold which binds to multiple receptors, possesses a wide variety of biological features and also has its basis in biologically active natural products. The first synthesis of 1,4-dihydropyridines was reported by Arthur Hantzsch in $1882 .{ }^{26} \mathrm{He}$ observed that in the process of synthesizing pyridine by a one pot three-component condensation reaction of acetoacetic ester, aldehyde and ammonia, an intermediate 1,4-dihydropyridine (1,4-DHP) 94 is formed, which could be isolated easily. Since then this reaction has been successfully employed in the synthesis of 1,4-DHPs and bears his name as "Hantzsch dihydropyridine synthesis" (Scheme 29).

The addition of nucleophiles to $\alpha$ - and $\gamma$ - positions of $N$ substituted pyridinium salts gives both 1,2- and 1,4-dihydropyridines. The regioselectivity of the addition reaction depends on the hardness of the nucleophile: hard nucleophiles preferentially attack at $\mathrm{C}-2$ whereas soft ones attack at C-4 position of the pyridinium salts. The addition is also believed to proceed at both the $\alpha$ - and $\gamma$-carbon centres under kinetic control and only at the $\gamma$-carbon under thermodynamic control. $^{27}$ The Kröhnke procedure ${ }^{28-30}$ and sodium dithionite reduction $^{31-33}$ are examples of reactions involving addition of nucleophiles at $\gamma$-position. The Kröhnke procedure, ${ }^{28-30}$ consisting of base-catalysed reaction of ketones with alkyl or $\mathrm{N}$-acyl pyridinium salts, was investigated years ago (Scheme 30). It is of particular synthetic interest since it constitutes a useful method of forming new carbon-carbon bonds to give $\gamma$-substituted 1,4dihydropyridines $95 .{ }^{22}$

Table 10 One-pot synthesis of 1,4-DHP under solvent free conditions using $\mathrm{HClO}_{4}-\mathrm{SiO}_{2}{ }^{a}$

\begin{tabular}{|c|c|c|c|c|}
\hline Entry & (Ar) 123 & 110 & $\begin{array}{l}\text { Reaction time } \\
\text { (min.) }\end{array}$ & $\begin{array}{l}\% \\
\text { yield }\end{array}$ \\
\hline 1 & $\mathrm{C}_{6} \mathrm{H}_{5}(123 a)$ & $110 b$ & 20 & 95 \\
\hline 2 & $p-\mathrm{CH}_{3}-\mathrm{C}_{6} \mathrm{H}_{4}(123 b)$ & $110 b$ & 25 & 90 \\
\hline 3 & $p-\mathrm{CH}_{3} \mathrm{O}-\mathrm{C}_{6} \mathrm{H}_{4}(123 \mathrm{c})$ & $110 b$ & 28 & 92 \\
\hline 4 & $p-\mathrm{Cl}-\mathrm{C}_{6} \mathrm{H}_{4}(\mathbf{1 2 3 d})$ & $110 b$ & 20 & 89 \\
\hline 5 & $p-\mathrm{OH}-\mathrm{C}_{6} \mathrm{H}_{4}(123 \mathrm{e})$ & $110 b$ & 26 & 90 \\
\hline 6 & $o-\mathrm{NO}_{2}-\mathrm{C}_{6} \mathrm{H}_{4}(\mathbf{1 2 3 f})$ & $110 b$ & 35 & 92 \\
\hline 7 & $o-\mathrm{Cl}-\mathrm{C}_{6} \mathrm{H}_{4}(123 \mathrm{~g})$ & 110b & 26 & 87 \\
\hline 8 & $p-\mathrm{NO}_{2}-\mathrm{C}_{6} \mathrm{H}_{4}(\mathbf{1 2 3 h})$ & 110a & 33 & 92 \\
\hline 9 & $o-\mathrm{CH}_{3} \mathrm{O}-\mathrm{C}_{6} \mathrm{H}_{4}(\mathbf{1 2 3 i})$ & $110 a$ & 42 & 90 \\
\hline 10 & $p-\mathrm{Br}-\mathrm{C}_{6} \mathrm{H}_{4}(\mathbf{1 2 3} \mathbf{j})$ & $110 a$ & 40 & 92 \\
\hline 11 & $o-\mathrm{Br}-\mathrm{C}_{6} \mathrm{H}_{4}(123 \mathrm{k})$ & $110 a$ & 40 & 89 \\
\hline 12 & 2-Furyl (123l) & $110 a$ & 52 & 86 \\
\hline 13 & 2-Thienyl (123m) & $110 a$ & 56 & 90 \\
\hline 14 & 3-Pyridyl (123n) & 110a & 55 & 82 \\
\hline 15 & $\mathrm{C}_{6} \mathrm{H}_{5}(1230)$ & $110 b$ & 20 & 94 \\
\hline 16 & $p-\mathrm{CH}_{3}-\mathrm{C}_{6} \mathrm{H}_{4}(123 p)$ & $110 b$ & 25 & 92 \\
\hline 17 & $o-\mathrm{CH}_{3} \mathrm{O}-\mathrm{C}_{6} \mathrm{H}_{4}(123 \mathrm{q})$ & $110 b$ & 25 & 90 \\
\hline 18 & $o-\mathrm{NO}_{2}-\mathrm{C}_{6} \mathrm{H}_{4}(123 \mathrm{r})$ & 110b & 22 & 91 \\
\hline
\end{tabular}




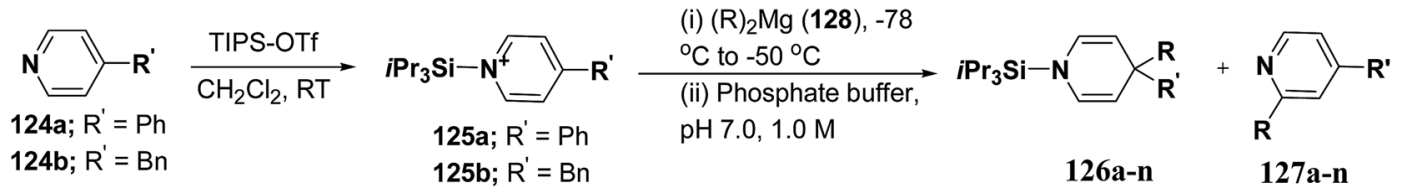

Scheme 39 Synthesis of 1,4-DHPs 126a-n via addition reaction of Grignard reagent to N-triisopropylsilylpyridinium ions $125 \mathrm{a}-\mathrm{b}$.

Comins, et al..$^{34}$ and Yamaguchi, et al. ${ }^{35}$ have reported the reaction of 1-acetylpyridinium chloride with alkyl Grignard reagent, which lead to the formation of 1,4-dihydropyridines 97 and 1,2-dihydropyridines 98 . $^{34 a}$ However, when a catalytic amount of $\mathrm{CuI}$ is present, the addition is regiospecific and resulted in the exclusive formation of 1,4-dihydropyridines 97 . Stoichiometric organocopper reagent (e.g. $\mathrm{R}_{2} \mathrm{CuLi}, \mathrm{RCu}$, $\mathrm{RCu} \cdot \mathrm{BF}_{3}$ ) also give 1,4-addition product and resulted into the formation of 1,4-dihydropyridines 97 (Scheme 31). ${ }^{36}$

Several hydride reagents e.g. $\mathrm{NaBH}_{4},{ }^{3} \mathrm{NaBH}_{3} \mathrm{CN},\left(\mathrm{PPh}_{3}\right)_{2^{-}}$ $\mathrm{CuBH}_{4},{ }^{37}\left(\mathrm{Ph}_{2} \mathrm{MeP}\right)_{3} \mathrm{CuBH}_{4},{ }^{38}$ Semmelhack's $" \mathrm{NaCuH}_{2}{ }^{{ }^{39}}$ and Semmelhack's " $\mathrm{LiCuH}_{2}{ }^{39}$ has been used for the regioselective synthesis of 1,4-dihydropyridines from 1-(phenoxycarbony1) pyridinium chloride 99a (generate in situ by the reaction between pyridine and phenyl chloriformate), but none of these procedure resulted into the regioselective formation of 1,4-DHP. Comins, et $a{ }^{40}{ }^{40}$ has used a copper hydrido reagent prepared from lithium tri-tert-butoxyaluminum hydride (3.0 equiv.) and copper bromide (4.5 equiv.) as a reducing agent for the regioselective reduction of 1-(phenoxycarbony1)pyridinium chloride 96a in almost quantitative yield (Scheme 32). Further this procedure has been extended to the variety of the 1-(alkoxy/

Table 11 Addition of various dialkylmagnesium reagents to $\mathrm{N}$-triisopropylsilylpyridinium ions $125 \mathrm{a}-\mathrm{b}$

\begin{tabular}{llllll}
\hline & & & & & \\
Entry & $\mathbf{1 2 5}$ & $\mathrm{R}_{2} \mathrm{Mg}(\mathbf{1 2 8})^{a}$ & Product & \% yield ${ }^{b}$ & $\begin{array}{l}\text { Product ratio } \\
\mathbf{1 2 6} / \mathbf{1 2 7} / \mathbf{1 2 5}(\%)^{c}\end{array}$ \\
\hline 1 & $\mathbf{1 2 5 a}$ & $\mathrm{Et}_{2} \mathrm{Mg}$ & $\mathbf{1 2 6 a}, \mathbf{1 2 7}$ & 78 & $90 / 4 / 6$ \\
2 & $\mathbf{1 2 5 a}$ & $n \mathrm{Bu}_{2} \mathrm{Mg}$ & $\mathbf{1 2 6 b}, \mathbf{1 2 7} \mathbf{b}$ & 82 & $100 / 0 / 0$ \\
3 & $\mathbf{1 2 5 a}$ & $\mathrm{Bn}_{2} \mathrm{Mg}$ & $\mathbf{1 2 6 c}, \mathbf{1 2 7} \mathbf{c}$ & 92 & $95 / 2 / 3$ \\
4 & $\mathbf{1 2 5 a}$ & $\mathrm{Ph}_{2} \mathrm{Mg}$ & $\mathbf{1 2 6 d}, \mathbf{1 2 7}$ & 0 & $5 / 95^{d} / 0$ \\
5 & $\mathbf{1 2 5 a}$ & $\mathrm{Me}_{2} \mathrm{Mg}$ & $\mathbf{1 2 6 e}, \mathbf{1 2 7}$ & 0 & $0 / 59 / 41$ \\
6 & $\mathbf{1 2 5 a}$ & $\mathrm{iPr}_{2} \mathrm{Mg}$ & $\mathbf{1 2 6 f}, \mathbf{1 2 7}$ & 91 & $99 / 0 / 1$ \\
7 & $\mathbf{1 2 5 a}$ & $t \mathrm{Bu}_{2} \mathrm{Mg}$ & $\mathbf{1 2 6 g}, \mathbf{1 2 7} \mathbf{g}$ & 56 & $80 / 3 / 17^{e}$ \\
8 & $\mathbf{1 2 5 a}$ & $\mathrm{Allyl}_{2} \mathrm{Mg}$ & $\mathbf{1 2 6 h}, \mathbf{1 2 7 h}$ & 20 & $20 / 78^{d} / 2$ \\
9 & $\mathbf{1 2 5 b}$ & $\mathrm{Et}_{2} \mathrm{Mg}$ & $\mathbf{1 2 6 i}, \mathbf{1 2 7 i}$ & 73 & $86 / 2 / 12$ \\
10 & $\mathbf{1 2 5 b}$ & $n \mathrm{Bu}_{2} \mathrm{Mg}$ & $\mathbf{1 2 6 j}, \mathbf{1 2 7 j}$ & 54 & $54 / 6 / 40$ \\
11 & $\mathbf{1 2 5 b}$ & $\mathrm{Bn}_{2} \mathrm{Mg}$ & $\mathbf{1 2 6 k}, \mathbf{1 2 7} \mathbf{k}$ & 85 & $95 / 0 / 5$ \\
12 & $\mathbf{1 2 5 b}$ & $\mathrm{iPr}_{2} \mathrm{Mg}$ & $\mathbf{1 2 6 1}, \mathbf{1 2 7 1}$ & 78 & $100 / 0 / 0$ \\
13 & $\mathbf{1 2 5 b}$ & $t \mathrm{Bu}_{2} \mathrm{Mg}$ & $\mathbf{1 2 6 m}, \mathbf{1 2 7 m}$ & 5 & $6 / 0 / 94^{f}$ \\
14 & $\mathbf{1 2 5 b}$ & $\mathrm{Allyl}_{2} \mathrm{Mg}$ & $\mathbf{1 2 6 n}, \mathbf{1 2 7 n}$ & 12 & $21 / 70 / 9$
\end{tabular}

${ }^{a}$ After addition of the organomagnesium compound $\mathrm{R}_{2} \mathrm{Mg}$ to the $\mathrm{N}$ silylpyridinium ion 125 at $-78{ }^{\circ} \mathrm{C}$ the mixture was slowly warmed to $-50{ }^{\circ} \mathrm{C} .{ }^{b}$ Isolated yield. ${ }^{c}$ According to ${ }^{1} \mathrm{H}$ NMR of the crude reaction product. ${ }^{d}$ Sum of 127 and non oxidized 1,2-addition product, which were both present. ${ }^{e}$ Yield $63 \%$, ratio $86 / 2 / 12$ when addition performed by warming the mixture from $-78{ }^{\circ} \mathrm{C}$ to room temperature. ${ }^{f}$ Yield $29 \%$, ratio $32 / 0 / 68$ when addition performed by warming the mixture from $-78{ }^{\circ} \mathrm{C}$ to room temperature. aryloxy/acyloxycarbony1)pyridinium chlorides $\mathbf{9 9 b - i}$ (generated in situ by the reaction between substituted pyridine and corresponding alkyl/phenyl chloroformate or acid chloride). This convenient one-pot preparation of 1-(alkoxycarbonyl)-1,4dihydropyridines by using the Comins' copper hydride complements the two-step procedure developed by Fowler. ${ }^{4}$

De Lucas, et al ${ }^{41}$ have developed a novel methodology for the synthesis of $N$-substituted 1,4-dihydropyridines 103a-d by the reaction of 2-amino-5-formyl- $4 \mathrm{H}$-pyran 101 with primary amines 57d, 62a, 70d and 102 in moderate yield (Scheme 33). The formation of 1,4-dihydropyridines involves cleavage of the $4 \mathrm{H}^{-}$ pyran ring by nucleophilic attack of the respective amine and subsequent 6-exo-dig cyclisation.

Bennasar, et al..$^{42}$ have developed a regioselective synthesis of 4-functionalized 3,5-diacyl-4-aryl-1,4-dihydropyridines 108a-e by the copper-mediated addition of functionalized arylmagnesium reagent 105a-e to the $N$-benzhydrilpyridinium salt 104,
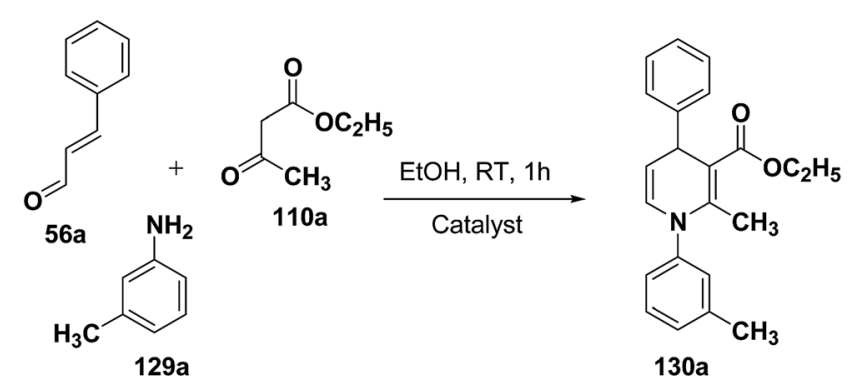

\begin{tabular}{lcc}
\hline Catalyst & Mole \% of catalyst & Isolated yield (\%) \\
\hline $\mathrm{InCl}_{3}$ & 20 & 45 \\
$\mathrm{PPh}_{3} \mathrm{HClO}_{4}$ & 20 & 50 \\
$\mathrm{KHSO}_{4}$ & 40 & 45 \\
$\mathrm{CAN}$ & 5 & 71 \\
\hline
\end{tabular}

Scheme 40 Screening of the catalysts for the three-component domino reaction between $56 a, 129 a$ and $110 a$.

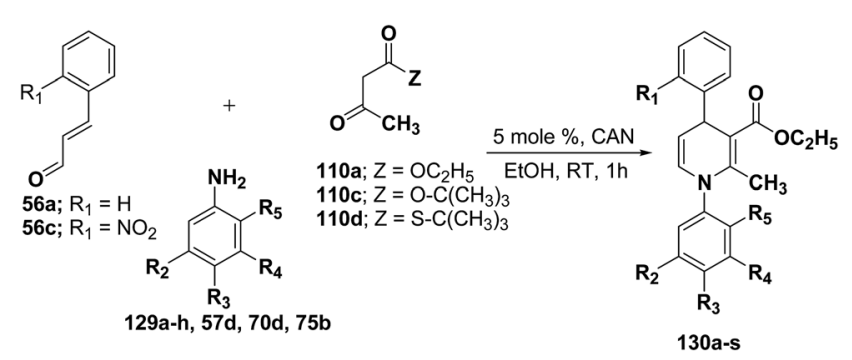

Scheme 41 Three-component domino reaction between 56, 110 and $129 a-h, 57 d \& 70 d$ 
Table 12 Scope and yields of the CAN-catalyzed synthesis of 1,4-dihydropyridines 130a-s

\begin{tabular}{|c|c|c|c|c|c|c|c|c|c|c|}
\hline Entry & Compound & 110 & 56 & $\mathrm{R}_{2}$ & $\mathrm{R}_{3}$ & $\mathrm{R}_{4}$ & $\mathrm{R}_{5}$ & Amine & Time (h) & Yield (\%) \\
\hline 1 & 130a & 110a & $56 a$ & $\mathrm{CH}_{3}$ & $\mathrm{H}$ & $\mathrm{H}$ & $\mathrm{H}$ & 129a & 1 & 74 \\
\hline 2 & $130 b$ & 110a & $56 a$ & $\mathrm{H}$ & $\mathrm{H}$ & $\mathrm{H}$ & $\mathrm{H}$ & $57 d$ & 1 & 71 \\
\hline 3 & $130 \mathrm{c}$ & 110a & $56 a$ & $\mathrm{H}$ & $\mathrm{CH}_{3}$ & $\mathrm{H}$ & $\mathrm{H}$ & $129 b$ & 1 & 70 \\
\hline 4 & 130d & 110a & $56 a$ & $\mathrm{H}$ & $\mathrm{F}$ & $\mathrm{H}$ & $\mathrm{H}$ & $129 c$ & 1 & 76 \\
\hline 5 & $130 \mathrm{e}$ & 110a & $56 a$ & $\mathrm{H}$ & $\mathrm{Cl}$ & $\mathrm{H}$ & $\mathrm{H}$ & 70d & 1 & 74 \\
\hline 6 & $130 f$ & 110a & $56 a$ & $\mathrm{CH}_{3}$ & $\mathrm{CH}_{3}$ & $\mathrm{H}$ & $\mathrm{H}$ & 129d & 1 & 70 \\
\hline 7 & $130 \mathrm{~g}$ & 110a & $56 a$ & $\mathrm{Cl}$ & $\mathrm{H}$ & $\mathrm{H}$ & $\mathrm{H}$ & $129 \mathrm{e}$ & 1 & 72 \\
\hline 8 & $130 h$ & 110a & $56 a$ & $\mathrm{H}$ & $\mathrm{Br}$ & $\mathrm{H}$ & $\mathrm{H}$ & $75 \mathrm{~b}$ & 1 & 74 \\
\hline 9 & $130 \mathbf{i}$ & $110 a$ & $56 a$ & $\mathrm{CH}_{3}$ & $\mathrm{H}$ & $\mathrm{CH}_{3}$ & $\mathrm{H}$ & $129 f$ & 1 & 72 \\
\hline 10 & 130j & $110 a$ & $56 a$ & $\mathrm{OCH}_{3}$ & $\mathrm{H}$ & $\mathrm{H}$ & $\mathrm{H}$ & $129 \mathrm{~g}$ & 1 & 65 \\
\hline 11 & 130k & $110 a$ & $56 c$ & $\mathrm{H}$ & $\mathrm{H}$ & $\mathrm{H}$ & $\mathrm{H}$ & $57 d$ & 1 & 50 \\
\hline 12 & $1301^{a}$ & $110 a$ & $56 a$ & $\mathrm{H}$ & $\mathrm{CH}_{3}$ & $\mathrm{H}$ & $\mathrm{CH}_{3}$ & $129 \mathrm{~h}$ & 1 & 72 \\
\hline 13 & $130 \mathrm{~m}$ & $110 \mathrm{c}$ & $56 a$ & $\mathrm{H}$ & $\mathrm{H}$ & $\mathrm{H}$ & $\mathrm{H}$ & $57 d$ & 2 & 52 \\
\hline 14 & 130n & 110c & $56 a$ & $\mathrm{H}$ & $\mathrm{CH}_{3}$ & $\mathrm{H}$ & $\mathrm{H}$ & $129 b$ & 2 & 61 \\
\hline 15 & 1300 & $110 \mathrm{c}$ & $56 a$ & $\mathrm{H}$ & $\mathrm{Cl}$ & $\mathrm{H}$ & $\mathrm{H}$ & $70 d$ & 2 & 65 \\
\hline 16 & 130p & 110d & $56 a$ & $\mathrm{H}$ & $\mathrm{H}$ & $\mathrm{H}$ & $\mathrm{H}$ & $57 d$ & 1 & 61 \\
\hline 17 & $130 q$ & 110d & $56 a$ & $\mathrm{H}$ & $\mathrm{F}$ & $\mathrm{H}$ & $\mathrm{H}$ & $129 c$ & 1 & 62 \\
\hline 18 & 130r & 110d & $56 a$ & $\mathrm{H}$ & $\mathrm{Cl}$ & $\mathrm{H}$ & $\mathrm{H}$ & 70d & 1 & 63 \\
\hline 19 & $130 \mathrm{~s}$ & 110d & $56 a$ & $\mathrm{H}$ & $\mathrm{CH}_{3}$ & $\mathrm{H}$ & $\mathrm{H}$ & $129 b$ & 1 & 61 \\
\hline
\end{tabular}
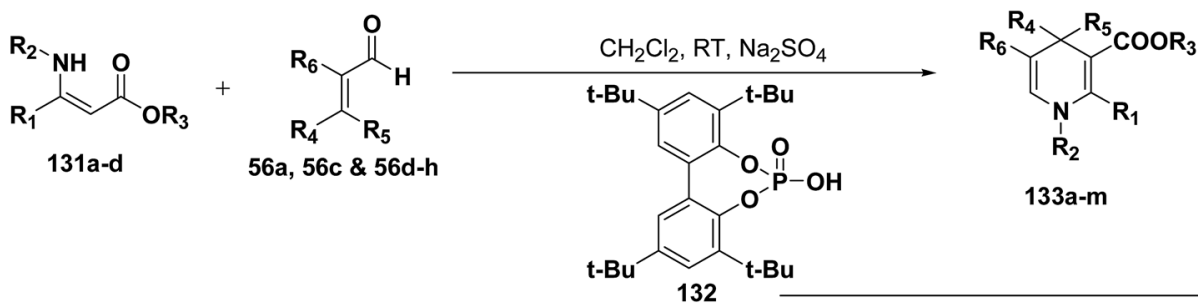

133a-m

131a; $R_{1}=C_{3}, R_{2}=B n, R_{3}=t-B u \quad 56 d ; R_{4}=R_{5}=C_{3}, R_{6}=H$ $131 \mathbf{b} ; R_{1}=\mathrm{CH}_{3}, R_{2}=\mathrm{Bn}, \mathrm{R}_{3}=\mathrm{Et} \quad \mathbf{5 6 e} ; \mathrm{R}_{4}=\mathrm{R}_{6}=\mathrm{CH}_{3}, \mathrm{R}_{5}=\mathrm{H}$ 131c; $R_{1}=P h, R_{2}=B n, R_{3}=E t$

$\begin{array}{llll}131 & 56 & 133 & (\%) \text { Yield }\end{array}$

131d; $\mathrm{R}_{1}=\mathrm{CH}_{3}, \mathrm{R}_{2}=\mathrm{Ph}, \mathrm{R}_{3}=t-\mathrm{Bu}$

56g: $\mathrm{R}_{4}=\mathrm{p}-\mathrm{OCH}_{2} \mathrm{Ph}_{-} \mathrm{C}_{6} \mathrm{H}_{4}, \mathrm{R}_{5}=\mathrm{R}_{6}=\mathrm{H} 131 \mathrm{a}$

56h: $\mathrm{R}_{4}=\mathrm{p}-\mathrm{N}\left(\mathrm{CH}_{3}\right)_{2}-\mathrm{C}_{6} \mathrm{H}_{4}, \mathrm{R}_{5}=\mathrm{R}_{6}=\mathrm{H}$ 131a

$131 \mathrm{a}$

$131 \mathrm{a}$

$131 a$

131b

131c

131c

$131 \mathrm{c}$

131d

$\begin{array}{lll}56 d & 133 a & 89 \\ 56 e & 133 b & 70\end{array}$

$\begin{array}{lll}56 e & 133 b & 70 \\ 56 a & 133 c & 89\end{array}$

$56 f \quad 133 d$

$56 \mathrm{~g} \quad 133 \mathrm{e}$

$\begin{array}{lll}\mathbf{5 6 g} & 133 \mathrm{e} & 39 \\ \mathbf{5 6 h} & \mathbf{1 3 3 f} & 66\end{array}$

56c 133g

$56 a \quad 133 \mathrm{~h}$

$56 a \quad 133 i \quad 71$

56f 133j 71

56a $133 k \quad 77$

$131 d$

Scheme 42 Synthesis of 1,4-dihydropyridines 133a-m catalyzed by Brønsted acid 132

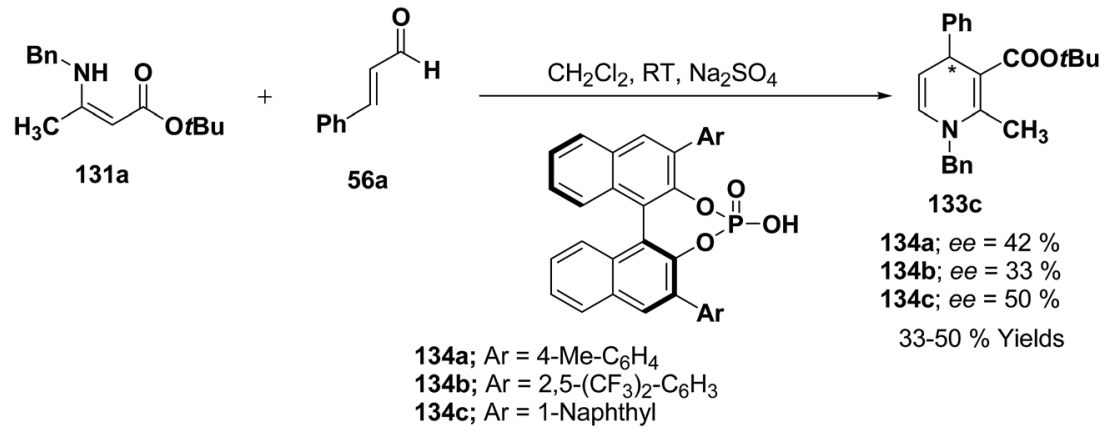

Scheme 43 Enantioselective synthesis of 1,4-dihydropyridine 133c catalyzed by chiral Brønsted acids $134 a-c$. 
<smiles>[R20]OC(=O)/C=C(/[R]OCc1ccccc1)N=P</smiles>

135a; $R_{1}=H, R_{2}=E t$

135b, $R_{1}=R_{2}=M e$

135c; $R_{1}=P h, R_{2}=E t$

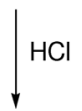

$\mathrm{Cl}^{-}$
One Pot synthesis

(i) $\mathrm{HCl}$

(ii) $56 a / 56 i$<smiles>[R8]C=CC1C(C(=O)O)=C([R])NC([R7])=C1C(=O)O[R20]</smiles>

138a-e

$136 a-c$

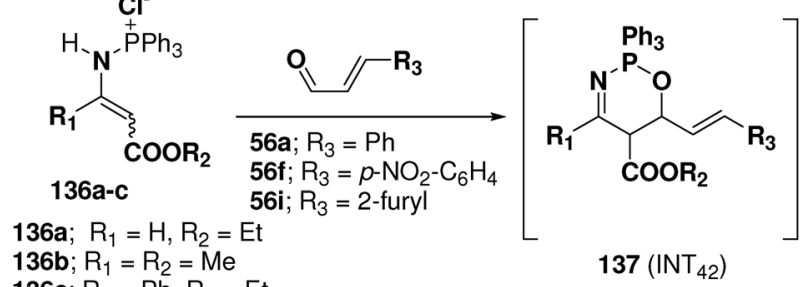

136c: $R_{1}=P h, R_{2}=E t$

\begin{tabular}{ccccllll}
\hline $\begin{array}{c}\text { Starting } \\
\text { Material }\end{array}$ & Product & $\mathbf{R}_{\mathbf{1}}$ & $\mathbf{R}_{\mathbf{2}}$ & $\mathbf{R}_{\mathbf{3}}$ & \multicolumn{3}{c}{ Reaction conditions } \\
\hline $\mathbf{1 3 6 a} / \mathbf{5 6 a}$ & $\mathbf{1 3 8 a}$ & $\mathrm{H}$ & $\mathrm{Et}$ & $\mathrm{C}_{6} \mathrm{H}_{5}$ & $\mathbf{T}\left({ }^{\circ} \mathbf{C}\right)$ & Time (h) & Yield (\%) \\
$\mathbf{1 3 6 a} / \mathbf{5 6 f}$ & $\mathbf{1 3 8 b}$ & $\mathrm{H}$ & $\mathrm{Et}$ & $\mathbf{p}-\mathrm{NO}_{2}-\mathrm{C}_{6} \mathrm{H}_{4}$ & 40 & 30 & 66 \\
$\mathbf{1 3 6 b} / \mathbf{5 6 a}$ & $\mathbf{1 3 8 c}$ & $\mathrm{Me}$ & $\mathrm{Me}$ & $\mathrm{C}_{6} \mathrm{H}_{5}$ & 40 & 20 & 65 \\
$\mathbf{1 3 6 c / 5 6 a}$ & $\mathbf{1 3 8 d}$ & $\mathrm{Ph}$ & $\mathrm{Et}$ & $\mathrm{C}_{6} \mathrm{H}_{5}$ & 40 & 25 & $51^{\mathrm{b}}$ \\
$\mathbf{1 3 6 c / 5 6 i}$ & $\mathbf{1 3 8 e}$ & $\mathrm{Ph}$ & $\mathrm{Et}$ & 2-furyl & 40 & 48 & $57^{\mathrm{b}}$ \\
\hline
\end{tabular}

a Purified by chromatography. ${ }^{b}$ Obtained in "one pot" process from phosphazene $135 \mathrm{c}$.

Scheme 44 Reaction of enamino-phosphonium salts 136 with $\alpha, \beta$-unsaturated aldehydes 55a, 56f and 56i: preparation of symmetrical dihydropyridines $138 \mathrm{a}-\mathrm{e}$

followed by acylation with trichloroacetic anhydride. The subsequent haloform reaction on 106a-e yields $107 \mathbf{a}-\mathbf{e}$, which on $\mathrm{N}$-deprotection gives 108a-e (Scheme 34).

Table 13 The reaction of imines $139 a-m$ with $78 a^{a}$

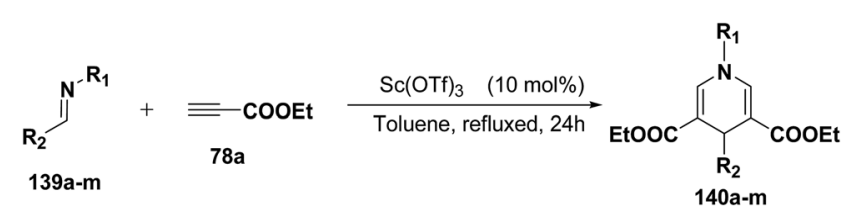

\begin{tabular}{llllll}
\hline Entry & Imine & $\mathrm{R}_{1}$ & $\mathrm{R}_{2}$ & Product 140 & Yield $^{b}(\%)$ \\
\hline 1 & 139a & $c$-Hex & $\mathrm{Ph}$ & $\mathbf{1 4 0 a}$ & $22^{c}$ \\
2 & $\mathbf{1 3 9 b}$ & $t$ - $\mathrm{Bu}$ & $\mathrm{Ph}$ & $\mathbf{1 4 0 b}$ & 18 \\
$3^{d}$ & $\mathbf{1 3 9 c}$ & $\mathrm{Bn}$ & $\mathrm{Ph}$ & $\mathbf{1 4 0 c}$ & 28 \\
4 & $\mathbf{1 3 9 d}$ & $\mathrm{CHPh}$ & $\mathrm{Ph}$ & $\mathbf{1 4 0 d}$ & 35 \\
5 & $\mathbf{1 3 9 e}$ & $\mathrm{Ph}$ & $\mathrm{Ph}$ & $\mathbf{1 4 0 e}$ & $45^{c}$ \\
6 & $\mathbf{1 3 9 f}$ & $p-\mathrm{MeOC}_{6} \mathrm{H}_{4}$ & $\mathrm{Ph}$ & $\mathbf{1 4 0 f}$ & $75^{c}$ \\
$7^{d}$ & $\mathbf{1 3 9 g}$ & $p-\mathrm{MeC}_{6} \mathrm{H}_{4}$ & $\mathrm{Ph}$ & $\mathbf{1 4 0 g}$ & $62^{c}$ \\
$8^{d}$ & $\mathbf{1 3 9 h}$ & $2,6-\mathrm{MeC}_{6} \mathrm{H}_{3}$ & $\mathrm{Ph}$ & $\mathbf{1 4 0 h}$ & 77 \\
9 & $\mathbf{1 3 9 i}$ & $p-\mathrm{MeOC}_{6} \mathrm{H}_{4}$ & $p-\mathrm{MeC}_{6} \mathrm{H}_{4}$ & $\mathbf{1 4 0 i}$ & 78 \\
10 & $\mathbf{1 3 9 j}$ & $p-\mathrm{MeOC}_{6} \mathrm{H}_{4}$ & $p-\mathrm{CI}^{-} \mathrm{C}_{6} \mathrm{H}_{4}$ & $\mathbf{1 4 0 j}$ & 54 \\
11 & $\mathbf{1 3 9 k}$ & $p-\mathrm{MeOC}_{6} \mathrm{H}_{4}$ & $p-\mathrm{FC}_{6} \mathrm{H}_{4}$ & $\mathbf{1 4 0 k}$ & 47 \\
12 & $\mathbf{1 3 9 1}$ & $p-\mathrm{MeOC}_{6} \mathrm{H}_{4}$ & $p-\mathrm{NO}_{2} \mathrm{C}_{6} \mathrm{H}_{4}$ & $\mathbf{1 4 0 1}$ & 34 \\
13 & $\mathbf{1 3 9 m}$ & $p-\mathrm{MeOC}_{6} \mathrm{H}_{4}$ & $\mathrm{PhCH}_{2} \mathrm{CH}_{2}$ & $\mathbf{1 4 0 m}$ & 0
\end{tabular}

${ }^{a} 133(0.5 \mathrm{mmol}), 78 \mathrm{a}(1.25 \mathrm{mmol}), \mathrm{Sc}(\mathrm{OTf})(0.05 \mathrm{mmol})$ in toluene $(5$ $\mathrm{mL})$ at reflux for $24 \mathrm{~h} .{ }^{b}$ Isolated yield. ${ }^{c}$ GC yield. ${ }^{d}$ BTF was used as a solvent instead of toluene.
Yao, et al. $^{43}$ have developed a simple, inexpensive and efficient one-pot synthesis of 1,4-dihydropyridine derivatives with excellent product yields at room temperature using catalytic amount of molecular iodine. Initially, benzaldehyde, 1,3-cyclohexanedione 109, ethyl acetoacetate 110a and ammonium acetate were stirred at room temperature in a few $\mathrm{mL}$ of ethanol. After 4 hours, only $56 \%$ of product 111a was realized after recrystallization of the crude product from ethanol (entry 1 , Table 8). To improve the product yields and to optimize the reaction condition, molecular iodine was used in catalytic amount (15 mol\%) and a reaction was carried out under similar reaction conditions to give the product 111a in 99\% yield (entry 2 ). The increase in the quantity of molecular iodine from 15 to $30 \mathrm{~mol} \%$ not only reduced the reaction time from 4 to $2.5 \mathrm{~h}$, but also enhanced the product yield from $56 \%$ to $99 \%$ (entry 3 ). Similarly, using $50 \mathrm{~mol} \%$ of iodine as catalyst the reaction time further reduced to $1.5 \mathrm{~h}$ along with a decrease in the yield of the product 111a (70\%) (entry 4).

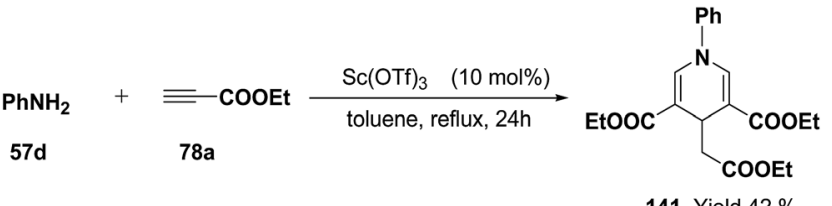

Scheme $45 \mathrm{Sc}(\mathrm{OTf})_{3}$ catalyzed reaction of aniline $57 \mathrm{~d}$ and 78a: preparation of 1,4-DHP 141. 
A range of aryl and alkyl aldehydes were subjected to react with 109, 110a and $\mathrm{NH}_{4} \mathrm{OAc}$ in the presence of either 15 or 30 mol\% of iodine to generate corresponding 1,4-DHP 111b. The results are summarized in Table 9, e.g. with $30 \mathrm{~mol} \%$ of iodine as catalyst, $p$-chlorobenzaldehyde is converted into the product in $6 \mathrm{~h}$ with 99\% yield, whereas the same reaction takes place within 40 min with $15 \mathrm{~mol} \%$ of iodine without significant loss of yield (Table 9, entries $9 \& 10$ ). In general, the yields are little less with $15 \mathrm{~mol} \%$ of catalyst and the reaction times are also short. Both aliphatic and aromatic aldehydes react equally good to give the products with excellent yields. The aryl group substituted with different groups and same groups located at different positions of the aromatic ring has not shown much effect on the formation of the final product.

Bazureaua, et $a l .{ }^{44}$ have developed a three component one pot microwave dielectric heating assisted liquid phase synthesis of 1,4-dihydropyridines using task specific ionic liquid as a soluble solid support. They synthesized the ILP bound aldehydes 113a-d in high yields by the esterification of PEG-ILPs

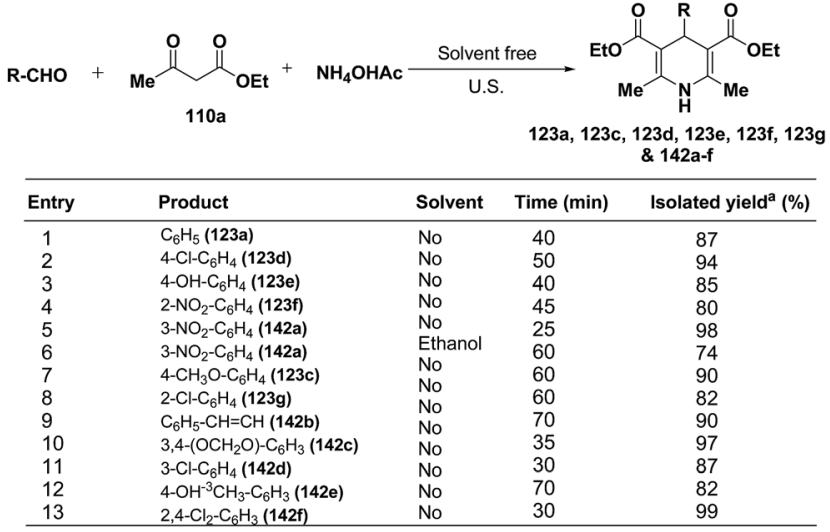

a Isolated yield based on the corresponding aldehydes.

112a-d with 4-formylbenzoic acid in dry $\mathrm{MeCN}$ with dicyclohexylcarbodiimide (DCC) and 5\% of dimethylamino pyridine (DMAP) as catalyst. The ILP bound 1,4-dihydropyridines 115 has been synthesized in an excellent yields via two methods. Method A involves the condensation of aldehydes 113a-d and 1.0 equiv. of $\beta$-ketoester ethyl acetoacetate 110a or methyl acetoacetate $\mathbf{1 1 0 b}$ and 1.0 equiv. of aminocrotonate $\mathbf{1 1 4}$ under microwave irradiation $\left(120{ }^{\circ} \mathrm{C}, 150 \mathrm{~W}, 50 \%\right.$ power level, time exposure: $10 \mathrm{~min}$ ), in the method B the IL-phase bound 1,4-DHP 115 was prepared by the condensation from $\beta$-ketoester 110a or 110b (2.0 equiv.) and $\mathrm{NH}_{4} \mathrm{OAc}$ (2.0 equiv.) using the same

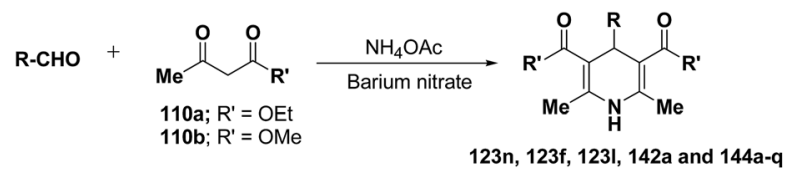

\begin{tabular}{|c|c|c|c|c|}
\hline Entry & Product (R) & 104 & Time (min) & Isolated yield (\%) \\
\hline 1 & 3-pyridyl (123n) & $110 a$ & $25[a]$ & 93 \\
\hline 2 & 4-Cl- $\mathrm{C}_{6} \mathrm{H}_{4}(144 \mathrm{a})$ & $110 b$ & $20^{\circ}$ & 91 \\
\hline 3 & 4-pyridyl (144b) & $110 a$ & $10[\mathrm{~b}]$ & 90 \\
\hline 4 & $4-\mathrm{Br}_{-} \mathrm{C}_{6} \mathrm{H}_{4}(144 \mathrm{c})$ & $110 b$ & 10 & 89 \\
\hline 5 & $\mathrm{Me}_{2} \mathrm{~N}-\mathrm{C}_{6} \mathrm{H}_{4}(\mathbf{1 4 4 d})$ & $110 \mathrm{~b}$ & 25 & 93 \\
\hline 6 & $\mathrm{Me}_{2} \mathrm{~N}-\mathrm{C}_{6} \mathrm{H}_{4}(144 \mathrm{e})$ & $110 a$ & 15 & 91 \\
\hline 7 & 2-pyridyl (144f) & $110 a$ & $20[c]$ & 93 \\
\hline 8 & 3- $\mathrm{NO}_{2}-\mathrm{C}_{6} \mathrm{H}_{4}(142 \mathrm{a})$ & $110 a$ & 5 & 95 \\
\hline 9 & $3-\mathrm{NO}_{2}-\mathrm{C}_{6} \mathrm{H}_{4}(\mathbf{1 4 4 g})$ & $110 b$ & 20 & 92 \\
\hline 10 & $2-\mathrm{NO}_{2}-\mathrm{C}_{6} \mathrm{H}_{4}(123 \mathrm{f})$ & $110 a$ & 25 & 92 \\
\hline 11 & 2-Furyl (123I) & $110 a$ & 10 & 95 \\
\hline 12 & 2-Furyl (144h) & $110 \mathrm{~b}$ & 15 & 98 \\
\hline 13 & $\beta$-Naphthyl (144i) & $110 a$ & 22 & 88 \\
\hline 14 & $\beta$-Naphthyl (144j) & $110 \mathrm{~b}$ & 25 & 89 \\
\hline 15 & $\mathrm{CH}_{3} \mathrm{CH}=\mathrm{CH}(144 \mathrm{k})$ & $110 b$ & 15 & 93 \\
\hline 16 & $\mathrm{CH}_{3} \mathrm{CH}=\mathrm{CH}$ (144I) & $110 a$ & 15 & 94 \\
\hline 17 & $\mathrm{C}_{6} \mathrm{H}_{4} \mathrm{CH}=\mathrm{CH}(144 \mathrm{~m})$ & $110 \mathrm{~b}$ & 20 & 86 \\
\hline 18 & $2,3-(\mathrm{OH})_{2}-\mathrm{C}_{6} \mathrm{H}_{3}(144 n)$ & $110 b$ & 25 & 89 \\
\hline 19 & $\mathrm{C}_{6} \mathrm{~F}_{5}(\mathbf{1 4 4 0})$ & $110 a$ & 45 & 90 \\
\hline 20 & $\mathrm{C}_{6} \mathrm{~F}_{5}(144 \mathrm{p})$ & $110 b$ & 45 & 90 \\
\hline 21 & 4- $\mathrm{CF}_{3}-\mathrm{C}_{6} \mathrm{H}_{4}(144 \mathrm{q})$ & $110 a$ & 30 & 95 \\
\hline
\end{tabular}

Scheme 48 Synthesis of 1,4-dihydropyridines in presence of $5 \mathrm{~mol} \%$ of the barium nitrate.

Scheme 46 Synthesis of 1,4-dihydropyridines under ultrasound at room temperature.
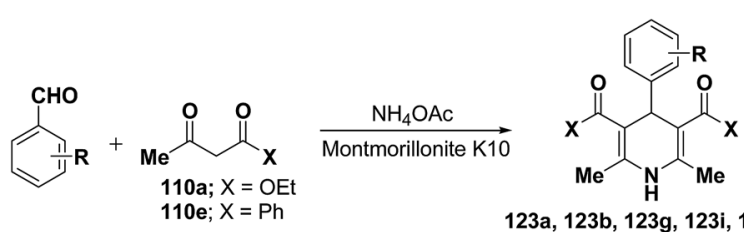

123a, 123b, 123g, 123i, 142a and 143a-c

$143 \mathrm{a} ; \mathrm{X}=\mathrm{Ph}, \mathrm{R}=m-\mathrm{NO} 2$

143b; $X=P h, R=O-C$

143c; $X=P h, R=H$

\begin{tabular}{clcc}
\hline Entry & Product (R) & Time (min) & Isolated yield (\%) \\
\hline 1 & $\mathrm{H}(\mathbf{1 2 3 a})$ & 30 & 65 \\
2 & $o-\mathrm{OMe}(\mathbf{1 2 3 i})$ & 40 & 83 \\
3 & $m-\mathrm{NO}_{2}(\mathbf{1 4 2 a})$ & 30 & 75 \\
4 & $o-\mathrm{Cl}(\mathbf{1 2 3 g})$ & 70 & 60 \\
5 & $p-\mathrm{Me}(\mathbf{1 2 3 b})$ & 60 & 60 \\
6 & $m-\mathrm{NO}_{2}(\mathbf{1 4 3 a})$ & 60 & 40 \\
7 & $o-\mathrm{Cl}(\mathbf{1 4 3 b})$ & 50 & 35 \\
8 & $\mathrm{H}(\mathbf{1 4 3 c})$ & 40 & 40 \\
\hline
\end{tabular}

Scheme 47 Synthesis of 1,4-dihydropyridines catalyzed by montmorillonite K10 clay.

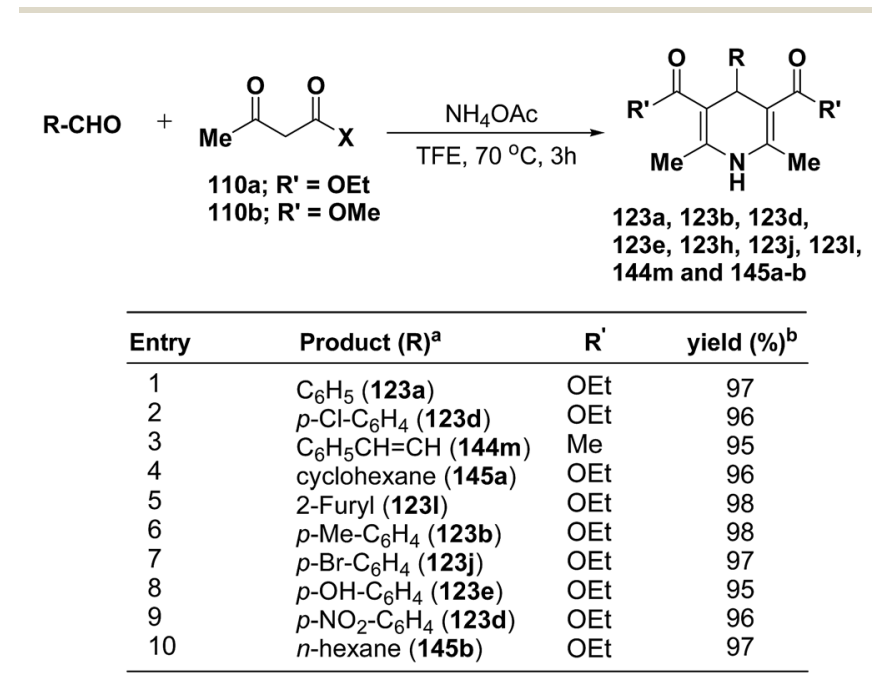

a Reaction condition: aldehyde $(1.0 \mathrm{mmol})$, acetoacetate ester (2.0 mmol), $\mathrm{NH}_{4} \mathrm{OAc}(1 \mathrm{mmol}), \mathrm{TFE}(2 \mathrm{~mL}), 3 \mathrm{~h} .{ }^{\mathrm{b}}$ |solated yield.

Scheme 49 Synthesis of 1,4-dihydropyridines through Hantzsch reaction in TFE. 
microwave reaction conditions $\left(120^{\circ} \mathrm{C}, 10 \mathrm{~min}\right)$ (Scheme 35$)$. ILphase, the bound products $\mathbf{1 1 5} \mathbf{a}-\mathbf{b}$ were subjected to cleavage by: (i) transesterification with $30 \%$ of $\mathrm{MeONa}$ in refluxed $\mathrm{MeOH}$ during $18 \mathrm{~h}$, (ii) saponification with $60 \%$ of $\mathrm{LiOH}$ in THF at room temperature, followed by controlled acidification with a solution of $3.0 \mathrm{M} \mathrm{HCl}$ to obtain the desired 1,4-DHP 116a-b in an good yield. Similarly 118a-b was synthesized by the condensation of 113a-d with $110 \mathrm{a}$ or $110 \mathrm{~b}$ (1.0 equiv.) and 117 (1.0 equiv.) and $\mathrm{NH}_{4} \mathrm{OAc}$ (2.0 equiv.) under the same microwave radiation condition. $\mathbf{1 1 8 a}-\mathbf{b}$ on transesterification followed by saponification yielded 119a-b.

J. H. Lee ${ }^{45}$ has described an efficient method for the synthesis of 1,4-DHP under mild reaction condition using Baker's yeast. In a typical procedure a solution of $100 \mathrm{~mL}$ of $\mathrm{pH}$ 7.0 phosphate buffer, $5.0 \mathrm{~g}$ of D-glucose, and $2.0 \mathrm{~g}$ of yeast extract was warmed at $35^{\circ} \mathrm{C}$. Further $5.0 \mathrm{~g}$ of dry active Baker's yeast was added to this solution and the mixture was stirred at
$30{ }^{\circ} \mathrm{C}$ for $30 \mathrm{~min}$, after which, acetoacetic ester 110a or 110b $(1.0 \mathrm{mmol})$ and ammonium acetate or 3-amino crotonitrile 120 were added. The mixture was stirred at room temperature for $24 \mathrm{~h}$ and then extracted with diethyl ether. The organic layer was dried and concentrated in vacuo and the resulting crude products were recrystallized using ether- $n$-hexane to afford pure products 121a-b and 122a-b in 46-70\% yields (Scheme 36).

The glycolytic pathway from D-glucose to pyruvate is one of the most universal metabolic pathway known. In yeast, glycolysis is supposed to be the main pathway for the catabolism of glucose. According to the classical concept of glycolysis, metabolic acetaldehyde, resulting in the formation of acetoin, should be released from pyruvate in aerobic conditions. It is assumed that this acetaldehyde is involved in this Hantzschtype reaction (Scheme 37).

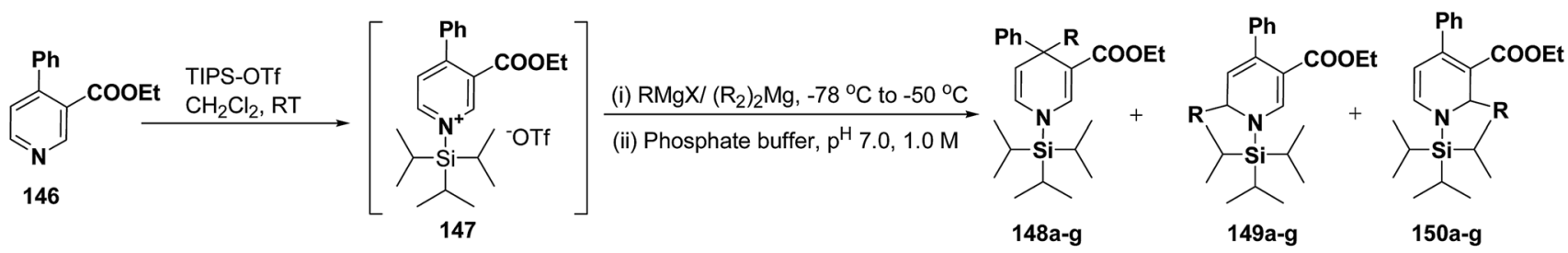

\begin{tabular}{|c|c|c|c|c|c|c|}
\hline \multirow[t]{2}{*}{ Entry } & \multirow[t]{2}{*}{ Nucleophile $\left(\mathrm{RMgx} / \mathrm{R}_{2} \mathrm{Mg}\right)^{\mathrm{a}}$} & \multirow[t]{2}{*}{$\mathrm{Cu}(\mathrm{I})$-salt (15 mol\%) } & \multicolumn{2}{|c|}{ Product/educt ratio ${ }^{b}$} & \multicolumn{2}{|c|}{ 1,4-dihydropyridines } \\
\hline & & & $148 / 149 / 150$ & $(148+149+150) / 146$ & Product No. & Yield $^{c}(\%)$ \\
\hline 1 & $\mathrm{MeMgBr}$ & - & $-d$ & - & $148 a$ & e \\
\hline 2 & $\mathrm{Me}_{2} \mathrm{Mg}$ & - & $-d$ & - & $148 a$ & e \\
\hline 3 & EtMgCl & - & $61 / 35 / 4$ & $58 / 42$ & $148 b$ & 20 \\
\hline 4 & $\mathrm{Et}_{2} \mathrm{Mg}$ & - & $64 / 35 / 4$ & $98 / 2$ & $148 b$ & 55 \\
\hline 5 & EtMgCl & $\mathrm{CuBe}_{\mathrm{SMe}}$ & $97 / 3 / 0$ & $33 / 67$ & $148 b$ & 15 \\
\hline 6 & EtMgCl & CuCN & $99 / 1 / 0$ & $70 / 30$ & $148 b$ & 25 \\
\hline 7 & $\mathrm{Et}_{2} \mathrm{Mg}$ & $\mathrm{CuBr} \mathrm{SMe}_{2}$ & $76 / 14 / 1$ & $44 / 55$ & $148 b$ & 23 \\
\hline 8 & iPrMgCl & - & $99 / 1 / 0$ & $70 / 30$ & $148 c$ & 63 \\
\hline 9 & $\mathrm{ipr}_{2} \mathrm{Mg}$ & - & $100 / 0 / 0$ & $97 / 3$ & $148 c$ & 91 \\
\hline 10 & tBuMgCl & - & $94 / 6 / 0$ & $40 / 60$ & $148 d$ & 47 \\
\hline 11 & $t \mathrm{Bu}_{2} \mathrm{Mg}$ & $\cdot$ & $86 / 14 / 0$ & $89 / 11$ & $148 d / 149 d$ & $56 / 5^{f}$ \\
\hline 12 & AllM̆g & - & $-d$ & - & $148 e$ & e \\
\hline 13 & $\mathrm{All}_{2} \mathrm{Mg}$ & - & $-d$ & - & $\begin{array}{l}140 e \\
1480\end{array}$ & e \\
\hline 14 & $\mathrm{BnMgCl}$ & - & $72 / 28 / 0$ & $69 / 31$ & $148 \mathrm{e}$ & $\begin{array}{l}\mathrm{e} \\
3817\end{array}$ \\
\hline 15 & $\mathrm{Bn}_{2} \mathrm{Mg}$ & - & $50 / 49 / 1$ & $98 / 2$ & 148f/149f & $38 / 7$ \\
\hline 16 & $\mathrm{BnMgCl}$ & $\mathrm{CuBe}_{\mathrm{SMe}} \mathrm{SM}_{2}$ & $95 / 5 / 0$ & $95 / 5$ & $148 f / 149 f$ & $45 / 24$ \\
\hline 17 & $\mathrm{BnMgCl}$ & $\mathrm{Me}_{2} \mathrm{~S}^{\mathrm{g}}$ & $85 / 15 / 0$ & $46 / 54$ & $148 f$ & 41 \\
\hline 18 & $\mathrm{Bn}_{2} \mathrm{Mg}$ & $\mathrm{CuBr} \mathrm{SMe}_{2}$ & $62 / 38 / 0$ & $66 / 34$ & $148 f$ & 40 \\
\hline 19 & $\mathrm{BnMgCl}$ & $\mathrm{CuCN}$ & $99 / 1 / 0$ & $95 / 5$ & $148 f$ & 28 \\
\hline 20 & $\mathrm{BnMgCl}$ & $\mathrm{CuCN}^{\mathrm{h}}$ & $59 / 41 / 0$ & $95 / 5$ & $148 f$ & $31 / 25$ \\
\hline 21 & $\mathrm{BnMgCl}$ & $\mathrm{Bu}_{4} \mathrm{~N}^{+} \mathrm{I}^{-}$ & $90 / 1-/ 0$ & $60 / 40$ & $148 f / 149 f$ & 38 \\
\hline 22 & $\mathrm{BnMgCl}$ & $\mathrm{Bu}_{4} \mathrm{~N}^{+} \mathrm{Br}^{-}$ & $92 / 8 / 0$ & $46 / 54$ & $148 f$ & 39 \\
\hline 23 & $\mathrm{BnMgCl}$ & $\mathrm{Bu}_{4} \mathrm{~N}^{+} \mathrm{Cl}^{-}$ & $85 / 15 / 0$ & $43 / 57$ & $148 f$ & 44 \\
\hline 24 & $\mathrm{PhMgCl}$ & - & $90 / 10 / 0$ & $13 / 87$ & $148 f / 149 g$ & 7 \\
\hline 25 & $\mathrm{Ph}_{2} \mathrm{Mg}$ & - & $98 / 2 / 0$ & $63 / 37$ & $148 \mathrm{~g}$ & 46 \\
\hline
\end{tabular}

a Compound 146 was dissolved in $\mathrm{CH}_{2} \mathrm{Cl}_{2}$ and treated with 1.0 equiv. of silyl triflate at room temperature. After 15 min the solution was cooled to $-75^{\circ} \mathrm{C}$ and 2.0 equiv. of the corresponding organomagnesium reagent was added. Work up was performed by addition of phosphate buffer $(\mathrm{pH} 7.0, \mathrm{c}=1.0 \mathrm{M})$ and extraction of the aqueous layer with $\mathrm{CH}_{2} \mathrm{Cl}_{2}$. ${ }^{b}$ According to ${ }^{1} \mathrm{H}$ NMR of the crude product. ${ }^{c}$ Isolated yield. ${ }^{d}$ Not determinable. ${ }^{e}$ Not isolated. ${ }^{f}$ Contaminated with $9 \% 148 \mathrm{~d}$.

${ }^{g}$ Addition of $20 \mathrm{~mol} \%{ }^{\mathrm{h}} 1.0$ equiv. 
Sridhar, et $a .^{46}$ have reported an efficient and convenient procedure for the one-pot synthesis 1,4-dihydropyridine derivatives 123a-r in excellent yields (Scheme 38) by the condensation of $\beta$-dicarbonyl compounds 110a or 110b, aldehydes and ammonium acetate, by using heterogeneous catalyst $\left(\mathrm{HClO}_{4}-\right.$ $\mathrm{SiO}_{2}$ ) under solvent-free conditions. The experimental procedure has been found very simple, convenient, and has the ability to tolerate a variety of other functional groups on phenyl ring of the aromatic aldehydes such as methoxy, nitro, hydroxyl and halides under the reaction conditions. Further the optimized reaction condition has been examined to prove the universality of this catalyst application. Various aromatic, aliphatic and heterocyclic aldehydes were selected to undergo the Hantzsch condensation in the presence of heterogeneous catalyst $\left(\mathrm{HClO}_{4}-\mathrm{SiO}_{2}\right)$. The results of this study are summarized in (Table 10).

Wanner, et $a .^{47}$ have synthesized $N$-silyl protected 1,4-DHP 126a-n by the addition reaction of dialkylmagnesium reagents $\left(\mathrm{R}_{2} \mathrm{Mg}\right.$ ) to $\mathrm{N}$-triisopropylsilylpyridinium ions 125a-b (Scheme 39). The $N$-triisopropylsilylpyridinium ions $\mathbf{1 2 5 a} \mathbf{a}$-b were generated in situ by the reaction of 4-substituted pyridines 124ab and triisopropylpyridinium-triflate (TIPS-OTf). The regioselectivity of 4-addition product of this reaction was quite satisfactory (Table 11, entries 1, 2, 3, 6, 7, 9, 10, 11 and 12).

Perumal, et al. ${ }^{48-50}$ has carried out an initial study in search for the suitable catalyst and solvent for the synthesis of 1,4DHP using cinnamaldehyde 56a, $m$-toluidine 129a and ethyl acetoacetate 110a. Author first assayed indium trichloride, ${ }^{\mathbf{4 4}}$ triphenylphosphonium perchlorate, ${ }^{\mathbf{4 5}}$ and potassium hydrogen sulfate as catalysts, ${ }^{\mathbf{4 6}}$ which have been successfully employed in related condensation reactions, but the yields obtained were only moderate, even with high catalyst loadings. The best results were obtained with cerium ammonium nitrate (CAN) in ethanol, which gave the desired dihydropyridine derivative in $71 \%$ isolated yield (Scheme 40). Further Perumal, et al. ${ }^{51}$ have developed cerium ammonium nitrate (CAN) catalyzed threecomponent domino reaction between aromatic amines $\mathbf{5 7 d}$, 70d \& 129a-h, $\alpha, \beta$-unsaturated aldehydes 56a \& 56c and alkyl acetoacetate 110a, 110c \& 110d to afford the 1,4-dihydropyridines 130a-s in moderate to good yields (Scheme 41, Table 12).

Renaud, et al. ${ }^{52}$ has developed Brønsted acid 132 catalyzed addition of $\beta$-enaminoacrylates $131 \mathrm{a}-\mathbf{d}$ to $\alpha, \beta$-unsaturated aldehydes 56a, 56c and 56d-h to afford the corresponding $N$ substituted 1,4-dihydropyridines 133a-m in $31-89 \%$ yields (Scheme 42).

Further author have also reported the enantioselective synthesis of 1,4-dihydropyridine 133c starting from 131a and 56a using three different chiral Brønsted acids 134a-c in ee 33$50 \%$ (Scheme 43).

Palacios, et al..$^{53}$ explored the reactivity of enaminophosphonium salts 136a-c derived from phosphazenes 135a-c with $\alpha, \beta-$ unsaturated aldehydes 56a, $56 \mathbf{f}$ and $56 \mathbf{i}$ (Scheme 44). The reaction of enaminophosphonium salt 135a, prepared by hydrochloric acid treatment of $N$-vinylic phosphazene 135a, with cinnamaldehyde 56a or $p$-nitrocinnamaldehyde $56 \mathrm{f}$ in refluxing $\mathrm{CH}_{2} \mathrm{Cl}_{2}$ led to the formation of 4-(2-phenylethenyl)-3,5-diethoxycarbonyl- 1,4-dihydropyridine 138a and 4-[2-(4-nitrophenyl)ethenyl]-3,5diethoxycarbonyl-1,4-dihydropyridine $\mathbf{1 3 8 b}$ in 66 and $62 \%$ yields, respectively. The formation of these dihydropyridines 138 could be explained by means of a formal $[4+2]$-cyclization process involving an initial 1,4-addition of the $\gamma$-carbon atom of the enaminophosphonium salt 136a to the carbonyl group of the aldehydes 56a to give the cycloadduct intermediate 1,2,5oxaazaphosphoranes $137\left(\mathrm{INT}_{42}\right)$ followed by regioselective attack of a second molecule of the phosphonium salt 130a (Scheme 44). 1,4-DHPs 138d and 138e were also obtained in "one pot" process from phosphazene 135c in 51 and $57 \%$ yields, respectively.

Fukuzawa, et al. ${ }^{54}$ have developed a procedure for the synthesis of $N$-substituted-1,4-dihydropyridines 140a-m in moderate to good yields by scandium(III) triflate catalyzed reaction of imines $139 a-m$ with ethyl propiolate $78 \mathbf{a}$ (2.5 equiv.) in toluene or benzotrifluoride (BTF) under refluxed conditions (Table 13).

Further, it has also been reported by the author's that the $\mathrm{Sc}(\mathrm{OTf})_{3}$ catalyzed reaction of aniline $\mathbf{5 7} \mathbf{d}$ and ethyl propiolate 78a (3.2 equiv.) yielded another 1,4-dihydropyridine 141 bearing three ester groups in $42 \%$ yield under the same reaction conditions (Scheme 45).

Wang, et $a .^{55}$ has developed a three-component one pot condensation of aldehydes, ethyl acetoacetate 110a and ammonium acetate to afford the 1,4-dihydropyridines 123a, 123c, 123d, 123e, 123f, 123g and 142a-f in 82-99\% yields under ultrasound irradiation without solvent and catalyst at room temperature (Scheme 46). The main advantages of this procedure are mild reaction condition, shorter reaction time and high product yield.

Zonouz, et al. ${ }^{56}$ have developed a three-component one pot condensation of aldehydes ethylacetoacetate 110a/

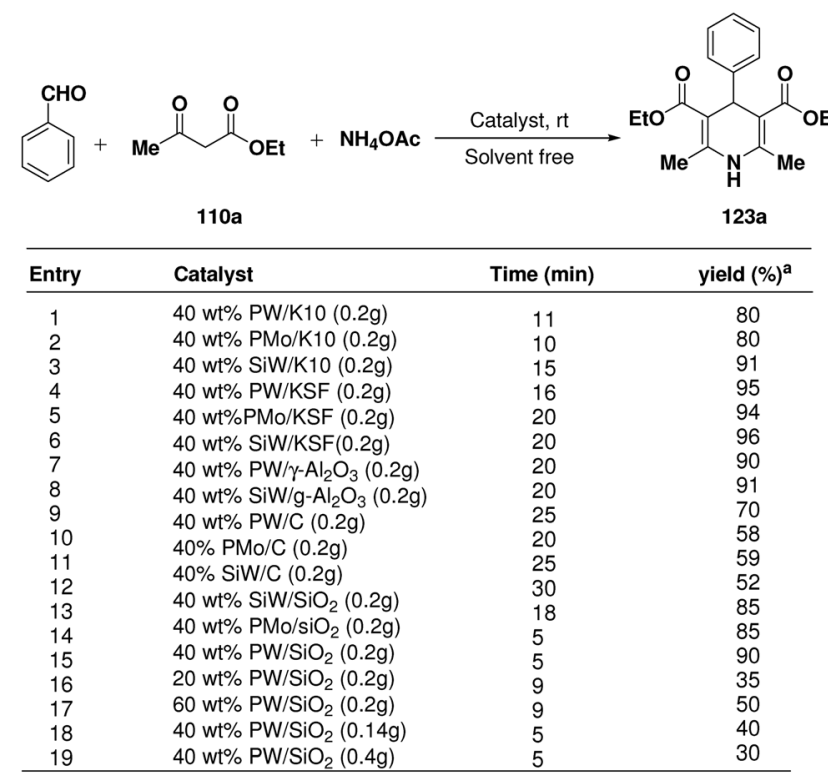

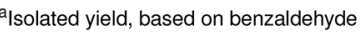

$\mathrm{H}_{3} \mathrm{PW}_{12} \mathrm{O}_{40}(\mathrm{PW}), \mathrm{H}_{4} \mathrm{SiW}_{12} \mathrm{O}_{40}(\mathrm{SiW})$, and $\mathrm{H}_{3} \mathrm{PMo}_{12} \mathrm{O}_{40}(\mathrm{PMo})$.

Scheme 51 Effect of different catalyst on the yield of 1,4dihydropyridine. 
Table 14 Synthesis of Hantzsch 1,4-dihydropyridines by the condensation of aldehydes, $\beta$-dicarbonyl compounds and ammonium acetate/ amines using $\mathrm{PW} / \mathrm{SiO}_{2}$ as catalyst

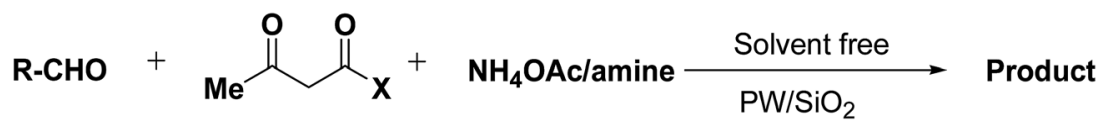

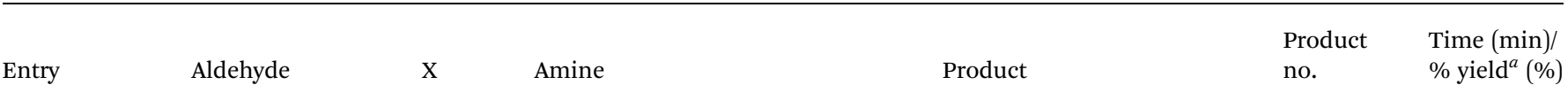<smiles>O=Cc1ccccc1</smiles>

OEt $\quad \mathrm{NH}_{4} \mathrm{OAc}$<smiles>O=Cc1cccs1</smiles>

OEt $\quad \mathrm{NH}_{4} \mathrm{OAc}$

2<smiles>O=Cc1ccco1</smiles>

OEt $\quad \mathrm{NH}_{4} \mathrm{OAc}$

3

4<smiles>Cc1ccc(C=O)cc1</smiles>

OEt $\quad \mathrm{NH}_{4} \mathrm{OAc}$<smiles>O=Cc1ccc(Cl)cc1</smiles>

OEt $\quad \mathrm{NH}_{4} \mathrm{OAc}$<smiles>O=CC=Cc1ccccc1</smiles>

$\mathrm{OMe} \quad \mathrm{NH}_{4} \mathrm{OAc}$<smiles>COc1ccc(C=O)cc1</smiles>

$\mathrm{Ph} \quad \mathrm{NH}_{4} \mathrm{OAc}$

6

7

8<smiles>COCCNCCOCCN</smiles><smiles>CCOC(=O)C1=C(C)NC(=NC)C(c2ccccc2)C1C(=O)OCC</smiles><smiles>CCOC(=O)C1=C(C(=O)OCC)C(c2cccs2)C(C(=O)OCC)=[N+](C)N1</smiles>

1231 4/98<smiles>CCOC(=O)C1=C(C)NC(=NC)C(C(=O)OCC)C1c1ccco1</smiles>

123b $35 / 96$<smiles>CCOC(=O)C1=C(C(=O)OCC)C(c2ccc(C)cc2)C(C)=NC(C)N1</smiles>

123d 8/92<smiles>CCOC(=O)N=C1NC(C)=C(C(=O)OCC)C(C(=O)OCC)C1c1ccc(Cl)cc1</smiles>

142b $20 / 91$<smiles>CCOC(=O)C1=C(C(=O)OCC)C(/C=C/c2ccccc2)C(C(=O)OCC)=C(C)N1</smiles>

151a $32 / 55$<smiles></smiles>

151b

$5 / 190$

$13 / 94$<smiles>C1CCC1</smiles>$$
\text { (n) }
$$<smiles>COC(=O)C1=C(C(=O)OC)N(CCO)C([N+](=O)[O-])=C(C(=O)OC)C1c1ccc([N+](=O)[O-])cc1</smiles> 


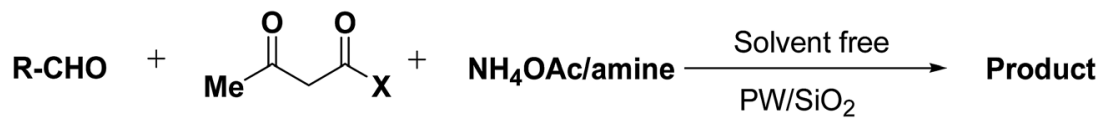

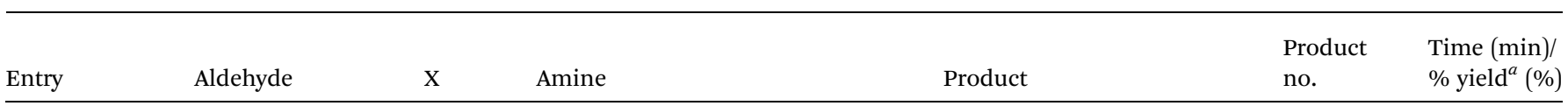

9<smiles>O=Cc1ccco1</smiles>

OMe

$\mathrm{OH}\left(\mathrm{CH}_{2}\right)_{2} \mathrm{NH}_{2}$

OMe $\quad \mathrm{OH}\left(\mathrm{CH}_{2}\right)_{2} \mathrm{NH}_{2}$<smiles>O=Cc1ccc(C=O)cc1</smiles><smiles>O=CC=Cc1ccccc1</smiles>

OEt $\quad \mathrm{PhNH}_{2}$

11

$10^{b}$

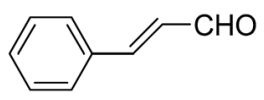

OEt 4-CI-PhNH<smiles>COC(=O)C1=C([N+](=O)[O-])N(CCO)C([N+](=O)[O-])=C(C(=O)O[Na])C1c1ccco1</smiles>

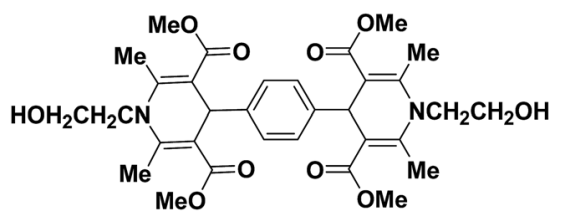

151d

$151 \mathrm{c}$

20/84<smiles>O=C(O)C1=C([N+](=O)[O-])C(c2ccccc2)C=CN1c1ccccc1</smiles>

151e<smiles>COC(=O)C1=C(Nc2ccccc2)N(c2ccccc2)C=CC1c1ccc(Cl)cc1</smiles>

\footnotetext{
${ }^{a}$ Isolated yield, based on aldehyde. ${ }^{b}$ Aldehyde : $\beta$-dicarbonyl compound : ethanolamine $(1: 3: 1.5)$.
}

phenylacetylacetone 110e and $\mathrm{NH}_{4} \mathrm{OAc}$ in the presence of a solid catalyst (montmorillonite K10 clay) to afford 1,4-dihydropyridines 123a, 123b, 123g, 123i, 142a and 143a-c in good yields (Scheme 47). This procedure has advantages such as short reaction time, high yield and simple reaction workup conditions.
Rawat, et al. ${ }^{57}$ have developed an efficient methodology for the three-component one pot condensation of aldehydes, alkylacetoacetate 110a/110b and $\mathrm{NH}_{4} \mathrm{OAc}$ using barium nitrate as a efficient catalyst to afford 1,4-dihydropyridines 123n, 123f, 1231, 142a and 144a-q (Scheme 48).

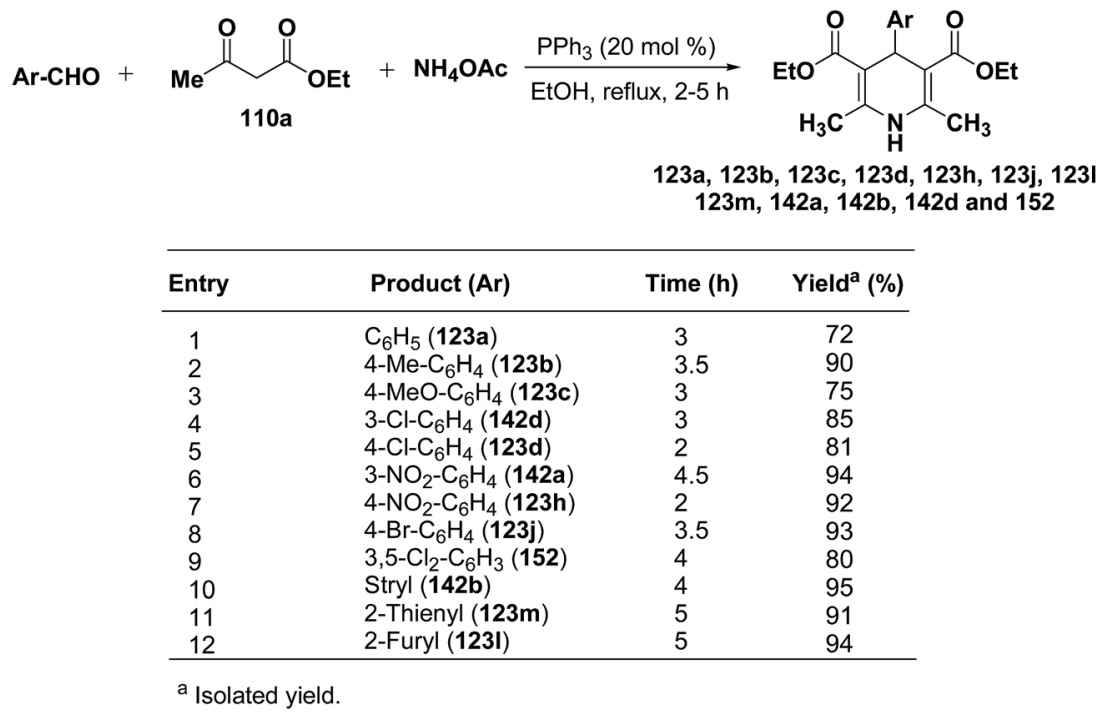

Scheme 52 Triphenylphosphine-catalyzed Hantzsch synthesis of 1,4-dihydropyridines. 
Heydari, et al. ${ }^{58}$ has synthesized 1,4-dihydropyridines 123a, 123b, 123d, 123e, 123h, 123j, 123l, 144m and 145a-b in excellent yields by the reaction of aldehydes, alkyl acetoacetate 110ab, and ammonium acetate (Scheme 49) at $70{ }^{\circ} \mathrm{C}$ in trifluoroethanol (TFE). The advantage of this reaction was the solvent (TFE), which can be readily separated from reaction products and recovered in excellent purity for reuse.

Wanner, et $a .^{59}$ have developed a methodology for the synthesis of 4,4-disubstituted 1,4-dihydronicotinates $148 \mathrm{a}-\mathrm{g}$ by the regioselective addition of Grignard reagents $\mathrm{RMgX}$ or $\mathrm{R}_{2} \mathrm{Mg}$ to nicotinic acid ester 146, activated with triisopropylsilyl triflate 147 (Scheme 50). The regioselectivity of this reaction, where 4-unsubstituted and 4-substituted pyridine derivatives were employed as starting materials, was examined. Depending on the structure of the organomagnesium reagent varying ratios of 1,2- (149a-g), 1,4- (148a-g), and 1,6-regioisomers (150a-g) were obtained but in all the cases 1,4-addition products were predominating one.

Rafiee, et al. ${ }^{60}$ have prepared 12-tungstophosphoric acid (PW) supported on different metal oxides and their catalytic performances have been evaluated in the three component condensation of benzaldehyde, ethyl acetoacetate 110a and ammonium acetate to afford the corresponding 1,4-dihydropyridine 123a (Scheme 51). A high catalytic activity was found over silica supported PW. Effect of PW loading, catalyst loading and solvent has been studied by the author to find out the best reaction condition. $40 \% \mathrm{PW}$ onto $\mathrm{SiO}_{2}(0.2 \mathrm{~g})$ under solvent-free condition has been found to be the best catalyst for the synthesis of 1,4-dihydropyridines.

A series of 4-aryl, $N$-alkyl, and $N$-aryl substituted 1,4-dihydropyridines 123a, 123b, 123m, 1231, 123d, 142b and 151a-f have been synthesized using different aldehydes in good to excellent yield in short reaction times (Table 14).<smiles></smiles>

123a, 123b, 123c, 123d, 123f, 123h,

$123 i, 123 \mathrm{I}, 123 \mathrm{~m}, 142 \mathrm{a}, 144 \mathrm{i}, 153 \mathrm{a}-\mathrm{d}$

\begin{tabular}{|c|c|c|c|}
\hline Entry & Product ( $R)$ & Time (h) & Yield $^{\mathrm{a}}(\%)$ \\
\hline 1 & $\mathrm{C}_{6} \mathrm{H}_{5}(123 \mathrm{a})$ & 3 & 80 \\
\hline 2 & $4-\mathrm{OMe}-\mathrm{C}_{6} \mathrm{H}_{4}(123 \mathrm{c})$ & 4 & 82 \\
\hline 3 & $4-\mathrm{F}-\mathrm{C}_{6} \mathrm{H}_{4}(153 \mathrm{~d})$ & 3.5 & 86 \\
\hline 4 & $4-\mathrm{Cl}-\mathrm{C}_{6} \mathrm{H}_{4}(123 \mathrm{~d})$ & 4 & 91 \\
\hline 5 & $4-\mathrm{CH}\left(\mathrm{CH}_{3}\right)_{2}-\mathrm{C}_{6} \mathrm{H}_{4}(153 \mathrm{a})$ & 5 & 81 \\
\hline 6 & $4-\mathrm{C}\left(\mathrm{CH}_{3}\right)_{3}-\mathrm{C}_{6} \mathrm{H}_{4}(153 \mathrm{~b})$ & 5 & 86 \\
\hline 7 & $4-\mathrm{NO}_{2}-\mathrm{C}_{6} \mathrm{H}_{4}(123 \mathrm{~h})$ & 3.5 & 82 \\
\hline 8 & $2-\mathrm{NO}_{2}-\mathrm{C}_{6} \mathrm{H}_{4}$ (123f) & 5.6 & 65 \\
\hline 9 & $3-\mathrm{NO}_{2}-\mathrm{C}_{6} \mathrm{H}_{4}(142 \mathrm{a})$ & 5 & 71 \\
\hline 10 & $\beta-$ Naphthyl (144i) & 5 & 72 \\
\hline 11 & $4-\mathrm{Me}-\mathrm{C}_{6} \mathrm{H}_{4}(123 \mathrm{~b})$ & 3 & 82 \\
\hline 12 & $2-\mathrm{OMe}-\mathrm{C}_{6} \mathrm{H}_{4}(123 \mathrm{i})$ & 6 & 61 \\
\hline 13 & 2-Furyl (123I) & 5.5 & 92 \\
\hline 14 & 2-Thienyl (123m) & 5 & 94 \\
\hline 15 & Isopropyl (153c) & 5 & 89 \\
\hline
\end{tabular}

a Isolated yield.

Scheme $53 \mathrm{CeCl}_{3} \cdot 7 \mathrm{H}_{2} \mathrm{O}$-catalyzed synthesis of Hantzsch 1,4-dihydropyridines.

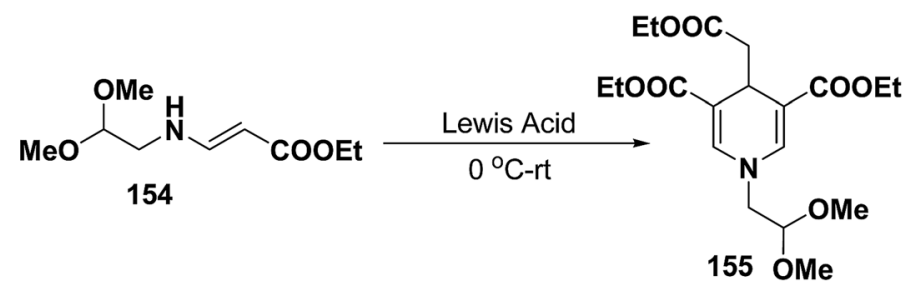

\begin{tabular}{lcllcl}
\hline Lewis Acid & Amount (equiv.) & Solvent & Time & Recovered 154 (\%) & $\mathbf{1 5 5}(\%)$ \\
\hline $\mathrm{BF}_{3} \cdot \mathrm{OEt}_{2}$ & 0.3 & $\mathrm{THF}$ & $10 \mathrm{~h}$ & - & 17 \\
$\mathrm{AlCl}_{3}$ & 0.3 & $\mathrm{THF}$ & $3 \mathrm{~h}$ & - & $<10$ \\
$\mathrm{Me}_{2} \mathrm{AICl}$ & 0.5 & $\mathrm{THF}$ & $10 \mathrm{~h}$ & 98 & - \\
$\mathrm{TiCl}_{4}$ & 0.2 & $\mathrm{DCM}$ & $10 \mathrm{~h}$ & - & 33 \\
\hline
\end{tabular}

Scheme 54 Optimization of Lewis acid catalysts for the synthesis of 1,4-dihydropyridine 155 
Debache, et al. ${ }^{61}$ have developed triphenylphosphinecatalyzed Hantzsch three-component reaction of an aromatic aldehydes, ethyl acetoacetate 110a and ammonium acetate to afford Hantzsch 1,4-dihydropyridines 123a, 123b, 123c, 123d, 123h, 123j, 123l, 123m, 142a, 142b, 142d and 152 in good to excellent yields (Scheme 52).

Yadav, et al. ${ }^{62}$ have developed an efficient one-pot synthesis of 1,4-dihydropyridines 123a, 123b, 123c, 123d, 123f, 123h, 123i, 1231, 123m, 142a, 144i, 153a-d in good to excellent yields via the $\mathrm{CeCl}_{3} \cdot 7 \mathrm{H}_{2} \mathrm{O}$-catalyzed Hantzsch three-component reaction of an aromatic aldehydes, ethyl acetoacetate 110a and ammonium acetate (Scheme 53).

Ajavakom, et al. ${ }^{63}$ have screened several Lewis acid catalysts such as $\mathrm{BF}_{3} \cdot \mathrm{OEt}_{2}, \mathrm{AlCl}_{3}$, and $\mathrm{TiCl}_{4}$ on $\beta$-amino acrylates 154, for the synthesis of 1,4-dihydropyridine 155 (Scheme 54). The yield of product 155 obtained from these initial screening of the Lewis acid catalyst were not satisfactory, which may be likely due to the decomposition of the acetal group in $\beta$-amino acrylate 154 under acidic conditions. Out of the several screened Lewis acid catalyst $\mathrm{TiCl}_{4}$ in dichloromethane was found to be best catalyst for the synthesis of 1,4-dihydropyridine 155 .

Several 1,4-dihydropyridines derivatives 141 and $\mathbf{1 5 7} \mathbf{a}-\mathbf{h}$ has been synthesized from $\beta$-amino acrylates $156 \mathbf{a}-\mathbf{i}$ using $\mathrm{TiCl}_{4}$ as a Lewis acid catalyst (0.2/0.5 equiv.) at $0{ }^{\circ} \mathrm{C}-\mathrm{rt}$ (Scheme 55).

$\mathrm{Li}$, et al. ${ }^{64}$ have screened several experimental conditions to synthesize 1,4-dihydropyridines by the condensation of (Z)-3-(4methoxyphenylamino)-1-phenylprop-2-ene-1-one (158a) with $p$ nitrobenzaldehyde in the presence of catalytic amount of Lewis acids. The reaction of 158 a with $p$-nitrobenzaldehyde in the presence of a catalytic amount of $\mathrm{TsOH} \cdot \mathrm{H}_{2} \mathrm{O}$, TFA or $\mathrm{NaAuCl}_{4}$ $\cdot 2 \mathrm{H}_{2} \mathrm{O}$ yielded the desired 1,4-DHP 159a in 71-79\% yield (Table 15 , entries 2-4). Increase in the aldehyde equivalent from 0.75 to 1.0 not only lessened the reaction time, but also enhanced the yield of the desired product (Table 15, entry $2 v s$. 6). The high yield of the 1,4-DHP 159 was achieved in the presence of $\mathrm{TsOH} \cdot \mathrm{H}_{2} \mathrm{O}$ as a catalyst (85-87\%; Table 15, entries 6 and 7).

\begin{tabular}{|c|c|c|c|c|c|}
\hline $\begin{array}{r}\mathrm{R}^{-\mathrm{H}} \\
156\end{array}$ & COOE & \multicolumn{4}{|c|}{141 and $157 \mathrm{a}-\mathrm{h}$} \\
\hline Entry & Acrylate & $\mathrm{TiCl}$ & $\mathrm{I}_{4}$ (equiv) & Product & Yield (\%) \\
\hline $\begin{array}{l}1 \\
2 \\
3 \\
4 \\
5 \\
6 \\
7 \\
8 \\
9 \\
10 \\
11\end{array}$ & $\begin{array}{l}156 \mathrm{a} \\
156 \mathrm{~b} \\
156 \mathrm{c} \\
156 \mathrm{~d} \\
156 \mathrm{e} \\
156 \mathrm{f} \\
156 \mathrm{f} \\
156 \mathrm{~g} \\
156 \mathrm{~g} \\
156 \mathrm{~h} \\
156 \mathrm{i}\end{array}$ & $\begin{array}{l}n-\mathrm{Bu} \\
n-\mathrm{C}_{18} \mathrm{H}_{37} \\
\mathrm{Bn} \\
\mathrm{HOCH}{ }_{2} \mathrm{CH}_{2} \\
\mathrm{Ph} \\
p-\mathrm{MeO}-\mathrm{C}_{6} \mathrm{H}_{4} \\
p-\mathrm{MeO}_{6}-\mathrm{C}_{6} \mathrm{H}_{4} \\
p-\mathrm{I}-\mathrm{C}_{6} \mathrm{H}_{4} \\
p-\mathrm{I}-\mathrm{C}_{6} \mathrm{H}_{4} \\
p-\mathrm{C}_{6} \mathrm{H}_{4} \\
m-\mathrm{Cl}-\mathrm{C}_{6} \mathrm{H}_{4}\end{array}$ & $\begin{array}{l}0.2 \\
0.2 \\
0.2 \\
0.2 \\
0.5 \\
0.2 \\
0.5 \\
0.2 \\
0.5 \\
0.5 \\
0.5\end{array}$ & $\begin{array}{l}157 \mathrm{a} \\
157 \mathrm{~b} \\
157 \mathrm{c} \\
157 \mathrm{~d} \\
141 \\
157 \mathrm{e} \\
157 \mathrm{e} \\
157 \mathrm{f} \\
157 \mathrm{f} \\
157 \mathrm{~g} \\
157 \mathrm{~h}\end{array}$ & $\begin{array}{l}81 \\
83 \\
79 \\
81 \\
82 \\
52 \\
76 \\
58 \\
79 \\
70 \\
76\end{array}$ \\
\hline
\end{tabular}

Scheme $55 \mathrm{TiCl}_{4}$ catalysed synthesis of 1,4-dihydropyridines 141 and 157a-h.
Tamaddon, et al. ${ }^{65}$ have developed a green, efficient one-pot synthesis of various 4-alkyl/aryl-1,4-dihydropyridines in an excellent yields via the Hantzsch three-component reaction of an aromatic/aliphatic aldehydes, alkyl acetoacetate 110a/110b and ammonium carbonate in water (Scheme 56).

Shimizu, et al. ${ }^{66}$ have developed an efficient one-pot synthesis of 1,4-dihydropyridines $161 \mathbf{a}-\mathbf{z}$ in moderate to good yields via the $\mathrm{Yb}(\mathrm{OTf})_{3}$-catalyzed Hantzsch three-component reaction of an aromatic aldehydes, 3,3-dimethoxy propionate 160 and aromatic amines in 1,4-dioxane at $90{ }^{\circ} \mathrm{C}$ (Scheme 57).

Wang, et al. ${ }^{67}$ have developed an efficient one-pot synthesis of 1,4-dihydropyridines in an excellent yields via the Hantzsch three-component reaction of an aromatic/aliphatic aldehydes, alkyl acetoacetate $\mathbf{1 1 0 a} / \mathbf{1 1 0 b}$ and ammonium acetate in PEG400 as solvent at $90{ }^{\circ} \mathrm{C}$ (Scheme 58). PEG-400 facilitates the reactants converting into corresponding products smoothly in excellent yields because of its good immiscibility with a number of organic reagents. Moreover, PEG-400 is inexpensive, thermally stable, nonvolatile, and nontoxic.

\subsection{Synthesis of enantiopure 1,4-dihydropyridines}

2.3.1. Resolution of racemic 1,4 -dihydropyridine carboxylic acids via diastereomeric salt formation. Chiral crystallization

Table 15 Optimization of catalyst for the synthesis of 1,4-dihydropyridine 159a

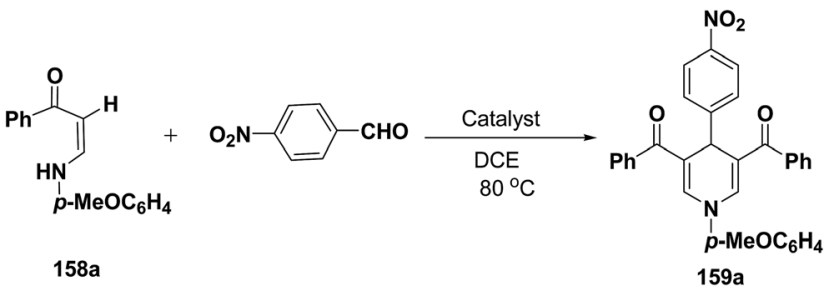

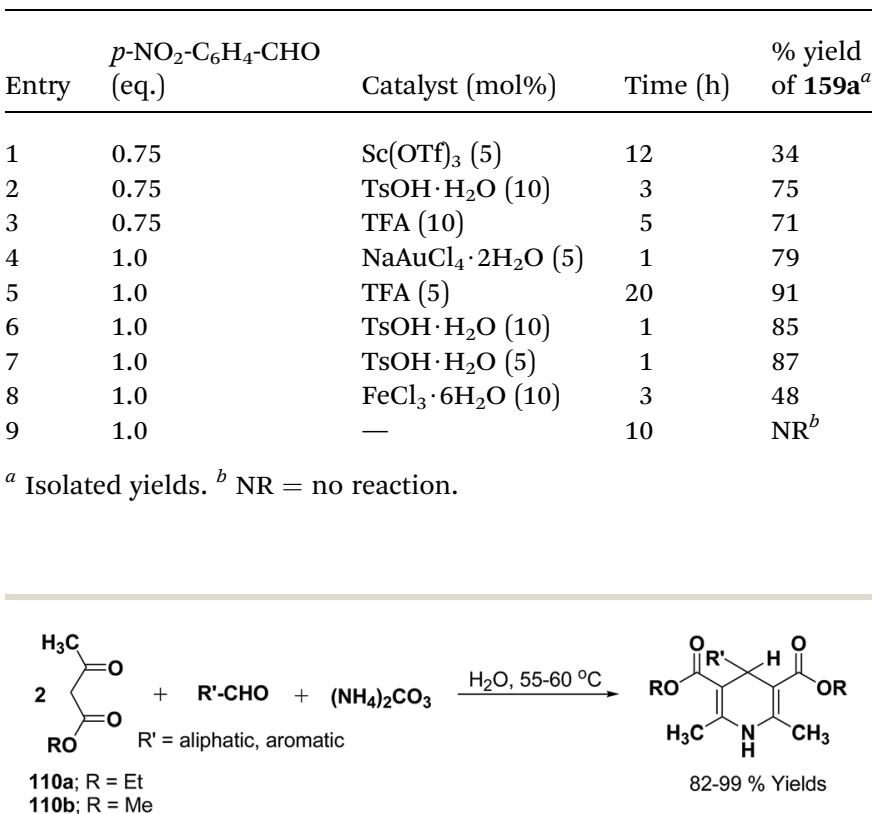

Scheme 56 Synthesis of 1,4-dihydropyridines using ammonium carbonate in water. 
with the use of resolving agents to form diastereomeric salts is a widely used technique for resolving chiral compounds. Cinchonidine, cinchonine and quinidine are the most commonly used natural chiral amine bases applied which are used to resolve racemic 1,4-dihydropyridinecarboxylic acid via forming their diastereomeric salts. It has been observed that these alkaloids

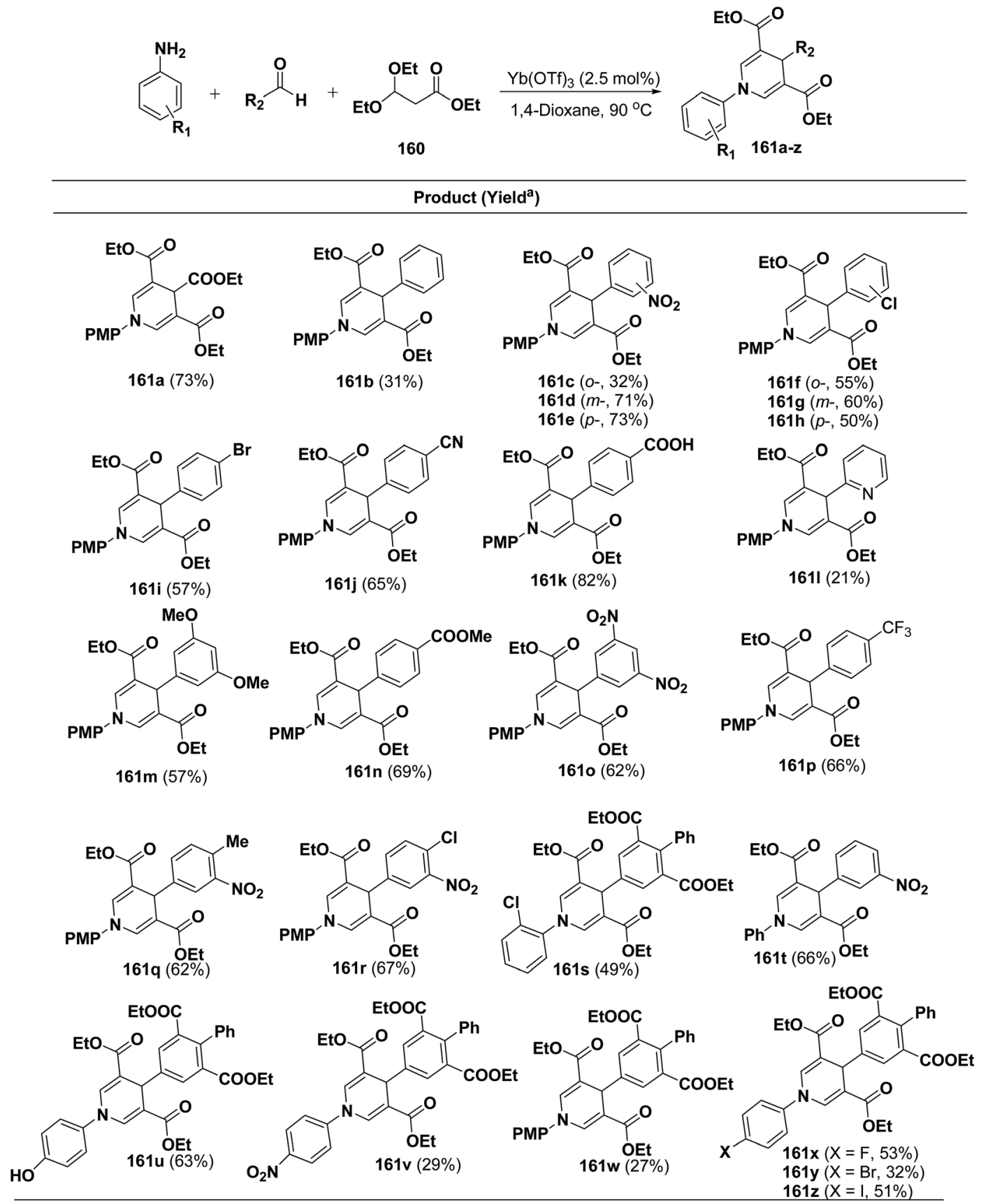

[a] Isolated yields based on arylamine. [b] PMP = p-Methoxyphenyl.

Scheme $57 \mathrm{Yb}(\mathrm{OTf})_{3}$ catalyzed one-pot synthesis of 1,4-DHPs 161a-z.

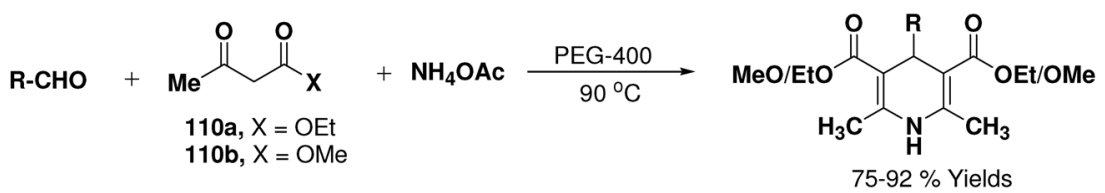


behave as quasi-mirror images and are used in a complementary way to obtain both enantiomers of 1,4-dihydropyridines in a pure form. The method involves treatment of racemic acid with a chiral base which leads to the formation of diastereomeric salts (Scheme 59). The enantiomer is then obtained in pure acid form by repeated crystallization followed by acidification. The other enantiomer is recovered from the mother liquor and resolved using other suitable chiral base reagent by going through the same procedure. The first resolution of racemic dihydropyridinecarboxylic acids through this method was carried out by Shibanuma, et $a l^{68}$ to synthesize nicardipine from 1-ethoxymethyl-5-methoxycarbonyl-2,6-dimethyl-4-( $m$-nitrophenyl)-1,4dihydropyridine-3-carboxylic acid $( \pm)$-162 using cinchonine and cinchonidine (Scheme 59). Various other 1,4-dihydropyridine derivatives have been synthesized similarly through optical resolution of racemic mixture of 1-ethoxymethylated dihydropyridines and by subsequently removing the ethoxymethyl group. ${ }^{69}$

Synthesis of optically-active 1,4-dihydropyridine derivatives from 1-ethoxymethylated carboxylic acid 162 involves protection and deprotection approach for NH group in 1,4-DHP ring. Use of unprotected racemic acid for direct resolution has also been investigated in detail. Zhang, et al. ${ }^{70}$ treated racemic acid $( \pm)$-165 with cinchonidine to form diastereomeric salt $(S)$ (+)-167 (Scheme 60). (S)-(+)-167 enantiomer was formed by repeated crystallization and further treatment with hydrochloric acid. When quinidine was used $(R)-(-)-166$ was formed.

The separation of $(R)$ - and $(S)$-amlodipine $\mathbf{1 7 0}$ has been achieved by treatment of racemic acid 168 with cinchonidine in methanol. Dilution with water formed a crystalline precipitate which was recrystallized to yield diastereomerically pure cinchonidine salt 169, which was further converted to enantiomerically pure $(R)$ - and $(S)$-amlodipine in several synthetic steps (Scheme 61). ${ }^{71}$

Various chiral acids have been used for the separation of racemic basic dihydropyridines. Racemic amlodipine $\mathbf{1 7 0}$ has been resolved using (1S)-(-)-camphanic acid chloride (Scheme 62) by Goldmann, et al. $^{72}$ The diastereomeric amides 171 obtained were easily separated chromatographically on Chiralcel OD column followed by crystallization from DMF/water.

Another remarkable method to get $R-(+)$ and $S-(-)$ amlodipine 170 is through $\mathrm{L}$ or D-tartaric acid respectively in DMSO.$^{73}$ It has been reported that $(R)$-amlodipine tartrate crystallizes out preferentially when naturally occurring $\mathrm{L}$-tartaric acid is used with racemic amlodipine in DMSO. Recently it has been described that $(S)$-isomer of amlodipine could also be obtained with L-tartaric acid just by changing the solvent system (Scheme 63). By using $\mathrm{DMF} / \mathrm{H}_{2} \mathrm{O}$ (85 : 15 ratio) desired $(S)-(-)-172$ crystallized out with $99 \%$ purity. ${ }^{74}$ By reacting 172 with benzenesulfonic acid, active pharmaceutical ingredient $(S)-(-)$-amlodipine besylate hemipentahydrate salt $\mathbf{1 7 3}$ was obtained.

2.3.2. Separation of racemic 1,4 -dihydropyridines by using chiral auxiliary. This synthetic strategy utilizes chiral auxiliary for the synthesis of optically active 1,4-dihydropyridines by forming diastereomeric esters which can be separated and eventually the chiral auxiliary can be regioselectively removed. Synthesis of 5-cyano-1,4-dihydropyridines from isoxazolo[5,4- $b]$

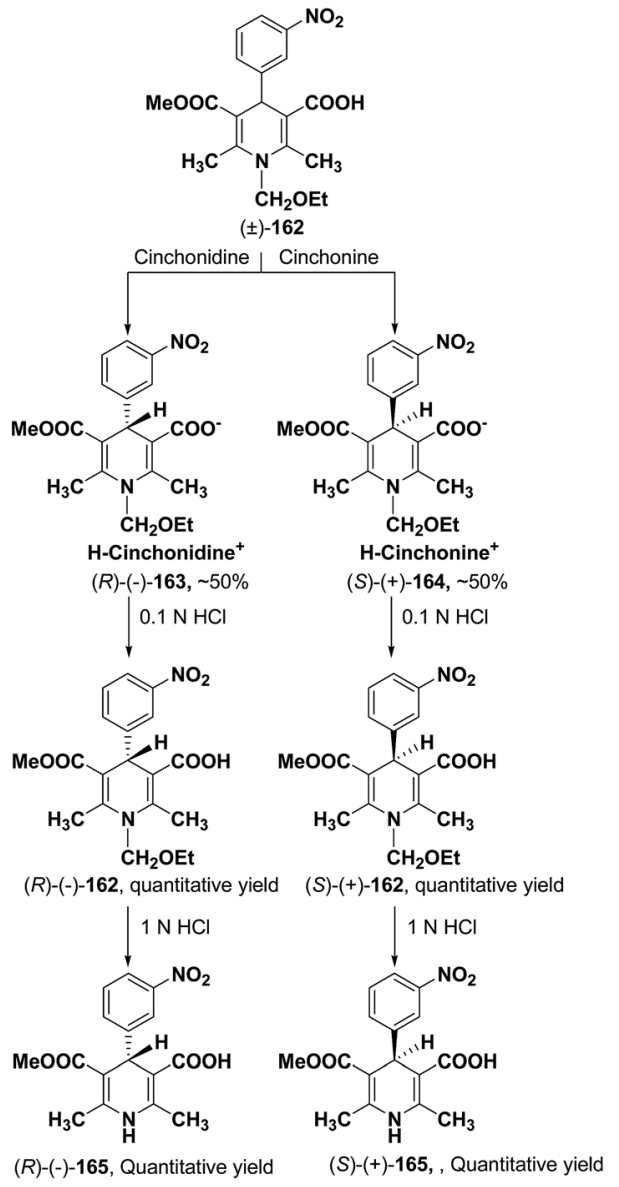

Scheme 59 Synthesis of enantiopure 1,4-dihydropyridines 165 via diastereomeric salt formation method.

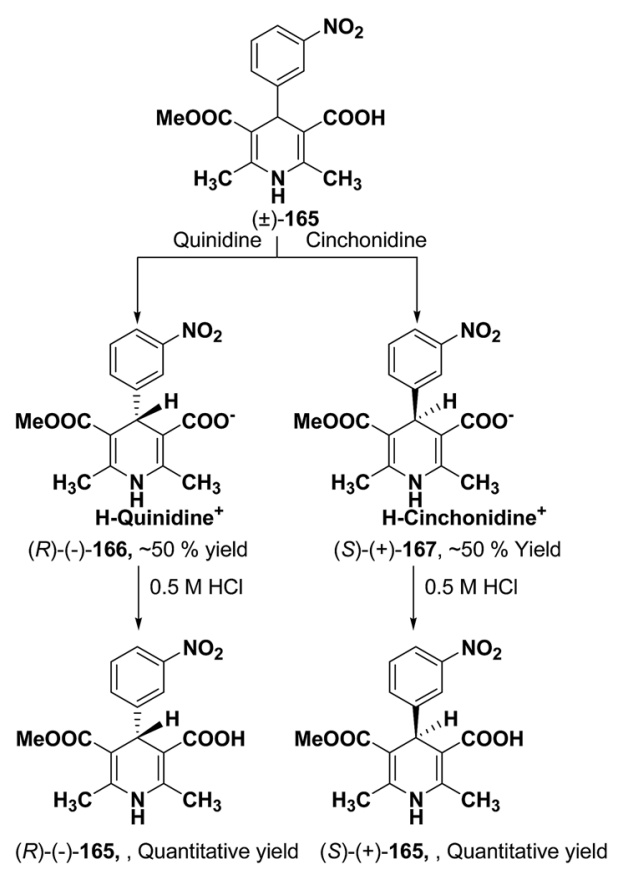

Scheme 60 Synthesis of chiral 1,4-dihydropyridine 165 via diastereomeric salt formation method. 
pyridines have been achieved by Taylor, et al. ${ }^{75}$ The monoester derivative 174 was reacted with nitrile oxide to produce isoxazolo[5,4- $b]$ pyridine 175 in 74\% yield (Scheme 64). Its saponification formed an acid which was then re-esterified with (-)-menthol. The resulting diastereomeric esters 176 were separated through flash chromatography, which on hydrolysis and decarboxylation yielded the desired 5-cyano-1,4dihydropyridine-3-carboxylic acid 177.

Arrowsmith, et al. ${ }^{76}$ esterified $( \pm)-\mathbf{1 7 8}$ using optically pure $(S)$ (+)-2-phenylethanol to give diastereomeric mixture 179. It was chromatographically separated on silica gel to form pure diastereomers and further treatment with sodium ethoxide and finally reduction of azide group by palladium on calcium carbonate yielded pure enantiomers $(R)-(-)$-amlodipine and $(S)$ (+)-amlodipine 170 (Scheme 65).
Lamm, et al. ${ }^{77}$ disclosed the formation of pure enantiomers of felodipine 185, a calcium channel antagonist by chromatographic separation of diastereomeric esters 183 prepared from (R)-1-( $p$-toluenesulfonyl)-3-tritylpropan-2-ol 181 (Scheme 66). This chiral auxiliary was removed easily by $\beta$-elimination reaction using potassium hydroxide in methanol at room temperature. Esterification of $\mathbf{1 8 4}$ with iodomethane successfully yielded $(R)$ - and $(S)$-enantiomers of felodipine $\mathbf{1 8 5}$.

Racemic isopropyl 1,4-dihydro-2,6-dimethyl-3-nitro-4pyridinylpyridine-5-carboxylate isomers with in vitro calcium channel modulating activities have been described by Vo, et al. ${ }^{78}$ Out of them the most promising 4-(2-pyridinyl) compound was resolved into pure enantiomers with the help of $\mathrm{L}_{\mathrm{L}}$-threonine 186 (Scheme 67). Through a multistep synthesis L-threonine was converted to $\beta$-aminocrotonate derivative 187 , which through
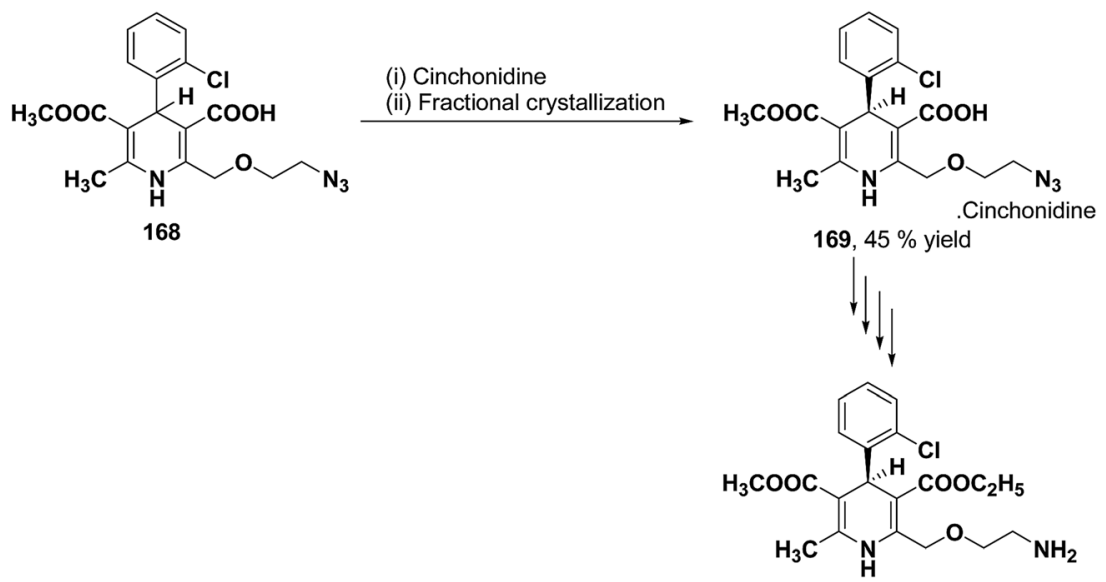

$(-)-170$

Scheme 61 Separation of $(R)$ - and (S)-amlodipine 170 by treatment of racemic acid 168 with cinchonidine in methanol.

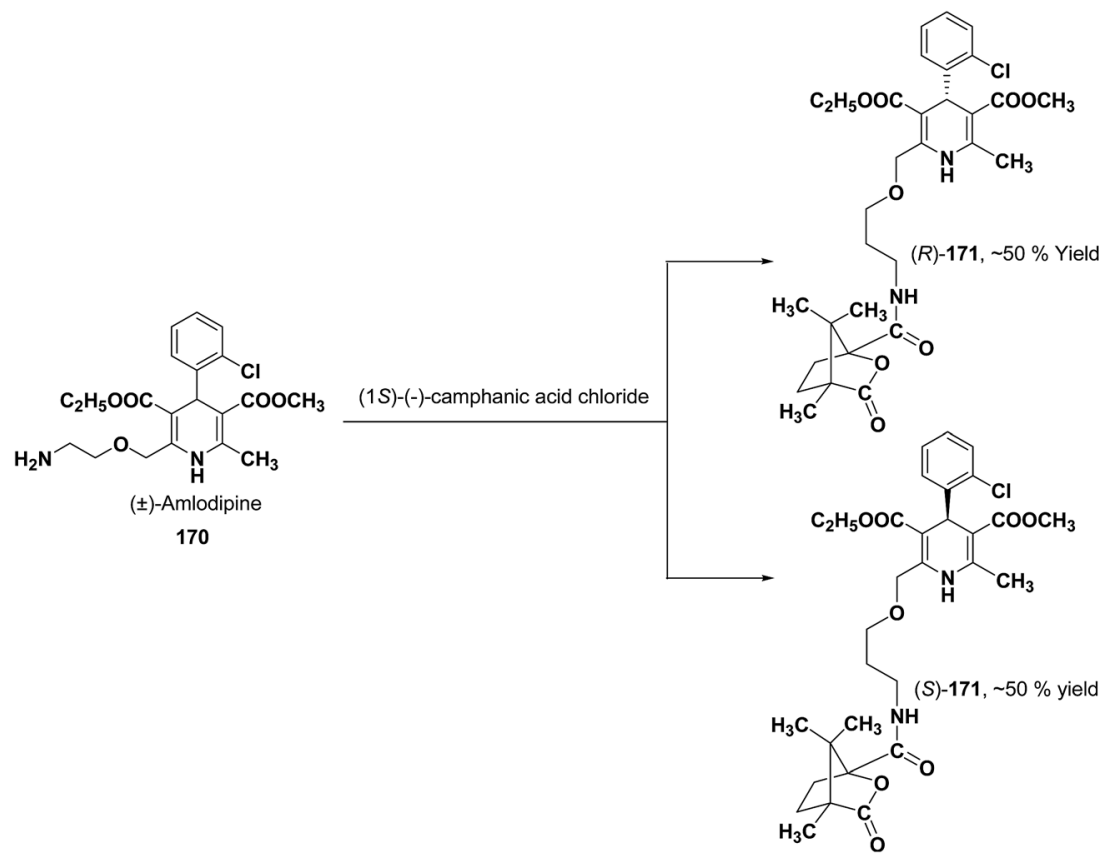

Scheme 62 Resolution of racemic amlodipine 170 using (1S)-(-)-camphanic acid chloride. 
Hantzsch condensation afforded the mixture of 1,4-DHP diastereomers 188 separable by silica gel column chromatography. This was followed by removal of chiral auxiliary using DBU to yield 189 and desired enantiopure (-)-190 and (+)-190 were synthesized using isopropyl bromide and potassium carbonate in DMF.

Similarly synthesis of $(S)-(-)$ - and $(R)-(+)$-enantiomers of 2nitrooxyethyl 1,4-dihydro-2,6-dimethyl-3-nitro-4-(2-trifluoromethylphenyl)pyridine-5-carboxylate ${ }^{79} 192$ exhibiting dual cardioselective agonist/smooth muscle selective antagonist activity ${ }^{80}$ were synthesized utilizing $\mathrm{D}$-threonine 191 as chiral auxiliary (Fig. 2). In both the cases the chiral esterifying group was easily removed by non-nucleophilic base 1,8-diazabicyclo [5.4.0]-undec-7-ene (DBU).

To synthesize chiral $\beta$-ketoester 195, $(4 R, 5 R)-(-)-2,3-O$-isopropylidine-D-threitol was used as chiral auxiliary (Scheme 68). ${ }^{81}$ Using 195 as chiral $\beta$-ketoester, phenylpropargyl aldehyde 194 and benzyl 3-amino-3-phenyl-2-propenoate 193, 1,4DHP diastereomers 196 were obtained which were resolved through HPLC. 2,2-Dimethyl-1,3-dioxolane-4-methanol and 2,3-O-isopropylidine-D-threitol moieties on the chiral ester were replaced by ethyl group through deprotection of diol by acidic treatment followed by transesterification in ethanol to afford 197.

2.3.3. Synthesis of enantiomerically pure 1,4-DHPs using chiral aldehydes. Synthetic methodology to synthesize 4-alkyl3,5-dialkoxycarbonyl-2,6-dimethyl-1,4-dihydropyridines 200a-c has been developed by utilizing chiral aldehydes 198a-c (Scheme 69). ${ }^{82}$ Enantiomerically pure 1,4-DHPs 200a-c were synthesized by Michael addition of ethyl aminocrotonate 114a to chiral $\alpha$-acetylacrylates $199 a-c$. The synthesis of $\alpha$-acetylacrylates 199a-c was carried out by knoevenagel condensation of methylacetyl acetate and the corresponding chiral aldehyde.

2.3.4. Organocatalytic asymmetric synthesis to form enantiomerically enriched dihydropyridines. Chiral
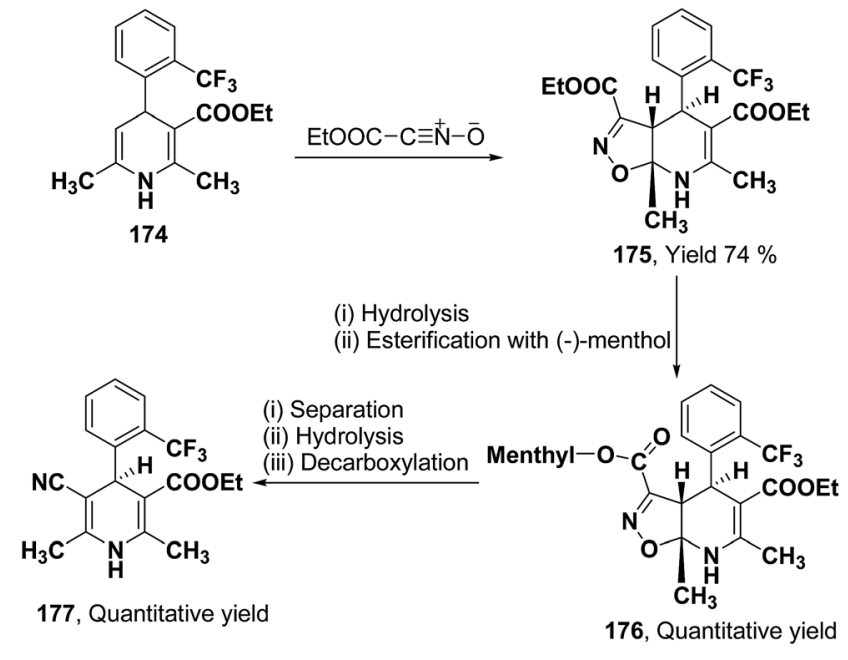

Scheme 64 Separation of 174 using nitrile oxide as a chiral auxiliary.

phosphonic acids 134b, 201a-c and 202 have been recognized as promising catalysts for asymmetric synthesis of 1,4-dihydropyridines (Scheme 70). A three-component cyclization of an $\alpha, \beta$-unsaturated aldehyde 56f, a primary amine $\mathbf{6 2 \mathrm { h }}$ and ethyl acetoacetate 110a in presence of chiral phosphonic acids 134b, 201a-c and 202 have been explored to generate chiral 1,4dihydropyridines 203 with excellent ee upto 98\% (Scheme 70). ${ }^{83}$ The screening of phosphonic acids 134b, 201a-c and 202 showed that increasing size of substituents at 3,3'-positions of the chiral catalyst and increase in the reaction temperature leads to enhanced enantioselectivities (Table 16). It was concluded that in $\mathrm{PhCN}$ at $50^{\circ} \mathrm{C}$ phosphonic acids 201c and 202 afforded 203 with $89 \%$ and $90 \%$ ee, respectively. Decreasing the amount of 202 from $20 \mathrm{~mol} \%$ to $10 \mathrm{~mol} \%$ led to an improved ee of 203 up to $92 \%$.
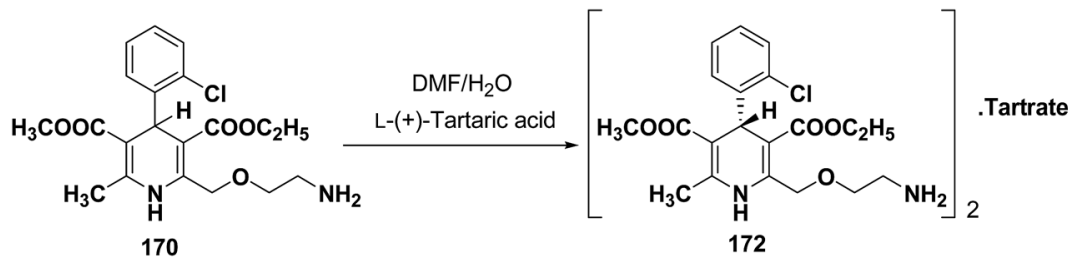

(S)-(-)-Amlodipine hemitartarate, $\sim 50 \%$ Yield

(DMF solvated) Benzenesulfonic acid IPA<smiles>CCOC(=O)C1=C(COCCN)NC(C)=C(C(=O)O[18OH])[C@@H]1c1ccccc1Cl</smiles>

(S)-(-)-Amlodipine besylate hemipentahydrate 173, Quantitative yield

Scheme 63 Resolution of $R-(+)$ and $S-(-)$ amlodipine 170 via diastereomeric salt formation with $L$ or D-tartaric acid, respectively in DMSO. 


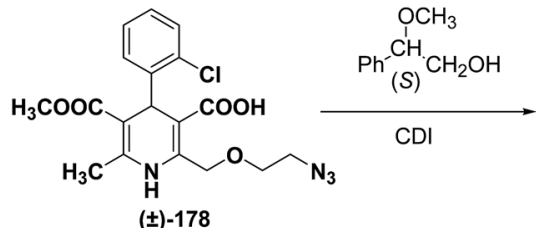

(士)-178

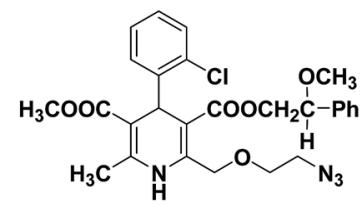

179, Quantitative yield
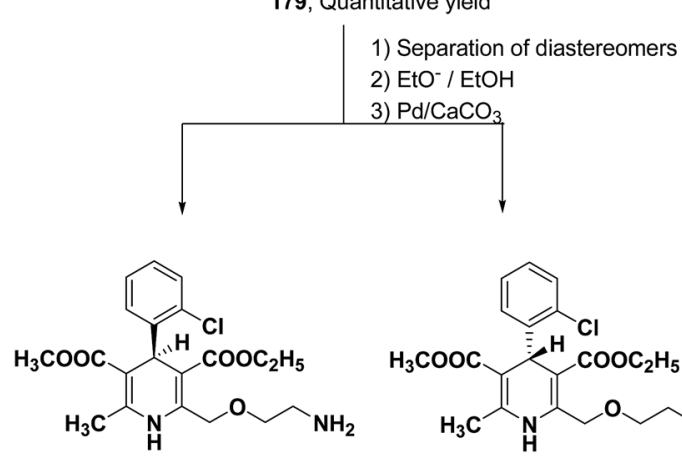

$(R)-(-)-170, \sim 50 \%$ yield

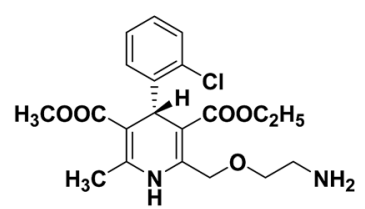

$(S)-(+)-170, \sim 50 \%$ Yield

Scheme 65 Resolution of 170 from 178 using optically pure (S)-(+)-2-phenylethanol.

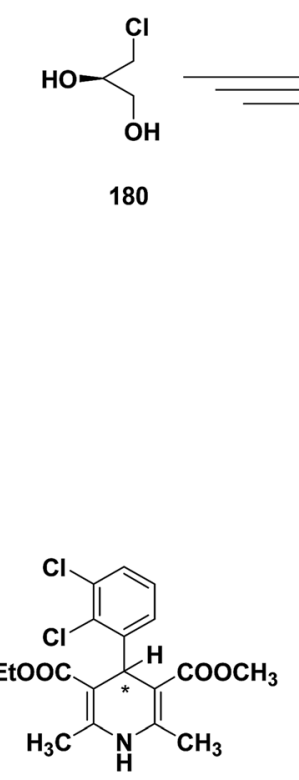

185 , yield $94 \%$ (i) $\mathrm{MeOH}, \mathrm{KOH}$

(ii) $\mathrm{CH}_{3}$ I, DMF<smiles>Cc1ccc(S(=O)(=O)CC(O)COC(c2ccccc2)(c2ccccc2)c2ccccc2)cc1</smiles><smiles>CC(=O)/C(=C/c1cccc(Cl)c1Cl)C(=O)OC(COC(c1ccccc1)(c1ccccc1)c1ccccc1)CS(=O)(=O)c1ccc(C)cc1</smiles>

(i) Ethyl 3-amino-crotonate, $\mathrm{C}_{5} \mathrm{H}_{5} \mathrm{~N}$, reflux, $1 \mathrm{~h}$ (ii) $\mathrm{CH}_{3} \mathrm{COOH}, \mathrm{H}_{2} \mathrm{O}, 60^{\circ} \mathrm{C}, 2 \mathrm{~h}$ (iii) Chromatographic separation of diastereomers

182<smiles>CCOC(=O)C1=C(C)NC(C)=C(C)C1(C1=C(C)NC(C)=C(C(=O)O)C1(c1cccc(Cl)c1Cl)c1cccc(Cl)c1Cl)c1cccc(Cl)c1Cl</smiles>

184 , yield $87 \%$

Scheme 66 Formation of enantiopure 185 using chiral auxiliary.

Yamamoto, et $a l .{ }^{84}$ described an efficient asymmetric synthesis of 1,4-dihydropyridine derivatives. The key step of this reaction was the stereoselective Michael addition using $t$-butyl ester of L-valine 207 as a chiral auxiliary to achieve good ee of $209(>95 \%)$ and moderate yield (Scheme 71). With this method, (+)-4-(3-chlorophenyl)-6-dimethoxymethyl-2methyl-1,4-dihydropyridine-3,5-dicarboxylic acid cinnamyl ester (+)-209 was obtained and was characterized as a promising $\mathrm{N}$-type calcium channel blocker with improved selectivity over L-type compared to its (-)- and racemic isomers.

\section{Utility of dihydropyridines in the synthesis of natural products}

3.1. Utility of 1,2-dihydropyridines in the synthesis of natural products

Kutney, et al. have synthesized two pyridocarbazole alkaloids, olivacine 212 and guatambuine 213 by utilizing the tricarbonylchromium complex 211 of the suitable 1,2-dihydropyridine, which was synthesized from indole 210 (Scheme 72). ${ }^{85}$ 
<smiles>[R]NC(C(C)=O)[C@H](C)OC(=O)/C=C(/C)N</smiles><smiles></smiles><smiles>[R]C1C(C(=O)O[I+])=C(C)NC(C)=C1[N+](=O)[O-]</smiles>

(-)-190, yield $69 \%$<smiles>[R]C1C(C(=O)OC(C)C)=C(C)NC(C)=C1[N+](=O)[O-]</smiles>

(+)-190, yield $69 \%$<smiles>[R][C@H]1C(C(=O)O[C@H](C)[C@H]([R])C(=O)OC)=C(C)NC(C)=C1[N+](=O)[O-]</smiles>

$(+)-188$ $\mathrm{CH}_{3} \mathrm{COCH}_{2} \mathrm{NO}_{2}$ $\mathrm{EtOH}$<smiles>[R]C(N[C@@H](C)[C@@H](C)OC(=O)C1=C(C)NC(C)=C([N+](=O)[O-])[C@H]1[R])C(=O)OC</smiles>

diastereomers

(ii) DBU<smiles>[R]C1C(C(=O)O)=C(C)NC(C)=C1[N+](=O)[O-]</smiles>

$(-)-189$<smiles>[R]C1C(C(=O)O)=C(C)NC(C)=C1[N+](=O)[O-]</smiles>

(+)-189

Scheme 67 Resolution of racemic isopropyl 1,4-dihydro-2,6-dimethyl-3-nitro-4-pyridinylpyridine-5-carboxylate using L-threonine.<smiles>CC(O)[C@H](N)C(=O)O</smiles>

191<smiles></smiles>

$(R)-(+)-192$<smiles>CC1=C(C(=O)OCCO[N+](=O)[O-])[SH](c2ccccc2C(F)(F)F)C(C(=O)O[N+](=O)[O-])=C(C)N1</smiles>

(S)-(-)-192

Fig. 2 Structures of D-threonine 191 and 2-nitrooxyethyl 1,4-dihydro-2,6-dimethyl-3-nitro-4-(2-trifluoromethylphenyl)pyridine-5-carboxylate 192.

The synthesis of $( \pm)$-elaeokanine A 216 has been achieved in a regioselective manner from 1-methoxycarbonyl salt of 3-(iPr) $)_{3}$ silyl pyridine $\mathbf{2 1 4}$ by Comins and Myoung. ${ }^{\mathbf{8}}$ The 1-methoxycarbonyl salt of 3-(iPr) $)_{3}$ silyl pyridine was first converted into the 1,2-dihydropyridine derivative $\mathbf{2 1 5}$, which was then converted into the $( \pm)$-elaeokanine $\mathrm{A}$ into several number of synthetic steps (Scheme 73).

2-Substituted-1,2-dihydropyridine and piperidines has been synthesized in regio- and stereoselective manner from unsubstituted pyridinium salt. The approach relies on stereoselective formation of $(E)$-isomer of $N$-pyridinium imidate 218 from amide $\mathbf{2 1 7}$ in which the nitrogen lone pair is oriented at the proper position to direct the addition of Grignard reagent 219 at the 2-position. This approach has been used for the synthesis of 2-substituted-1,2-dihydropyridine 220 and $R$-(-)-coniine 221 (Scheme 74). ${ }^{87}$

2,3-Disubstituted-1,2-dihydropyridines 224 and 225 have been synthesized from the 3-substituted pyridinium salts 222 and 223, respectively (Scheme 75). This methodology has been applied for the synthesis of (-)-L-733 061 (226) and (-)-CP-
99994 (227), two members of a new class of highly potent, nonpeptide, substance $\mathrm{P}$ antagonists. ${ }^{\mathbf{8}}$

A simple synthesis of the fused tetrahydro-imidazopyridine 229 was accomplished via selective addition of protected guanidine 228 to $\mathrm{N}$-carbomethoxy-1,2-dihydropyridine $\mathbf{1}$ in the presence of bromine at room temperature. Base-mediated semicleavage of the aminal gave 4-substituted 2-aminoimidazole 230 (Scheme 76). With this new method, natural marine metabolite 3-amino-1-(2-aminoimidazol-4-yl)-prop-1ene (marine $\mathrm{C}_{6} \mathrm{~N}_{4}$ 2-aminoimidazole alkaloids) 231 and its derivatives may be prepared starting from pyridine. ${ }^{89}$

The asymmetric synthesis of 2,6-disubstituted 3-piperidinols having a 2,3-cis and 2,6-trans relative stereochemistry has been accomplished from 2-substituted 1,2-dihydropyridine 233 (synthesized from unsubstituted pyridinium salt 232) via a onepot, highly diastereoselective epoxidation-nucleophilic addition with a heteroatom nucleophile or an organometallic reagent. This methodology was applied to the expedient asymmetric synthesis of (+)-julifloridine 234 in four steps (Scheme 77). ${ }^{90}$ 


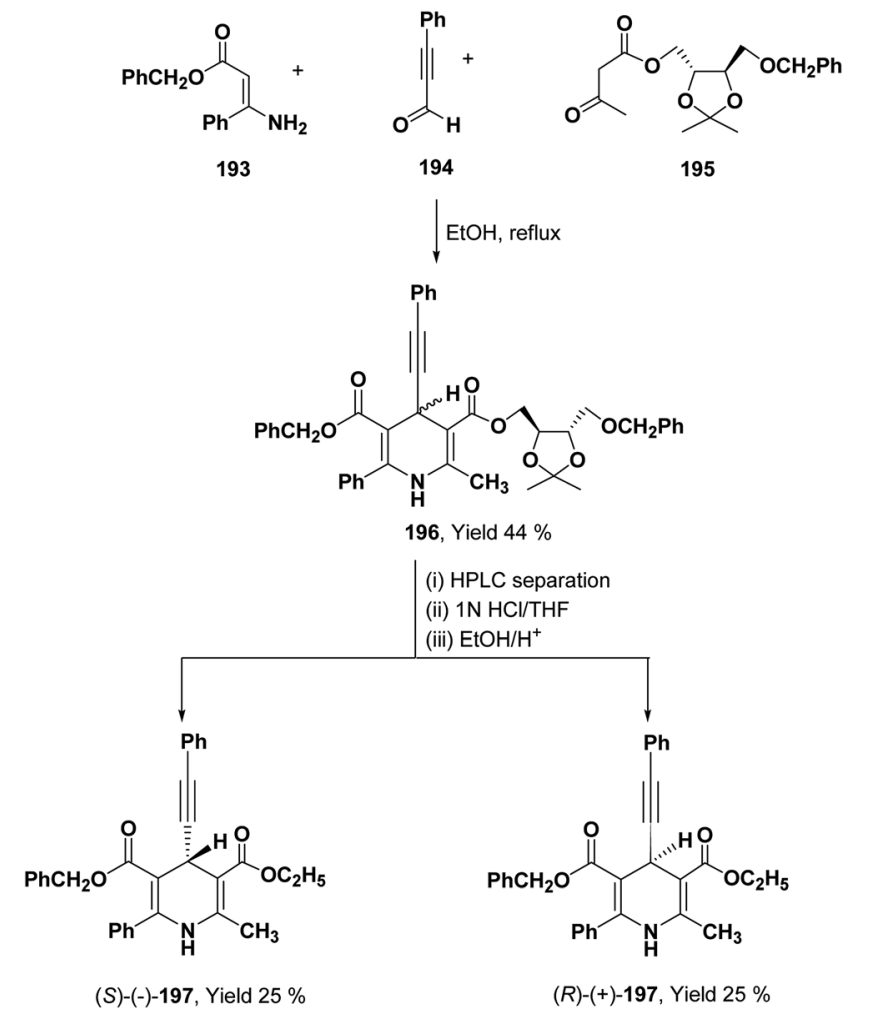

Scheme 68 Use of $(4 R, 5 R)-(-)-2,3-O$-isopropylidine-D-threitol was used as chiral auxiliary in the separation of 1,4-DHP.
Table 16 Effect of phosphonic acids 134b, 201a-c and 202 and increase in the reaction temperature on the enantioselectivity of 203

\begin{tabular}{|c|c|c|c|c|c|}
\hline Catalyst & Solvent & $\begin{array}{l}\text { Temperature } \\
\left({ }^{\circ} \mathrm{C}\right)\end{array}$ & Yield (\%) & ee $(\%)$ & Product \\
\hline 201a & $\mathrm{CHCl}_{3}$ & 25 & 72 & 19 & $(S)-203$ \\
\hline $134 b$ & $\mathrm{CHCl}_{3}$ & 25 & 85 & 19 & $(S)-203$ \\
\hline $201 b$ & $\mathrm{CHCl}_{3}$ & 25 & 62 & 31 & $(S)-203$ \\
\hline 201c & $\mathrm{CHCl}_{3}$ & 25 & 67 & 73 & $(S)-203$ \\
\hline 201c & $\mathrm{CHCl}_{3}$ & 40 & 80 & 80 & $(S)-203$ \\
\hline 201c & $\mathrm{CHCl}_{3}$ & 50 & 85 & 82 & $(S)-203$ \\
\hline 201c & PhCN & 50 & 82 & 89 & $(S)-203$ \\
\hline 202 & $\mathrm{CHCl}_{3}$ & 25 & 69 & 64 & $(R)-203$ \\
\hline 202 & $\mathrm{CHCl}_{3}$ & 50 & 86 & 72 & $(R)-203$ \\
\hline 202 & PhCN & 50 & 83 & 90 & $(R)-203$ \\
\hline $202(10 \mathrm{~mol} \%)$ & $\mathrm{PhCN}$ & 50 & 82 & 92 & $(R)-203$ \\
\hline
\end{tabular}

Marine metabolites pyrrole-2-aminoimidazole oroidine, hymenidin and clathrodine have been synthesized via one pot oxidative bromine mediated addition of 2-aminopyrimidine 237 to the $N$-acyl-1,2-dihydropyridine 236 to form compound $\mathbf{2 3 8}$. The $N$-acyl-1,2-dihydropyridine was synthesized by the reaction of pyrrole-2-carbonyl chloride $\mathbf{2 3 5}$ with pyridine followed by the reduction using sodium borohydride. The compound 238 was treated with hydroxylamine hydrochloride and resulted into the formation of amide $\mathbf{2 3 9}$ and $\mathbf{2 4 0}$. The treatment of amide $\mathbf{2 3 9}$ and $\mathbf{2 4 0}$ with trifluoroacetic acid in dichloromethane resulted

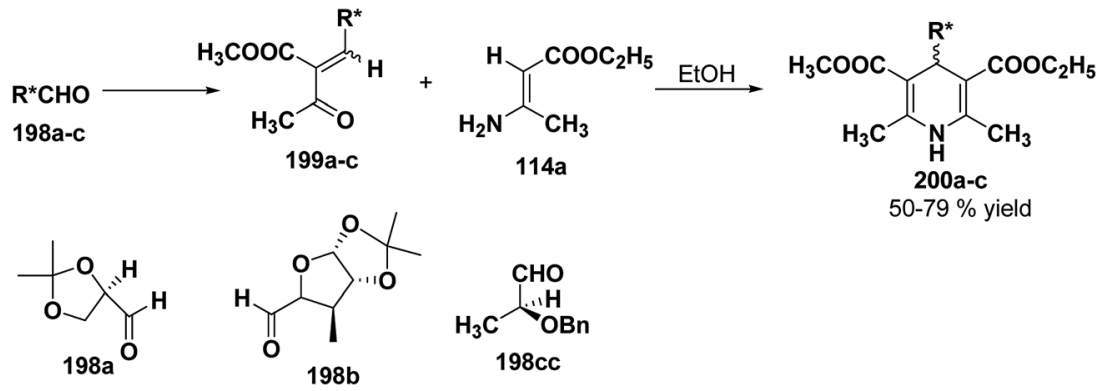

Scheme 69 Synthesis of chiral 1,4-DHPs 200a-c using chiral aldehydes.

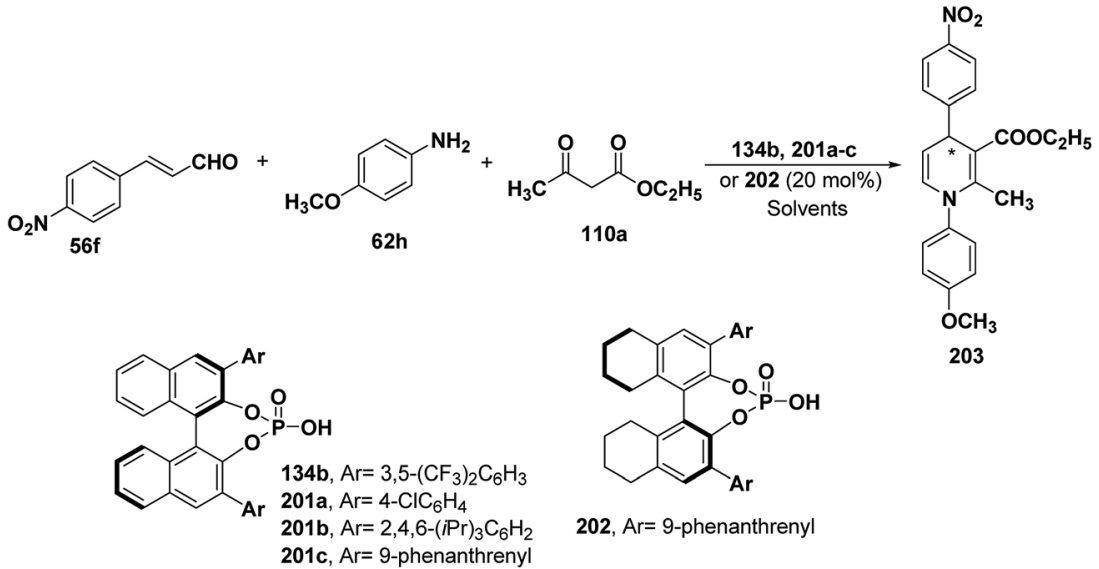

Scheme 70 Chiral phosphonic acids catalyzed synthesis of 1,4-DHP 203. 


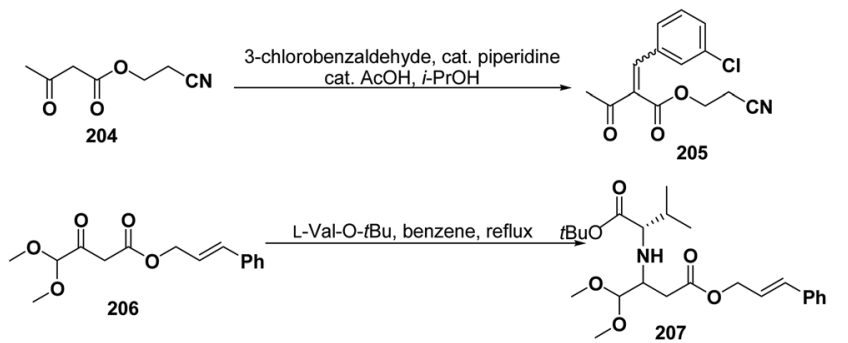

(i) 205, LDA, THF, $-78^{\circ} \mathrm{C}$ then $-35^{\circ} \mathrm{C}$ (ii) $1 \mathrm{M} \mathrm{HCl}$ aq, $\mathrm{rt}$

(iii) $\mathrm{AcONH}_{4}, \mathrm{EtOH}, 50^{\circ} \mathrm{C}$, then $120^{\circ} \mathrm{O}$

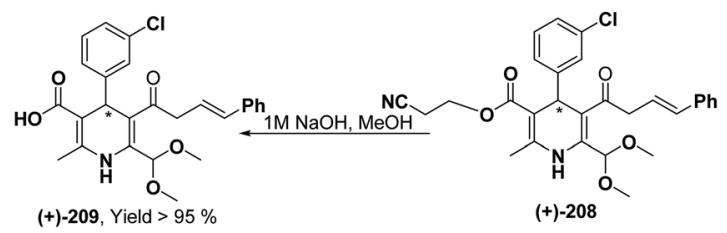

Scheme 71 Stereoselective synthesis of 1,4-dihydropyridine 209. into the formation of oroidine $\mathbf{2 4 1}$ and hymenidine 242 or clathrodine $\mathbf{2 4 3}$ in good yields (Scheme 78). ${ }^{\mathbf{9 1}}$

Stereoselective synthesis of L-picolic acid and $(2 S, 3 S)-3-$ hydroxypipecolic acid were achieved from a chiral 1,2-dihydropyridine intermediate 244. L-Picolic acid 248 has been obtained via reduction of $\mathbf{2 4 4}$ to $\mathbf{2 4 5}$, removal of chiral auxiliary yields 246, oxidation yields 247 and basic hydrolysis of 247 yields L-picolic acid 248. (2S,3S)-3-Hydroxypipecolic acid 253 was obtained in five steps (i) tandem hetero Diels-Alder reaction of $\mathbf{2 4 4}$ with oxygen to yield $\mathbf{2 4 9}$, (ii) alane reduction to yield 250, (iii) $N$ and $O$-protection to afford 251, (iv) reduction of double bond to yield 252, and (v) sharpless oxidation to yield 253 (Scheme 79). L-Picolic acid is a naturally occurring nonproteinogenic $\alpha$-amino acid and many biological alkaloids contain this moiety as a key structural unit or are derived from it. (2S,3S)-3-Hydroxypipecolic acid is found in febrifugine a potent antimalarial agent. Both L-picolic acid and (2S,3S)-3hydroxypipecolic acid are conformationally constrained amino acids relevant to the study of peptide structure and drug design. $^{.2}$

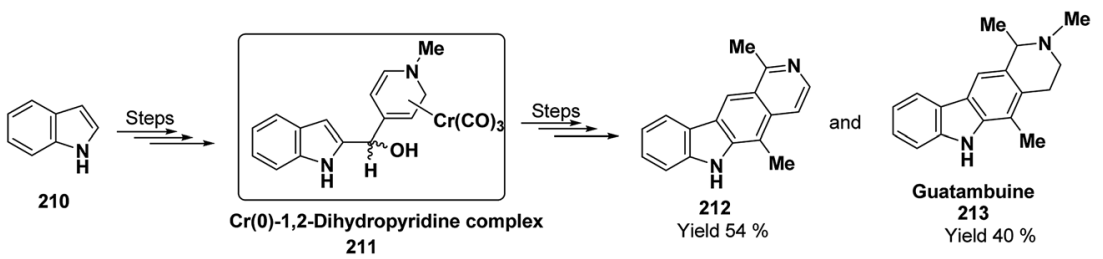

Scheme 72 Synthesis of pyridocarbazole alkaloids.

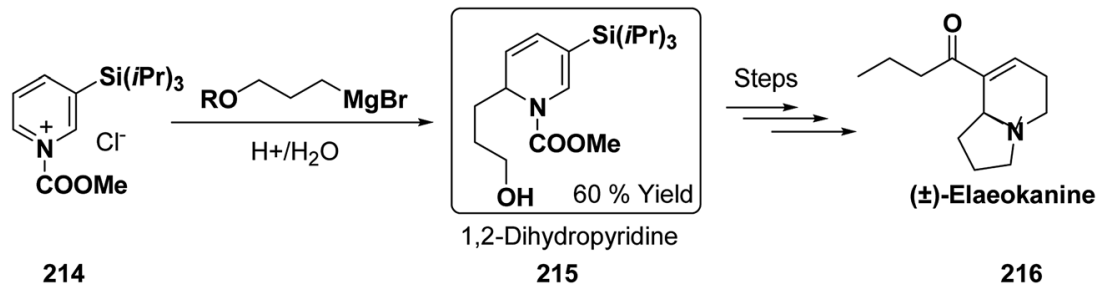

Scheme 73 Synthesis of $( \pm)$-elaeokanine A using 1,2-dihydropyridine derivative.<smiles>CC(C)[C@H](CO[Bi])NC(=O)c1ccccc1</smiles>

217

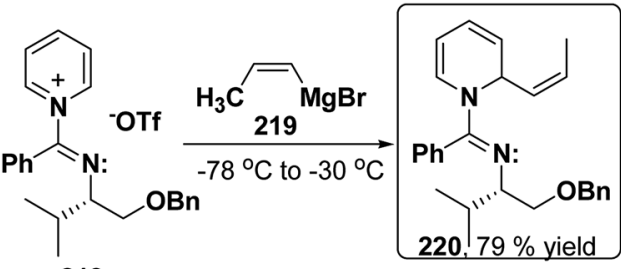

218
2-Substituted-1,2-DHP<smiles>[3H][AsH2][AsH2]</smiles><smiles>CCCC1CCCCN1</smiles>

R-(-)-Coniine 


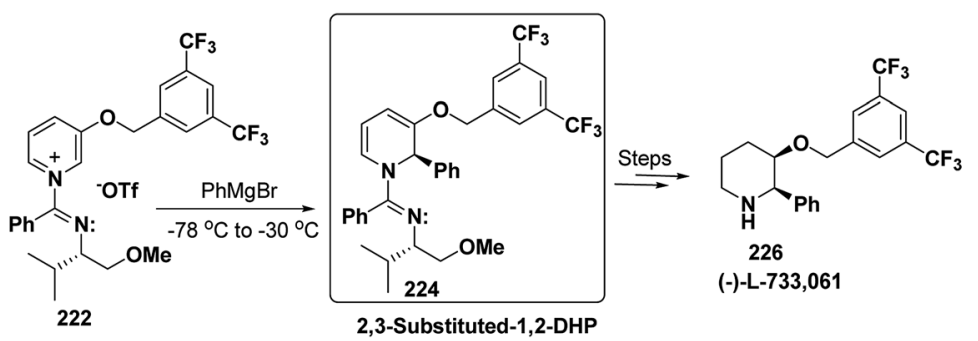

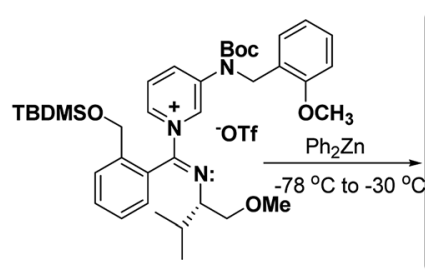

223

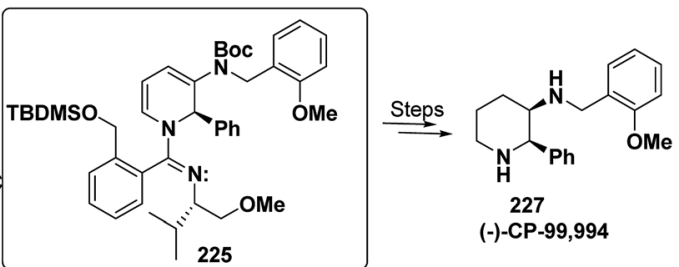

2,3-Substituted-1,2-DHP

Scheme 75 Synthesis of 2,3-disubstituted-1,2-DHP: synthesis of (-)-L-733, 061 and (-)-CP-99, 994.
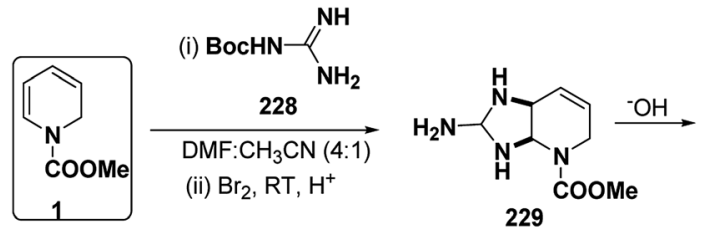

229

Yield $67 \%$

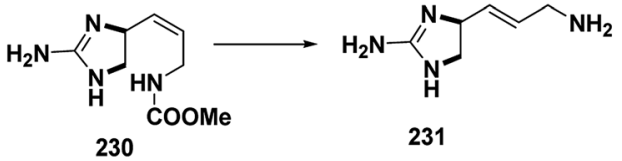

3-amino-1-(2-aminoimidazol-4-yl)prop-1-ene

Scheme 76 Synthesis of marine $\mathrm{C}_{6} \mathrm{~N}_{4} 2$-aminoimidazole alkaloids.

\subsection{Utility of 1,4-dihydropyridine in the synthesis of natural products}

Yohimbines are pentacyclic indole alkaloids containing five chiral centres. A convergent six steps synthesis of $( \pm)$-pseudoyohimbines has been accomplished from methyl- $\beta$ - $(\beta$-pyridyl) acrylate 254 (Scheme 80 ). Methyl- $\beta$-( $\beta$-pyridyl)acrylate 254 was converted into pyridinium salt 256 using tryptophyl bromide 255, which was then converted into 1,4-dihydropyridine derivative 257. The 1,4-dihydropyridine 257 was converted into ( \pm )-pseudo-yohimbines 258 in several steps. ${ }^{93}$

Indoloquinolizine alkaloid, deplancheine has been synthesized starting from pyridinium salt 256. The pyridinium salt 256 was reduced to 1,4-dihydropyridine derivative 259 using sodium dithionate. The treatment of 1,4-dihydropyridine with $\mathrm{HCl} \cdot \mathrm{MeOH}$ resulted into the formation of cyclised product 260. The chloride salt 261 was synthesized using $\mathrm{HCl} \cdot \mathrm{H}_{2} \mathrm{O}$ from $\mathbf{2 6 0}$, which was reduced selectively to yield $( \pm)$-deplancheine 262 in good yield (Scheme 81). ${ }^{94}$

Vinoxine is amino indole alkaloid and its first total synthesis is based on the intramolecular cyclisation of suitably substituted 1,4-dihydropyridine-indole conjugate 265. The dihydripyridine-indole conjugate was synthesized by the reaction between methyl 2-(1H-indol-1-yl)acetate 263 and pyridinium salt 264 in the presence of LDA in THF. The intramolecular cyclization reaction on compound 265 was

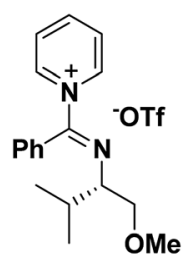

232

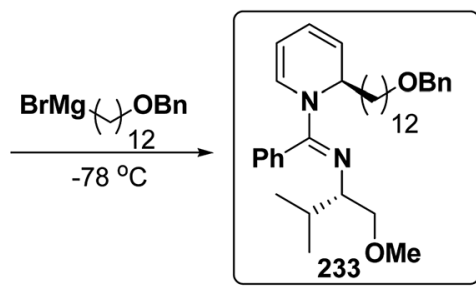

2-Substituted-1,2-DHP

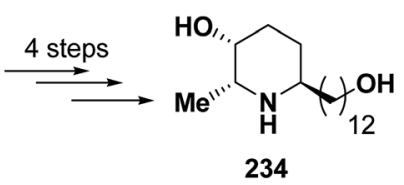

(+)-Julifloridine

$\sim 12 \%$ overall yield

Scheme 77 Synthesis of (+)-julifloridine from 1,2-dihydropyridine. 


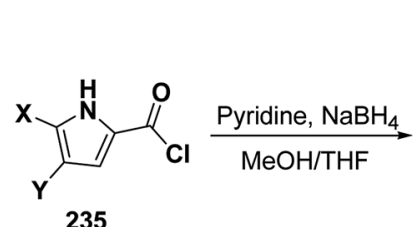

235<smiles>[Y]c1cc(C(=O)N2C=CC=CC2)[nH]c1[Y6]</smiles>

1,2-DHP

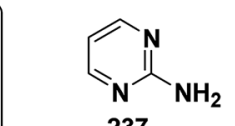

237

$\mathrm{Br}_{2}, \mathrm{DMF} / \mathrm{AcCN}$<smiles>[X]c1cc(C(=O)N2CC=CC3C2N=C2N=CC=CN23)[nH]c1[X]</smiles>

236a; $\mathrm{X}=\mathrm{Y}=\mathrm{H}$ (yield $38 \%$ )

236b; $X=H, Y=B r$ (yield 24\%)

236c, $X=Y=B r$ (yield 20\%)

240a; $X=Y=H$ (yield $51 \%$ )

240b; $X=H, Y=B r($ yield $66 \%)$

240c; $X=Y=B r($ yield $6 \%$ )<smiles>[X]c1cc(C(=O)N2CC=Cc3[nH]c(N)nc32)[nH]c1[Y20]</smiles><smiles>[Y6]c1cc(C(=O)NC/C=C\c2cnc(N)[nH]2)[nH]c1[Y]</smiles>

239

$X=Y=B r($ yield $47 \%$ )

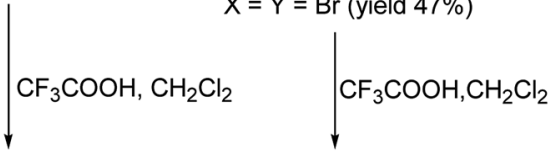<smiles>[X]c1cc(C(=O)NCC=Cc2c[nH]c(N)n2)[nH]c1[X]</smiles>

Hymenidine 242; $\mathrm{X}=\mathrm{H}, \mathrm{Y}=\mathrm{Br}$ (yield $42 \%$ ) Clathrodine 243; $X=Y=H$ (yield 40\%)<smiles>Nc1nc(/C=C/CNC(=O)c2cc(Br)c(Br)[nH]2)c[nH]1</smiles>

Yield $71 \%$

Scheme 78 Synthesis of oroidine, hymenidine and clathrodine using 1,2-dihydropyridine as an intermediate.

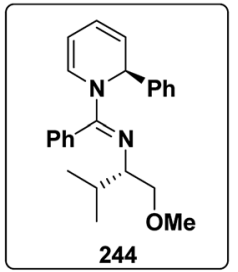

Chiral 1,2-DHP derivative

$\mathrm{O}_{2}, \mathrm{hv}$ methylene blue $\mathrm{CH}_{2} \mathrm{Cl}_{2},-78^{\circ} \mathrm{C}$

Tandem hetero Diels-Alder reaction

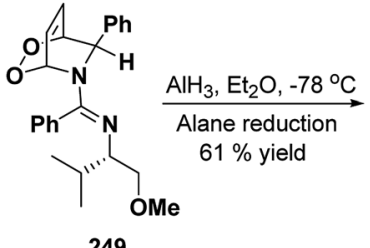

249

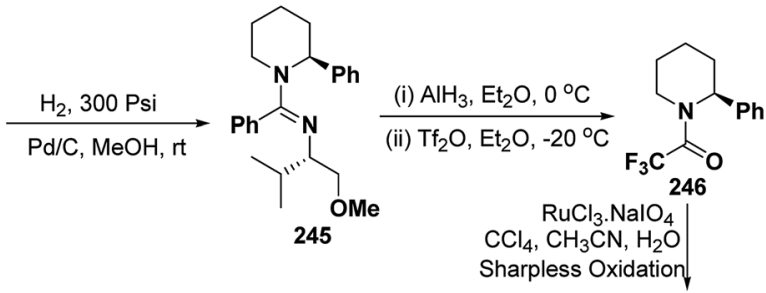

Sharpless Oxidation

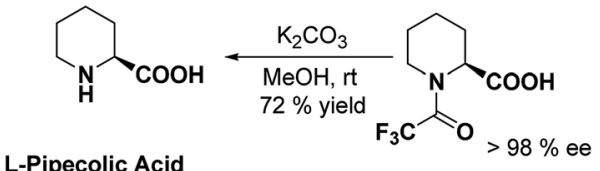

248

247

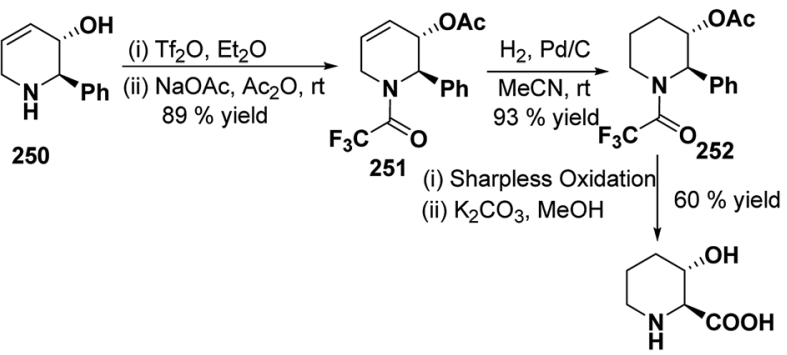

(2S, 3S)-3-Hydroxypipecolic acid 
carried out using $\mathrm{C}_{6} \mathrm{H}_{6} \cdot \mathrm{HCl}$ to afford 266. The chloride salt 267 of 266 was synthesized using $4 \mathrm{~N} \mathrm{HCl}$ followed by the esterification and selective reduction afford the vinoxine $\mathbf{2 6 8 b}$ in good yield (Scheme 82). ${ }^{95}$
Bosch, et $a l .{ }^{96}$ has reported the synthesis of vinoxine analogue bearing C-16 methoxycarbonyl substituent, 19,20dihydro-16-epivinoxine 275 . The synthesis of 19,20-dihydro-16epivinoxine 275 has been achieved from 3-ethyl-4-pyridine<smiles>COC(=O)/C=C/c1ccc2c(c1)NCC2CC[n+]1cccc(/C=C/C(=O)OC)c1</smiles><smiles>COC(=O)C(C(=O)OC)C1C=CN(CCC2CNc3ccccc32)C=C1</smiles>

1,4-Dihydropyridine

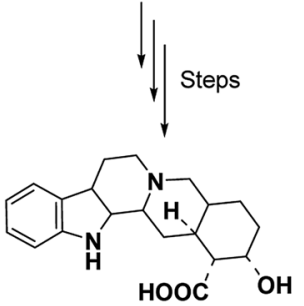

(士)-pseudo-yohimbines

Scheme 80 Synthesis of $( \pm)$-pseudo-yohimbines.

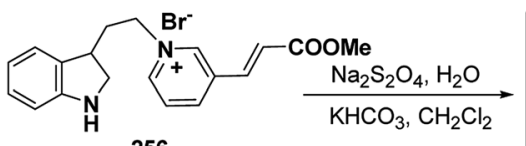

256

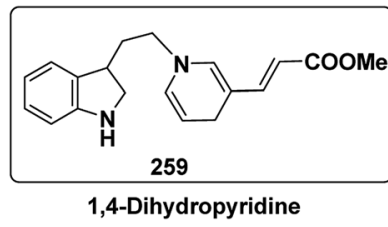

$\stackrel{\mathrm{HCl} . \mathrm{MeOH}}{\mathrm{rt}}$<smiles>COC(=O)/C=C/C1=CN2CCc3c([nH]c4ccccc34)C2C1</smiles>
$\triangle, 5 \mathrm{~h}$

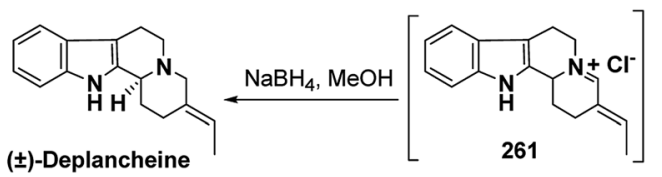

262 , yield $25 \%$

Scheme 81 Synthesis of $( \pm)$-deplancheine.

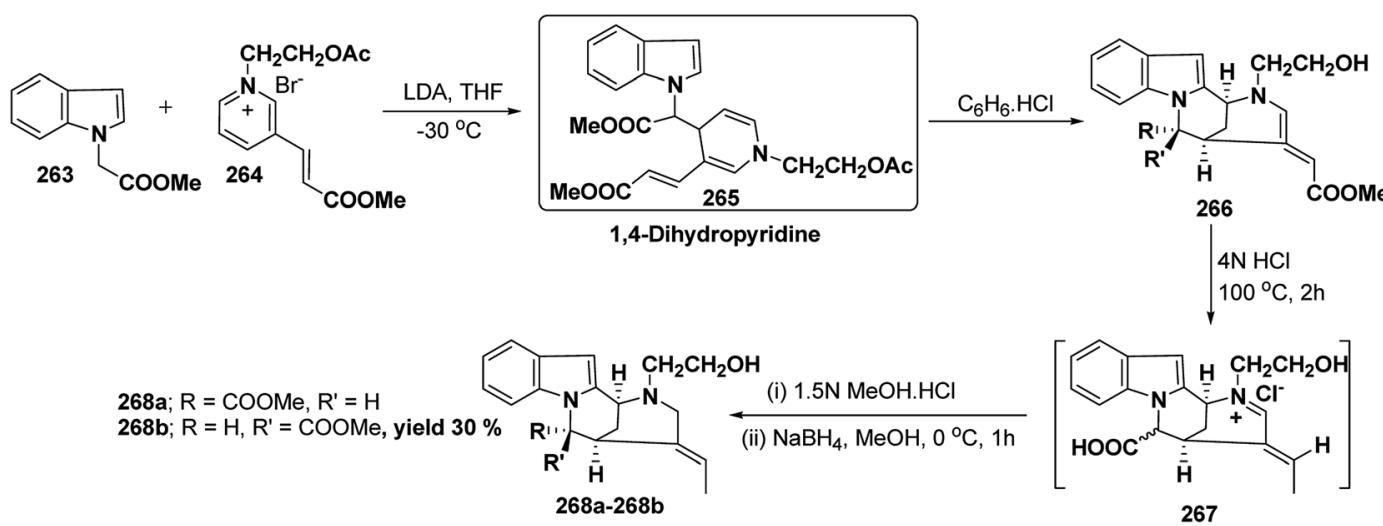

Scheme 82 Synthesis of vinoxine $268 \mathrm{~b}$. 
carboxylate 269 via the synthesis of 1,4-dihydropyridine analogue 274 (Scheme 83).

An efficient route for the synthesis of tetracyclic ABCD ring substructures of Strychnos alkaloids has been carried out by synthesizing the 1,4-dihydropyridine 277 derivative from indole-2-carboxylate 276 and 264. The compound 1,4-dihydropyridine 277 was converted into disulfane analogue 278 in six steps, which was converted into pentacyclic compound 279 by generating the carbanion of compound 278 using DMTSF (dimethyl(methylthio)sulfonium fluoroborate). The resulting pentacyclic compound has been converted into tubifolidine $\mathbf{2 8 0}$ by treating 279 with RANEY® Ni. Tubifoline 281 and 19,20dihydroakummicine $\mathbf{2 8 2}$ were synthesized by first $N$-protection with methyl carboxylate and desulferisation to yield 281 followed by treatment with sodium methoxide and photolysis, respectively (Scheme 84). ${ }^{97}$
Ervitsine 289 is a minor 2-acylindole alkaloid isolated in 1977 from Pandaka boiteau. The first total synthesis of ervitsine 289 through a straightforward, biomimetic sequence involving only three separate synthetic steps (Scheme 85) has been reported by Bennasar, et al. ${ }^{98}$ The key intermediate was the iminium cation $\mathbf{2 8 6}$. The iminium cation $\mathbf{2 8 6}$ was synthesized from 1,4-dihydropyridine derivative 285 using $\mathrm{Me}_{2} \mathrm{~N}^{+}=\mathrm{CH}_{2} \mathrm{I}^{-}$. The 1,4-dihydropyridine derivative 285 was synthesized using 2acetyl indole $\mathbf{2 8 3}$ and pyridinium salt $\mathbf{2 8 4}$. The iminium cation 286 would undergo regioselective cyclization to the bridged tetracyclic system 287, which was converted into $N$-methyl ervitsine 289a and ervitsine 289b into two synthetic steps first by treatment with $m$ CPBA to yield 288 followed by borohydride reduction. A short four-step synthesis of $N$-methyl ervitsine involving the nucleophilic addition of acetyl indole to pyridinium salt, with subsequent $\mathrm{C}_{6} \mathrm{H}_{5} \mathrm{SeBr}$-promoted cyclization

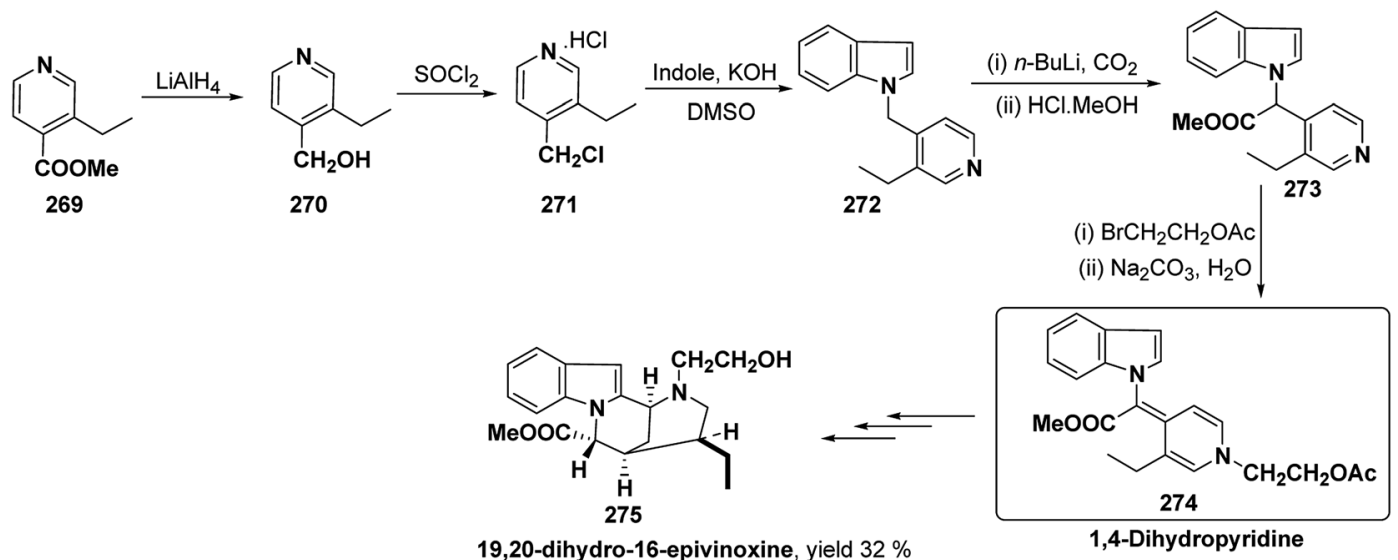

Scheme 83 Synthesis of 19,20-dihydro-16-epivinoxine 275.

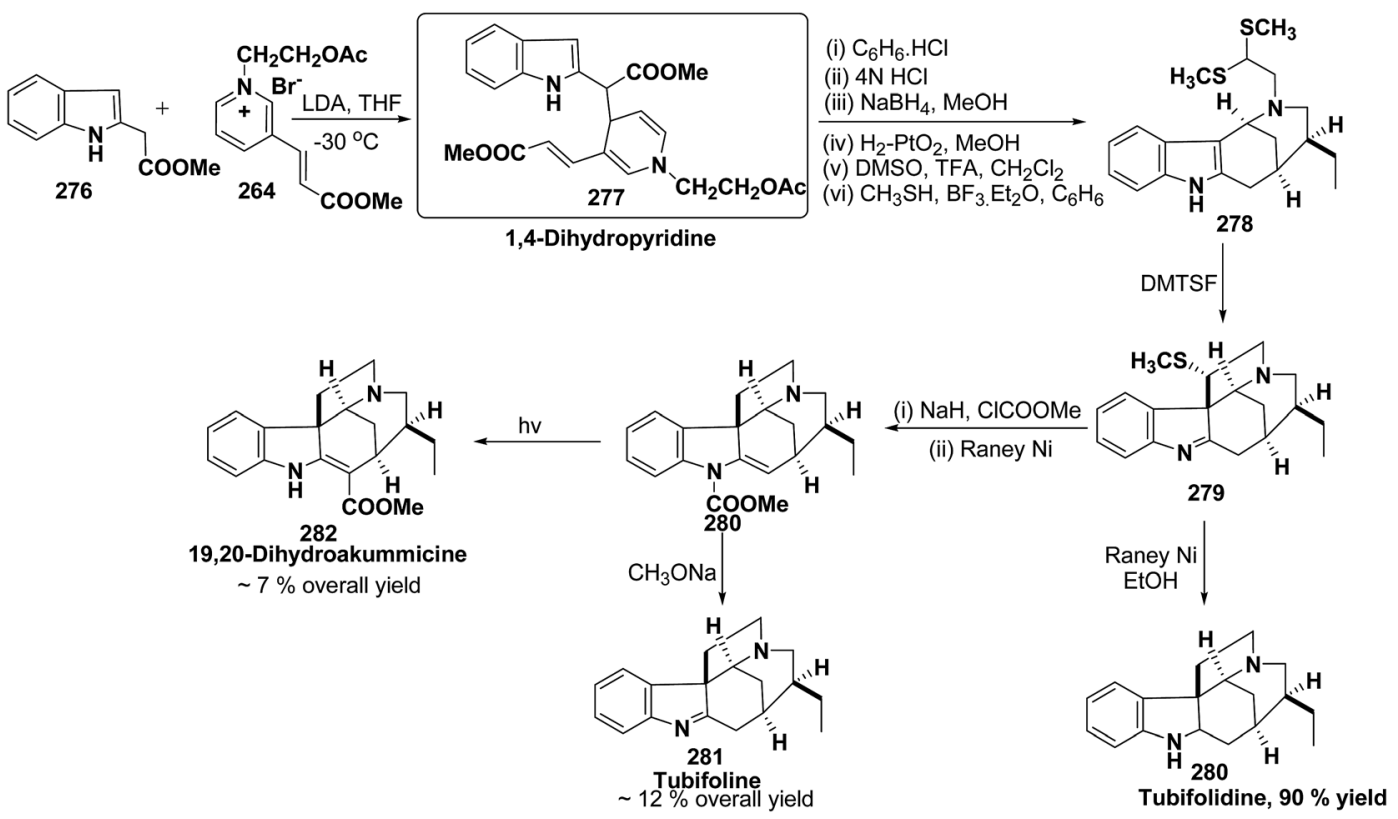

Scheme 84 Synthesis of tubifolidine 280, tubifoline 281 and 19,20-dihydroakummicine 282 . 
of 1,4-dihydropyridine instead of $\mathrm{Me}_{2} \mathrm{~N}^{+}=\mathrm{CH}_{2} \mathrm{I}^{-}$promoted cyclization has been further reported by Bennasar, et al. ${ }^{99}$

The first total synthesis of $( \pm$ )-2,7-dihydropleiocarpamine 295 has been reported by Bennasar, et al. ${ }^{\mathbf{1 0 0}}$ via the synthesis of 1,4-dihydropyridine 291 as an intermediate (Scheme 86). The 1,4-dihydropyridine 291 was synthesized from nucleophilic addition of $\mathbf{2 6 3}$ on pyridinium salt 290 in the presence of LDA in THF. The key step is the photocyclization of the tetracyclic chloroacetamide $\mathbf{2 9 4}$ to give the required six membered ring via closure of C-6/C-7 bond formed by diradical coupling, which was not achieved by electrophilic cyclization.

The ervatamine alkaloids (19,20-dehydroervatamine 307, 20-epiervatamine 308 and ervatamine 309) constitute a group of 2-acylindole alkaloids. Bennasar, et al. ${ }^{101}$ has reported the total synthesis of 19,20-dehydroervatamine and 20-epiervatamine, whereas ervatamine was synthesized from 19,20dehydroervatamine via catalytic hydrogenation. The intermediate 1,4-dihydropyridine 299 formed via the nucleophilic attack of $N$-benzyl-2-acetyl indole 296 to the $\gamma$-position of the pyridinium salt 297. The 1,4-dihydropyridine 298 was functionalized to give 3,5-diacyl-1,4-dihydropyridine 299, which was reduced to tetrahydropyridine 300, and was further converted to cis-fused pentasubstituted piperidines $(19,20$-dehydroervatamine 307, 20-epiervatamine 308 and ervatamine 309) in number of steps by using suitable reagents (Scheme 87).

Bennasar, et $a .^{\mathbf{1 0 2}}$ has reported a general route for the synthesis of tetracyclic ring system of silicine-methuenine alkaloids $\mathbf{3 1 1}$ and $\mathbf{3 1 2}$. The key step in the synthesis was the selective reduction of the intermediate 299 by using $\mathrm{PtO}_{2}$ followed by debenzylation to afford 301, which on cyclisation using trimethylsilyl polyphosphate PPSE yielded 310 (Scheme 88). The compound $\mathbf{3 1 0}$ was further converted into tetracyclic ring system of silicine-methuenine alkaloids 311 and 312 in number of steps. The 1,4-dihydropyridine intermediate 299 was synthesized according to the literature procedure reported by Bennasar, et al. $^{\mathbf{1 0 1}}$
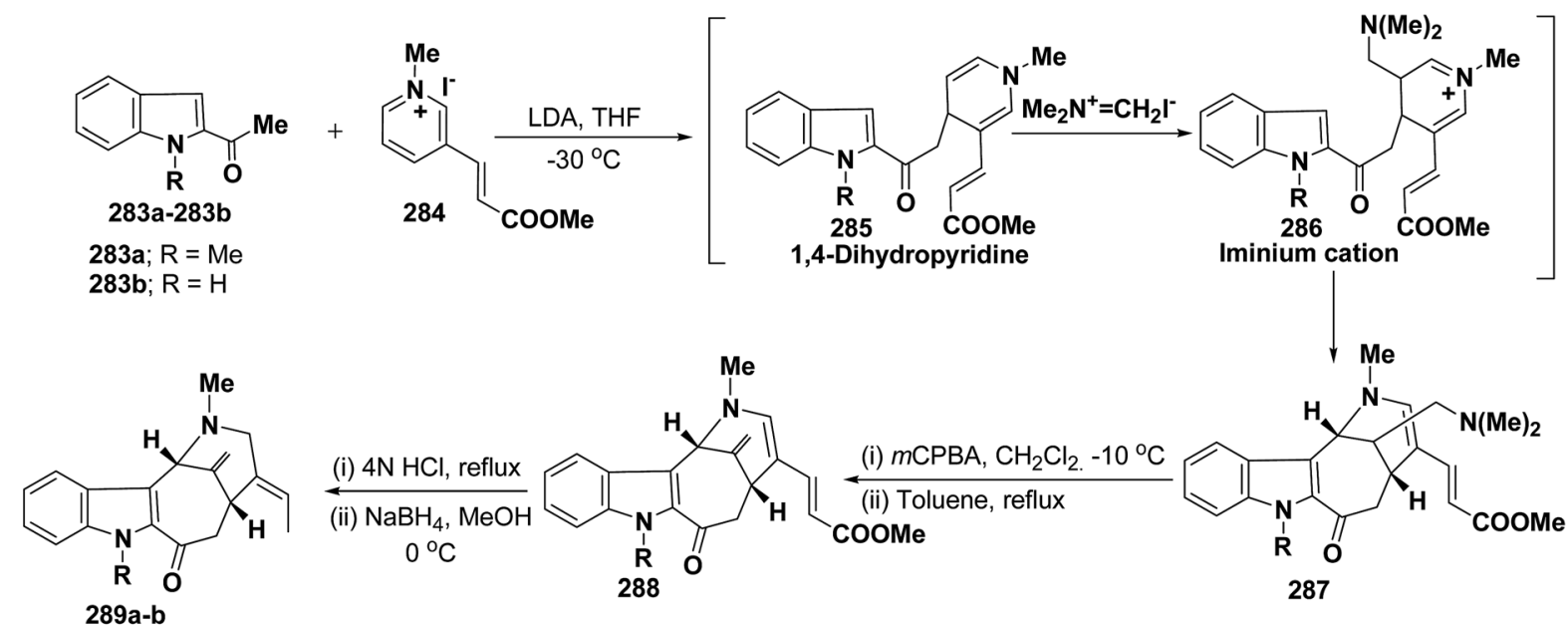

$N$-Methyl ervistine 289a; $\mathrm{R}=\mathrm{Me}$ Ervitsine 289b; $\mathrm{R}=\mathrm{H}$, yield $65 \%$

Scheme 85 Synthesis of $N$-methyl ervitsine $289 \mathrm{a}$ and ervitsine $289 \mathrm{~b}$.

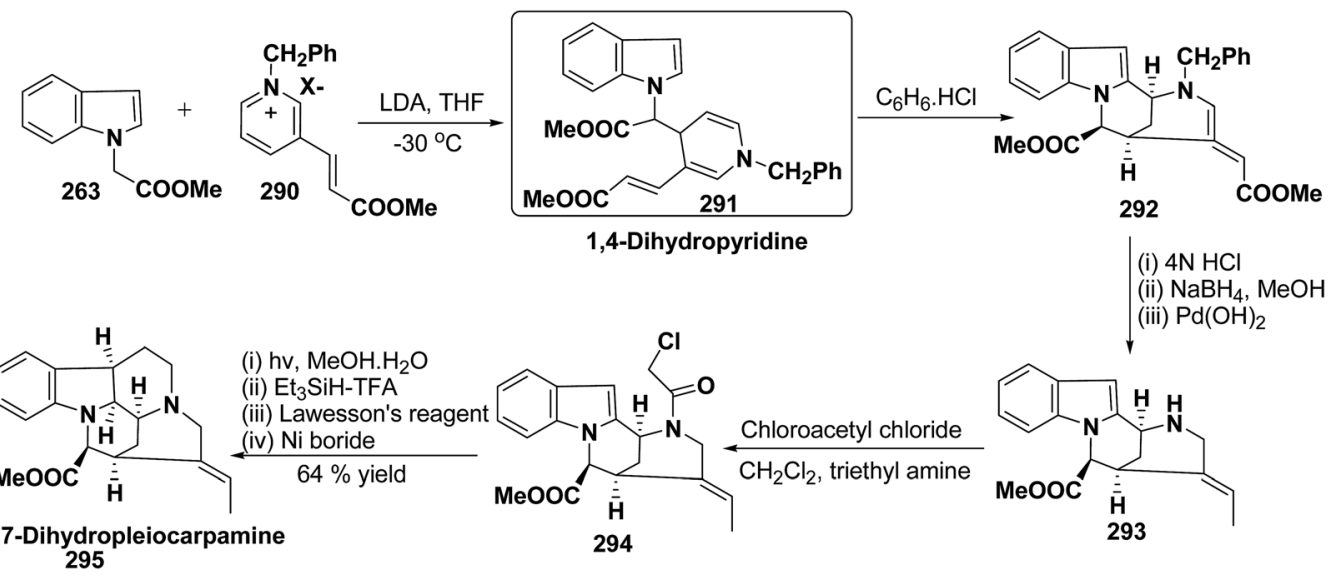

Scheme 86 Synthesis of $( \pm)$-2,7-dihydropleiocarpamine 295. 
Bennasar, et $a .^{103}$ has reported a general route for the synthesis of 6-oxo-16-episilicine $\mathbf{3 2 0}$ (a silicine-methuenine alkaloid), involving the nucleophilic addition of an acetylindole enolate 296 to the pyridinium salt 284 to yield 1,4dihydropyridine 313 as an intermediate. The 1,4-dihydropyridine $\mathbf{3 1 3}$ was functionalized to give 3,5-diacyl-1,4- dihydropyridine $\mathbf{3 1 4}$, which was reduced to tetrahydropyridine 315, and was subjected to PPSE-induced cyclisation to yield 316. Hydrolysis of compound 316 using $\mathrm{MeOH} \cdot \mathrm{H}_{2} \mathrm{O}, \mathrm{HCl}$ followed by decarboxylation using 2,2'-dithiobis-(pyridine- $N$ oxide) yielded 317, which on $N$-debenzylation yielded 318. The debenzylated compound 318 on reduction using $\mathrm{NaBH}_{3} \mathrm{CN}$

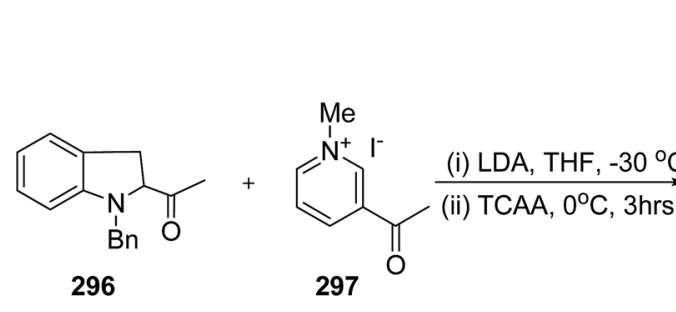

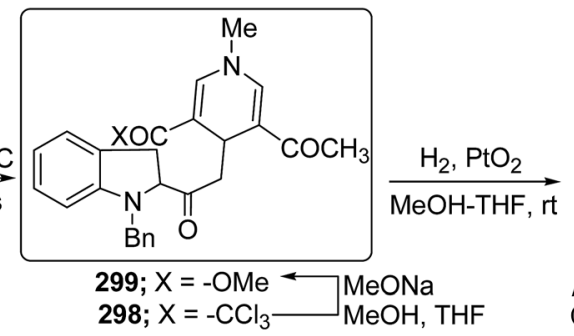

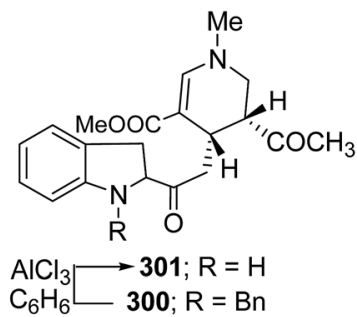

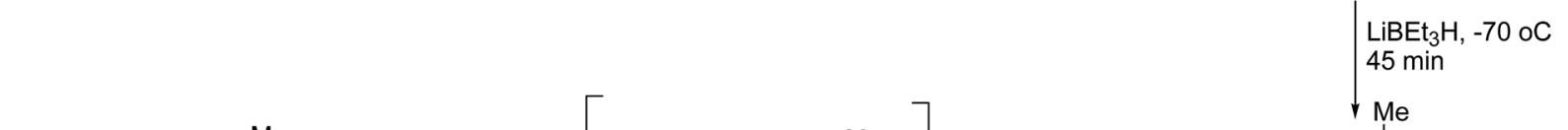<smiles>[X]C(C)C12CC(=O)C3Nc4ccccc4C3CC1(COC)CN(C)C2</smiles>

(i) $\mathrm{NaBH}_{3} \mathrm{CN}, \mathrm{MeOH}$ (ii) $\mathrm{MnO}_{2}, \mathrm{CHCl}_{3}$

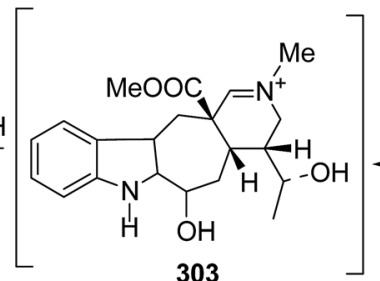
(i) $\mathrm{Me}_{2} \mathrm{~N}^{+}=\mathrm{CH}_{2}{ }^{-}$ (ii) $\mathrm{CH}_{3}$ l, DMSO, $30 \mathrm{~min}$.

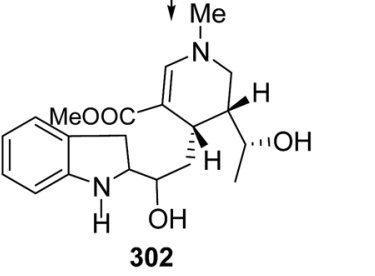

$304 ; \mathrm{X}=\mathrm{OH} \square \mathrm{MsCl}, \mathrm{TEA}$
$305, \mathrm{XMs} \longleftarrow \mathrm{O}$

303

$306, \mathrm{X}=\beta$-Cl

DBU, DMSO-toluene, $80-100^{\circ} \mathrm{C}$

or

from 305: $n-\mathrm{Bu}_{3} \mathrm{SnH}, \mathrm{AIBN}$, benzene, reflux<smiles>[R]C1CN(C)C[C@]2(C)C[C@@H]3c4ccccc4N[C@@H]3C(=O)C[C@H]12</smiles>

307; $\mathrm{R}=(E)=\mathrm{CHCH}_{3}$

19,20-Dehydroervatamine, overall yield $=8 \%$

308; $\mathrm{R}=\alpha$-Et, $\beta \mathrm{H}$

20-Epiervatamine, overall yield $=\sim 7 \%$

309, $\mathrm{R}=\beta$-Et, $\alpha$ - $\mathrm{H}$

Ervatamine, Overall yield $=\sim 9 \%$

Scheme 87 Synthesis of 19,20-dehydroervatamine 307, 20-epiervatamine 308 and ervatamine 309
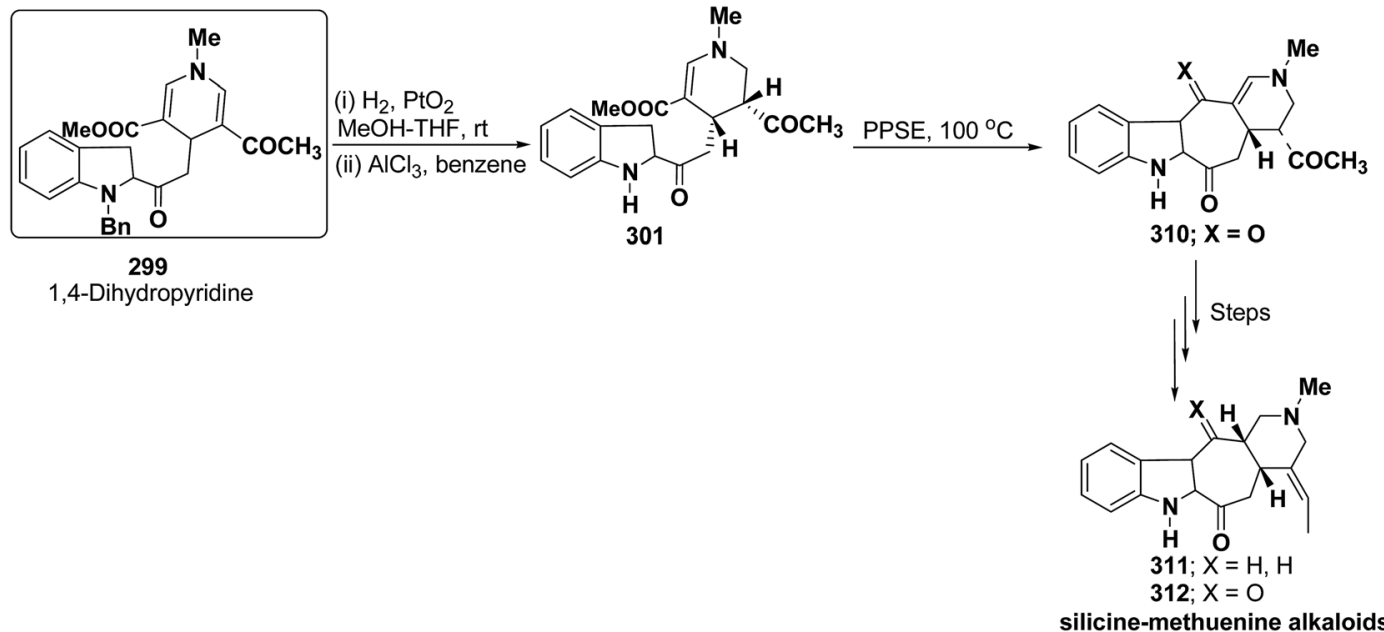

Scheme 88 Synthesis of silicine-methuenine alkaloids 311 and 312. 
yields 319, which on oxidation with $\mathrm{MnO}_{2}$ yield 6-oxo-16episilicine 320 (Scheme 89).

Pyridoacridines are a family of alkaloids based on $1 \mathrm{H}$-pyrido $[4,3,2, m n]$ acridine skeleton. The synthesis of pyridoacridine ring 329 of alkaloid amphimedine 330 was achieved by condensing ${ }^{t}$ butyl-protected 2-lithio-1,4-DHP 324 with 3,4-disubstituted cyclobutanediones 325 to yield 326 followed by thermolysis to yield 327 . The conversion of 327 in aniline derivative $\mathbf{3 2 8}$ was achieved using hydroxylamine hydrochloride and oxidation with ${ }^{t}$-BuOOH in presence of $\mathrm{KOH}$ yielded dihydroquinoline hydroquinine ring system 329. The Boc-protected 2-lithio-1,4-DHP was synthesized by the reaction between the Grignard reagent of $N$-(2-bromophenyl)2,5-dimethylpyrrole 321 with $N$-carboxyphenylpyridinium chloride (Scheme 90). ${ }^{\mathbf{1 0 4}}$
Akagerine $\mathbf{3 3 8}$ is a tetracyclic indole alkaloid. A formal stereoselective synthesis of akagerine 338 had been reported via pentacyclic dilactam 337. ${ }^{105}$ The intermediate dilactam 337 was synthesized starting from 1,4-dihydropyridine 333, which was synthesized from the nucleophilic attack of the $N$-acetyl indole 331 on pyridinium salt 332. Compound 333 was converted into 334 using sulfonic acid. The hydroxyl group of the compound $\mathbf{3 3 4}$ was removed via first triflation followed by reduction to afford compound 335. The key step is the formation of piperidine ring of compound 336, which was accomplished by cyclization of thionium ion generated by Pummerer rearrangement using TFAA in presence of 2,6-di $(t$ butyl)pyridine. Dilactam 337 was obtained by the treatment of compound $\mathbf{3 3 6}$ with tributyltin hydride in benzene (Scheme 91). ${ }^{106}$

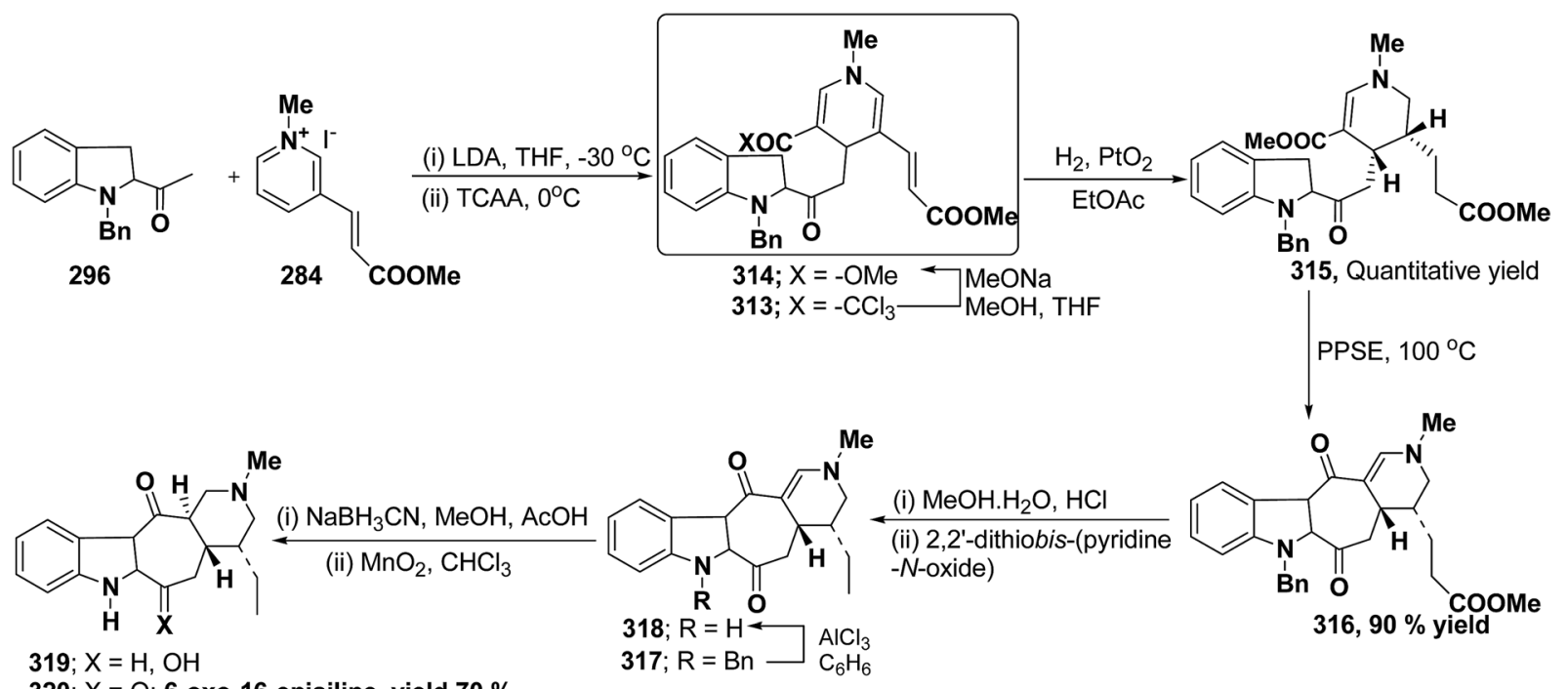

320; $X=0 ; 6$-oxo-16-episiline, yield $70 \%$

Scheme 89 Synthesis of 6-oxo-16-episilicine 320
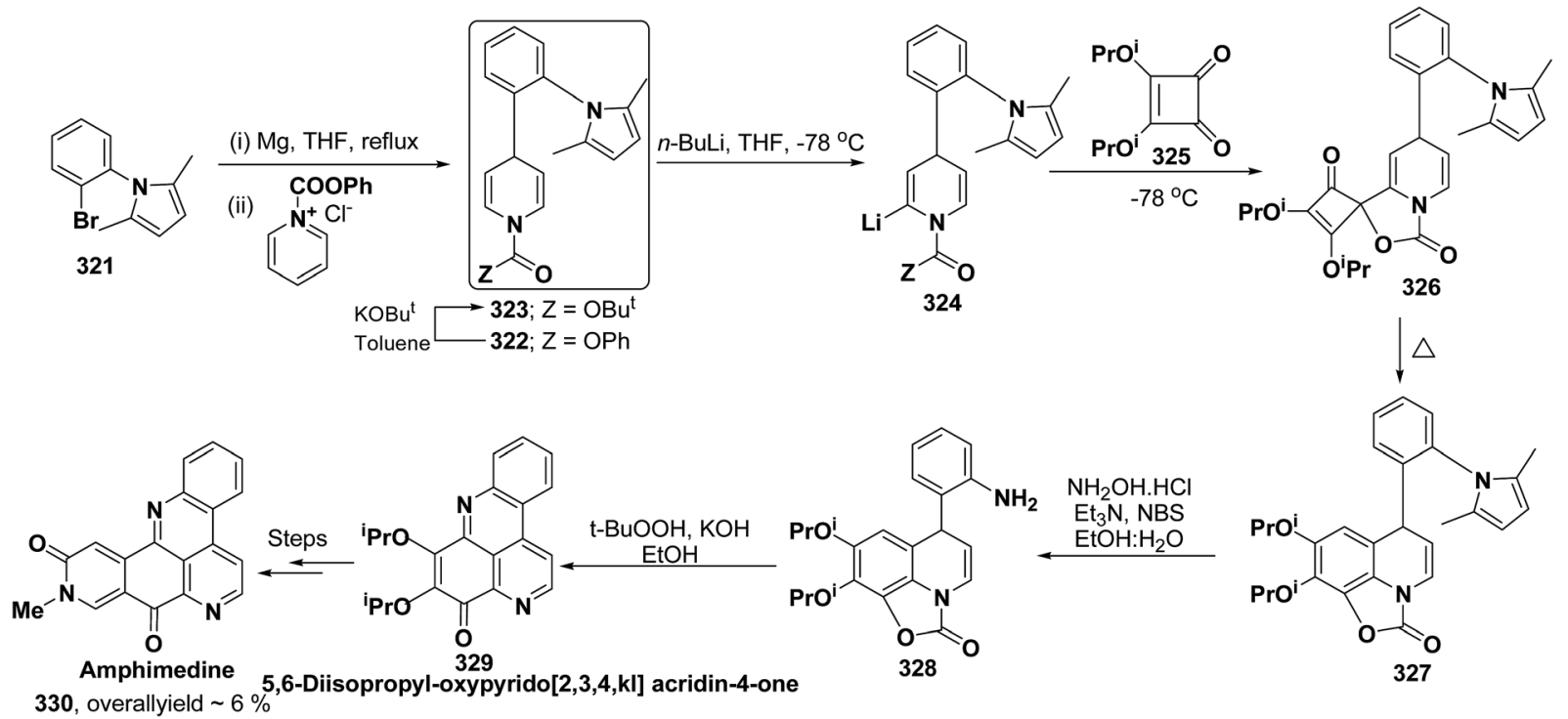

Scheme 90 Synthesis of 5,6-diisopropyl-oxypyrido[2,3,4,kl]acridin-4-one 330. 
<smiles>CC(=O)n1ccc2ccccc21</smiles>

331

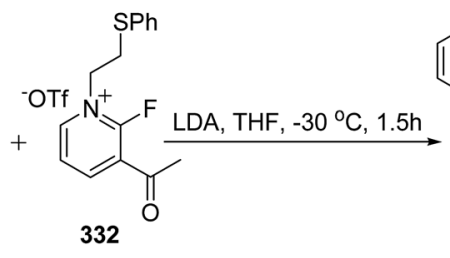<smiles>CC(=O)C1=C(F)N(CCc2ccccc2)C=CC1CC(=O)n1ccc2ccccc21</smiles>
$\underset{\mathrm{MeOH}, \mathrm{Lil}, \mathrm{rt}, 2 \mathrm{~h}}{\stackrel{\mathrm{C}_{6} \mathrm{H}_{6}, \mathrm{TsOH}}{\longrightarrow}}$ 3330

(i) $\mathrm{Tf}_{2} \mathrm{O}, 1,8$-bis(dimethylamino)naphthalene -30 to $-10^{\circ} \mathrm{C}, 1 \mathrm{~h}$

(ii) $\mathrm{Bu}_{3} \mathrm{SnH}, \mathrm{Pd}(\mathrm{Ph})_{4}, \mathrm{LiCl}$, THF, reflux, $1 \mathrm{~h}$

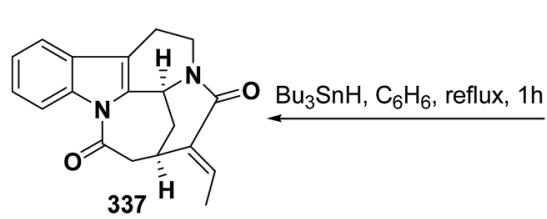

Dilactam, $72 \%$ yield

Steps $\downarrow \downarrow$<smiles>C/C=C(/C=O)[C@H]1C[C@H]([13CH3])[C@@H]2c3c(c4ccccc4n31)CCN2C</smiles>

Akagerine

Scheme 91 Synthesis of dilactam 337.<smiles></smiles>

336, Overall yield $71 \%$ from 335<smiles>C/C(O)=C1/C(=O)N(CCc2ccccc2)[C@H](C)/C(=C\CSc2ccccc2)C[C@@H]1C(=O)O</smiles><smiles>C/C=C1/C(=O)N(CCc2ccccc2)C[C@H]1C1CC(=O)n2c(cc3ccccc32)C1</smiles>

335 , Overall yield $45 \%$ from 334 $\frac{\text { (i) } m \text { CPBA, DCM, }-70^{\circ} \mathrm{C}, 0.5 \mathrm{~h} \text {; }}{\text { (ii) TFAA, 2,6-di(tert-butyl)pyridine, }}$ $\mathrm{CH}_{2} \mathrm{Cl}_{2}$, rt, $0.5 \mathrm{~h}$ then reflux for $1.5 \mathrm{~h}$

35

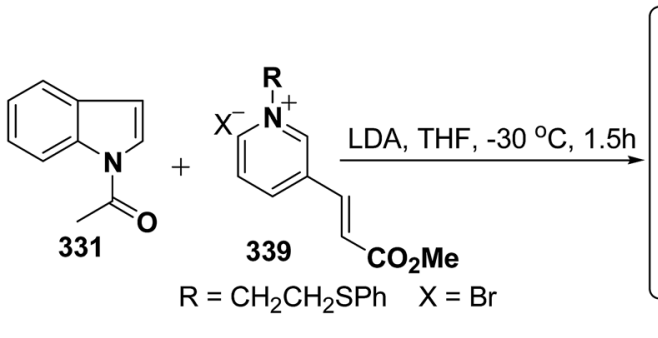

$$
\mathrm{R}=\mathrm{CH}_{2} \mathrm{CH}_{2} \mathrm{SPh} \quad \mathrm{X}=\mathrm{Br}
$$<smiles>C/C=C1/CN2CCc3c([nH]c4ccccc34)[C@H]2C[C@H]1CCOC</smiles>

344<smiles>C=C[AsH2]</smiles><smiles>C/C=C1/CN2CCc3c([nH]c4ccccc34)[C@H]2C[C@H]1/C(=C\O)COC</smiles>

Geissoschizine, overall yield $52 \%$

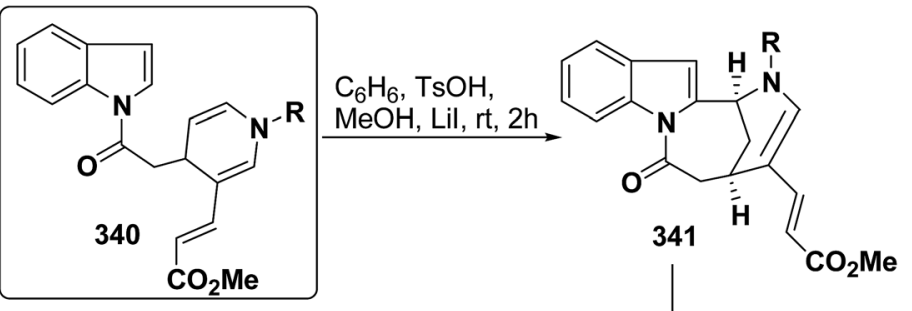

1,4-DHP (i) $2.5 \mathrm{~N} \mathrm{HCl}, \mathrm{MeOH}$, reflux, $2 \mathrm{~h}$,

(ii) $\mathrm{NaBH}_{4}, 0^{\circ} \mathrm{C}$<smiles></smiles>

MeONa, MeOH:THF (4:1),

$\mathrm{rt}, 3 \mathrm{~h}$<smiles>[R]N1C/C(=C/C)[C@H]2C[C@@H]1CC(=O)n1c2cc2ccccc21</smiles>

(i) TFAA, DCM, rt, 0.5h, $\quad$ 342a R $=\mathrm{CH}_{2} \mathrm{CH}_{2} \mathrm{SPh}$

(ii) $\mathrm{mCPBA}, \mathrm{CH}_{2} \mathrm{Cl}_{2},-70^{\circ} \mathrm{C} \longrightarrow \mathbf{3 4 2 b} \mathrm{R}=\mathrm{CH}_{2} \mathrm{CH}_{2} \mathrm{~S}(\mathrm{O}) \mathrm{Ph}$

Scheme 92 Synthesis of geissoschizine 345. 
Formal synthesis of $( \pm)$-geissoschizine had been carried out using 1,4-dihydropyridine derivative $340{ }^{107}$ The 1,4dihydropyridine derivative $\mathbf{3 4 0}$ was synthesized from nucleophilic attack of the $N$-acetyl indole 331 on pyridinium salt 339. Compound $\mathbf{3 4 0}$ was converted into $\mathbf{3 4 1}$ using sulfonic acid in benzene, which on treatment with $\mathrm{HCl}$ followed by borohydride reduction yielded 342a. Compound 342a was first converted into sulfone $\mathbf{3 4 2} \mathbf{b}$, followed by treatment with sodium methoxide resulted into the formation of compound 343, which on desulferisation using tributyltin hydride and AlBn give compound 344 (Scheme 92). Compound $\mathbf{3 4 4}$ has been converted into geissoschizine $\mathbf{3 4 5}$ by Yamada, et al. ${ }^{108}$
A concise total synthesis of $( \pm)$-camptothecin and natural (+)-camptothecin has been reported starting from 2-fluoro-1,4dihydropyridine adduct $351 .{ }^{109}$ The 1,4-DHP adduct 351 was achieved from compound 346 in three steps. 2-Fluoro-1,4dihydropyridine adduct 351 on oxidation with DDQ resulted into the formation of compound 352, which on treatment with hydrogen atom donor tris(trimethylsilyl)silane-AIBN give compound 353 (Scheme 93). Formation of the pyran ring in compounds 354 and 20-dioxycamptothecin 355 takes place by the treatment of compound 353 with DIBAL and borohydride reduction. 20-Dioxycamptothecin 355 was further used for the synthesis of $( \pm)$-camptothecin and natural $(+)$-camptothecin via the literature procedure. ${ }^{\mathbf{1 1 0}}$

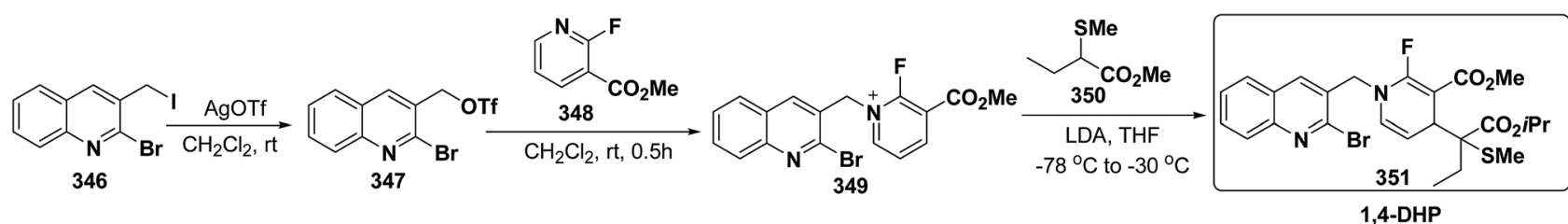

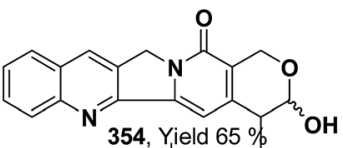
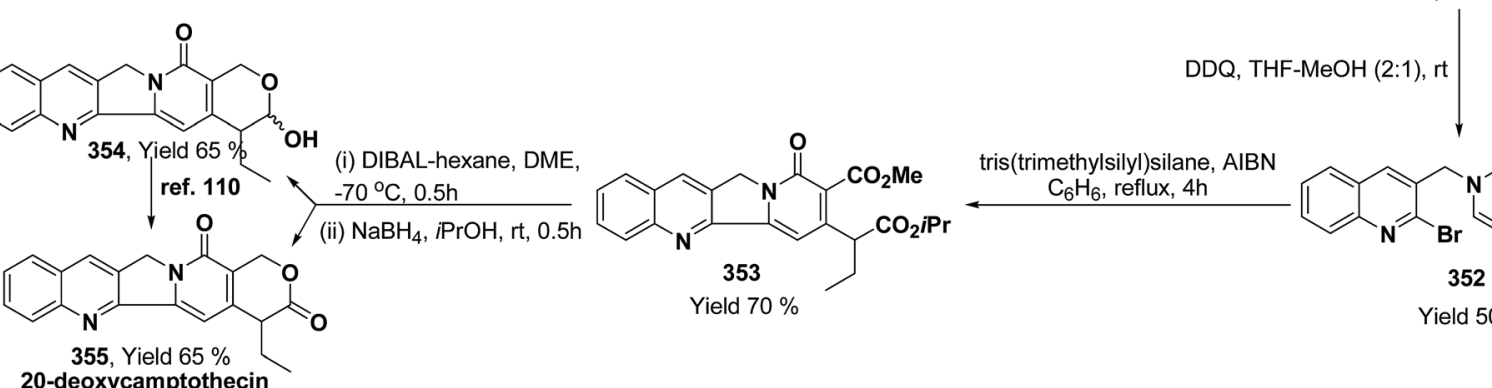

,4-DHP tris(trimethylsilyl)silane, AIBN
$\mathrm{C}_{6} \mathrm{H}_{6}$, reflux, $4 \mathrm{~h}$

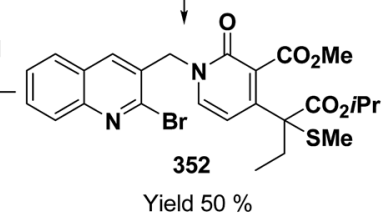

20-deoxycamptothecin
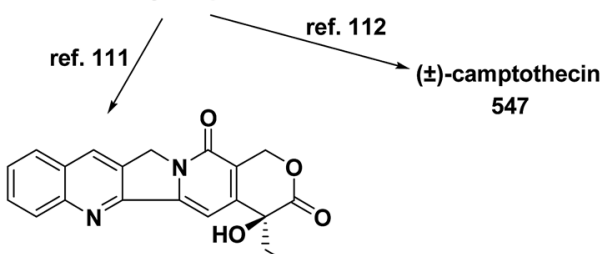

(+)-camptothecin

356

Scheme 93 Synthesis of $( \pm)$-camptothecin and natural (+)-camptothecin.<smiles>CCC1=C(O)OC(C(C)(C)C)[Se]1</smiles>

349<smiles>CC[C@]1(O)C(=O)OCc2c1cc1n(c2=O)Cc2cc3ccccc3nc2-1</smiles>
Yield $60 \%$<smiles>COC(=O)C1=C(F)C(C2OC(C(C)(C)C)OC2OC)C=CN1Cc1cc2ccccc2nc1Br</smiles><smiles>CC(C)C(C)O</smiles>

tris(trimethylsilyl)silane, AIBN $\mathrm{C}_{6} \mathrm{H}_{6}$, reflux, $4 \mathrm{~h}$

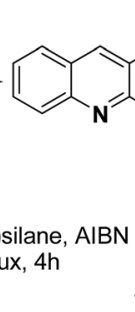

(i) DIBAL-hexane, DME, $-70^{\circ} \mathrm{C}, 0.5 \mathrm{~h}$

(ii) $\mathrm{NaBH}_{4}, \mathrm{iPrOH}, \mathrm{rt}, 0.5 \mathrm{~h}$<smiles>CC[C@]1(c2cc3n(c(=O)c2C(=O)O)Cc2cc4ccccc4nc2-3)O[C@H](C(C)(C)C)OC1=O</smiles>

Scheme 94 Synthesis of (+)-camptothecin 356. 
The synthesis of natural (+)-camptothecin 356 has been reported by the nucleophilic addition of a chiral auxiliary 357 to the pyridinium salt 349 (Scheme 94). The remaining synthetic steps are similar as used in Scheme 93. ${ }^{109}$
Putkonen, et al. ${ }^{\mathbf{1 1 1}}$ has reported the total synthesis of $( \pm)$-tangutorine 368 and modified the first synthetic procedure reported by Berner, et al. ${ }^{112}$ For the synthesis of ( \pm )-tangutorine 368, desired quinoline derivative 362 was reacted with<smiles>COC(=O)C1CCc2ncccc2C1=O</smiles><smiles>COC(=O)C1CCC2=C(CC=CN2CCc2c[nH]c3ccccc23)C1=O</smiles>

$\mathrm{HCl}-\mathrm{MeOH}, \mathrm{rt}, 65 \mathrm{~h}$

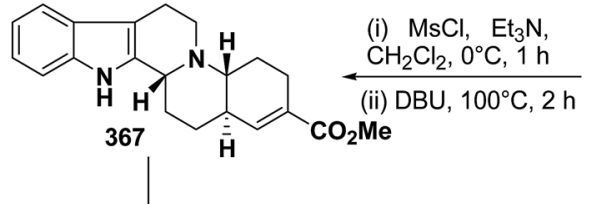
$\mathrm{LiAlH}_{4}, \mathrm{THF}, \mathrm{rt}, 4 \mathrm{~h}$.

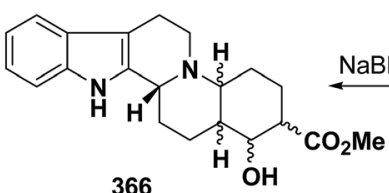
366<smiles>CC(C)(C)[Mg]</smiles>

(士)-Tangutorine, Overall yield $20 \%$

Scheme 95 Synthesis of $( \pm)$-tangutorine 368
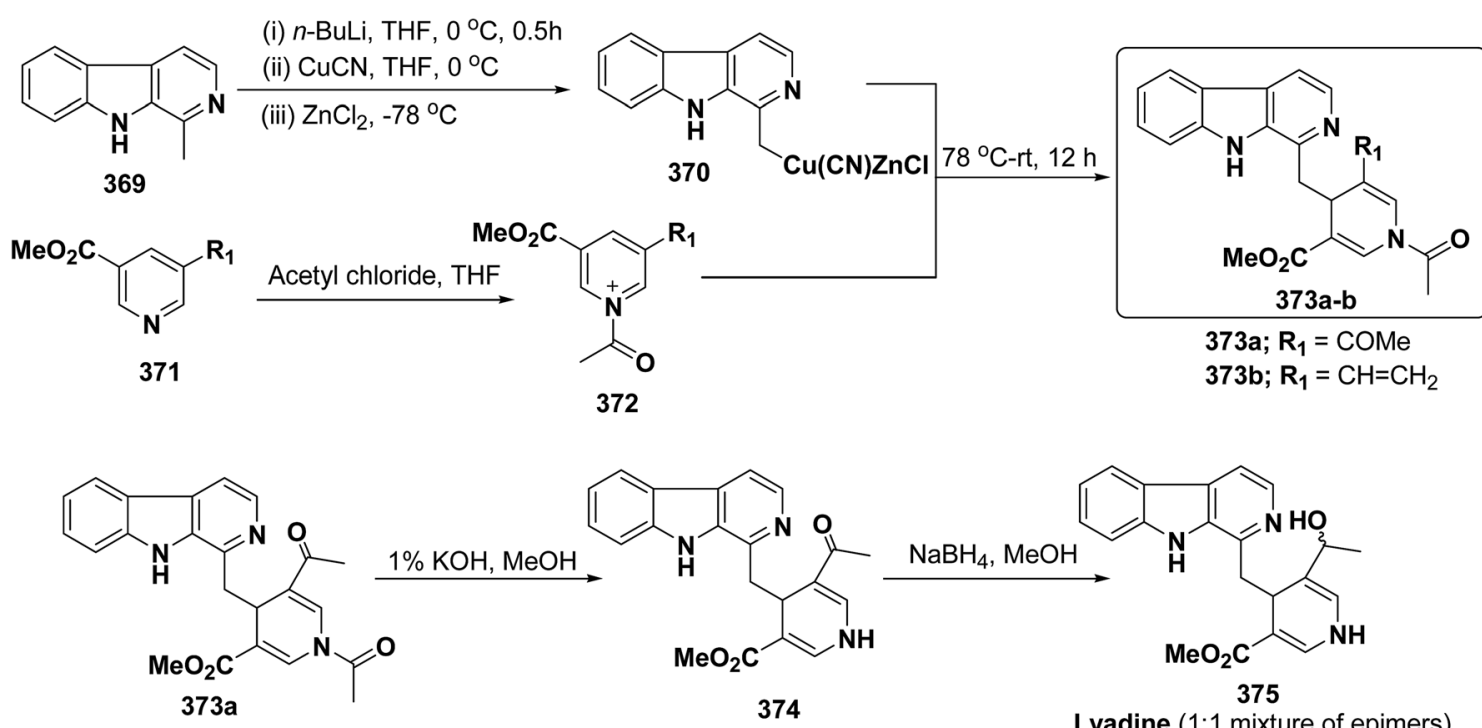

Lyadine (1:1 mixture of epimers)<smiles>C=CC1=CN(C(C)=O)C=C(C(=O)OC)C1Cc1nccc2c1[nH]c1ccccc12</smiles>

$373 b$<smiles>C=CC1=CNC=C(C(C)=O)C1Cc1nccc2c1[nH]c1ccccc12</smiles>

376

Lyaline, Overall yield $12 \%$

Scheme 96 Synthesis of lyadine 375 and lyaline 376 
tryptophyl bromide 255 to afford pyridinium salt 363. Since the total yield of the tangutorine skeleton was relatively low due to the different stereoisomers formed in the Fry reaction. ${ }^{112}$ The total synthesis of indole alkaloid $( \pm)$-tangutorine 368 has been carried out using dithionite reduction of pyridinium salt 363 to afford the 1,4-dihydropyridine intermediate 365. Cyclization of compound 364 in $\mathrm{HCl} / \mathrm{MeOH}$ to compound 365 and reduction with sodium borohydride in glacial acetic acid for overnight yielded a mixture of isomers of compound 366. ( \pm )-Tangutorine 368 was afforded after dehydration of compound 366 and finally reduction of the ester group in compound 367 (Scheme 95).

The harman-1,4-dihydropyridines $373 \mathbf{a}-\mathbf{b}$, which constitutes the original proposed structures for the indole alkaloid lyadine $\mathbf{3 7 5}$ and lyaline $\mathbf{3 7 6}$ have been synthesized by Bennasar, et al. ${ }^{113}$ (Scheme 96). The harman-1,4-dihydropyridines 373a-b were synthesized starting from harman 369 and pyridine 371. The nucleophilic addition reaction of Grignard reagent of harman 370 with pyridinium salt 372 prepared from pyridine 371 . The harman-1,4-dihydropyridine 373a was converted into lyadine 375 in two synthetic steps first by $N$ deacetylation followed by borohydride reduction, whereas lyaline 376 was obtained from the $N$-deacetylation of compound $373 \mathbf{b}$.

Amat, et al. ${ }^{114}$ has proposed a model for the synthesis of Strychnos alkaloid e.g. dihydroakuammicine $\mathbf{3 8 0}$ could be obtained starting from a suitable functionalized enantiopure 2(1,4-dihydro-4-pyridylmethyl)indole 377 (Scheme 97).

The nucleophilic addition of indole acetic ester 381 and $N$ alkyl pyridinium salt 382a-b followed by acid cyclization gave a mixture of expected tetracyclic compound 383a-b along with regioisomer 384a-b (Scheme 98). It is probably the bulkiness of chiral auxiliary hinders the approach of the nucleophile to the adjacent 4-position of pyridine ring.
The strategy for the synthesis of tetracyclic precursors ABCD of dihydroakuammicine using chiral auxiliary suffers two major drawbacks (i) low facial stereoselectivity due to inefficient coordination of nucleophile with the chiral auxiliary and (ii) low regioselectivity due to bulkiness of chiral auxiliary. ${ }^{114}$

\section{Medicinal importance of dihydropyridines}

The first synthesis of 1,4-dihydropyridine (1,4-DHP) nucleus was reported in 1881 by A. Hantzsch. ${ }^{26 a}$ It took 80 years to test these compounds for their biological activity, and finally Bossert and Vater at Bayer AG got the Hantzsch type 1,4-DHP possessing outstanding coronary vasodilator activity. ${ }^{115}$ Nifedipine, the 2-nitrophenyl derivative (Table 17) was then introduced for the treatment of coronary diseases. ${ }^{116}$ Due to the resemblance with NADH and also interesting biological activities, subsequently several other 1,4-DHPs (Table 17) have been introduced for clinical use as hypertensive agents that have a worldwide market of several billion dollars. ${ }^{17}$ Amlodipine (Norvasc), with sales of more than $\$ 5$ billion in recent years is among the top-five best selling drugs. DHP's have also been explored as anti-inflammatory, ${ }^{118}$ anti-tumor, ${ }^{119}$ antitubercular, ${ }^{120}$ anti-convulsant activity ${ }^{121}$ etc. 1,4-DHP drugs can be divided into three generations depending on their pharmacologic and pharmacokinetic profiles. ${ }^{122}$ Because of the short duration and rapid onset of vasodilator action, nifedipine activated sympathetic tone. ${ }^{123}$ Therefore, in the quest of better therapeutic standard, the first-generation drug, nifedipine has been extensively modified. The second generation drugs exert less sympathetic reflex by designing slow-release formulations of preparations of the short-acting drugs. ${ }^{124}$

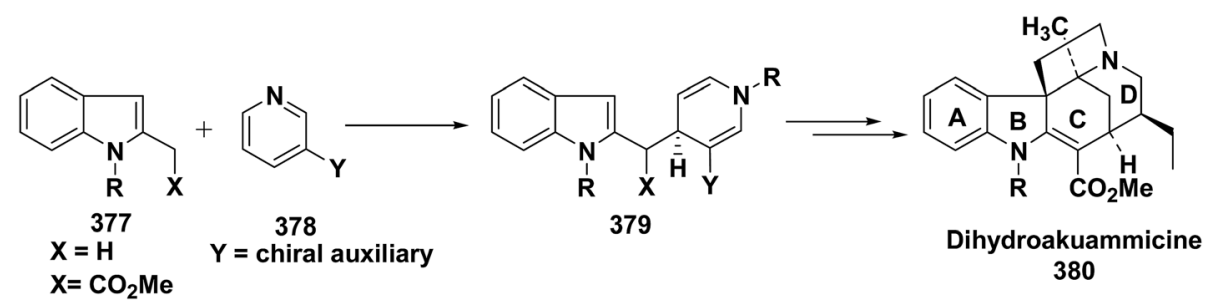

Scheme 97 Proposed procedure for the synthesis of dihydroakuammicine 380 .

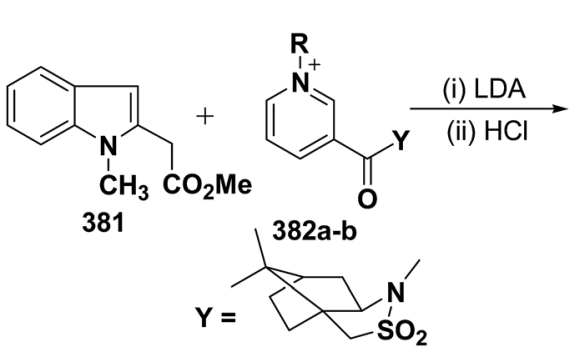

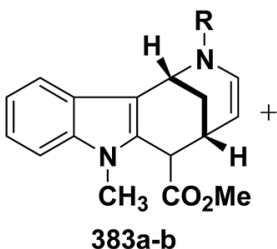

a $\mathrm{R}=\mathrm{CH}_{3}(10 \%)$

b $R=B n(27 \%)$

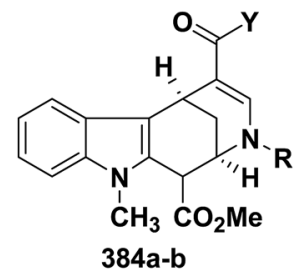

$(28 \%)$

Scheme 98 Synthesis of tetracyclic precursors 383 and 384 of dihydroakuammicine. 
Table 17 Commercially important 1,4-DHP's<smiles>[Y]C(=O)c1c(C)[nH]c(C)c1-c1ccccc1[X]</smiles>

DHP Drug
Brand name

Procardia, Adalat

$2-\mathrm{NO}_{2}$

$-\mathrm{Me}$

$-\mathrm{Me}$

$\mathrm{Me}$
$-\mathrm{Me}$

$-\mathrm{CH}_{2} \mathrm{CHMe}_{2}$

$\mathrm{Me}$

\section{Nimodipine}<smiles>CC(=O)C1=C(C)NC(C)=C(C(=O)OCCN(C)Cc2ccccc2)C1c1cccc([N+](=O)[O-])c1</smiles>

$\mathrm{Me}$

\section{Nicardipine}<smiles>CCOC(=O)C1=C(C)NC(C)=C(C(C)=O)C1c1cccc([N+](=O)[O-])c1</smiles>

\section{Cardif, Nitrepin,} Baylotensin

$3-\mathrm{NO}_{2}$

$-\mathrm{Me}$

- Et

$\mathrm{Me}$

Nitrendipine<smiles>CCOC(=O)C1=C(C)NC(C)=C(C(C)=O)C1c1cccc(Cl)c1Cl</smiles>

Plendil

$-\mathrm{Me}$

- Et
$\mathrm{Me}$ 
Table 17 (Contd.)<smiles>[R20]OC(=O)C1=C(C)NC([Y])=C(O[R])C1c1ccccc1[X]</smiles>

DHP Drug<smiles></smiles>

DynaCirc, DynaCirc CR

$3^{\text {rd }}$ generation<smiles>CCCCCCCCCCCOC(=O)C1=C(C)NC(C)=C(C(C)=O)C1c1cccc([N+](=O)[O-])c1</smiles>

Pranidipine
$\mathrm{X}$

${ }^{3}=\mathrm{N}^{\mathrm{N}} \mathrm{N}^{\mathrm{N}}$

$-\mathrm{CHMe}_{2}$

$\mathrm{Me}$

Y
$3-\mathrm{NO}_{2}$

$-\mathrm{Me}$

$-\mathrm{CH}_{2} \mathrm{CH}=\mathrm{CHPh}$

$\mathrm{Me}$<smiles>CC(=O)C1=C(C)NC(C)=C(C(=O)OC(C)(C)N(C)CN(C)CCC(c2ccccc2)C(C)C)C1c1cccc([N+](=O)[O-])c1</smiles>

\section{Lercanidipine}<smiles>CC(=O)OC1=C(C)NC(C)=C(C(=O)OC2CCN(Cc3ccccc3)C2)[C@H]1c1cccc([N+](=O)[O-])c1</smiles>

\section{Barnidipine}<smiles>CC(=O)C1=C(C)NC(C)=C(C(=O)O[C@H]2CCCN(Cc3ccccc3)C2)C1c1cccc([N+](=O)[O-])c1</smiles>

\section{Barnidipine}

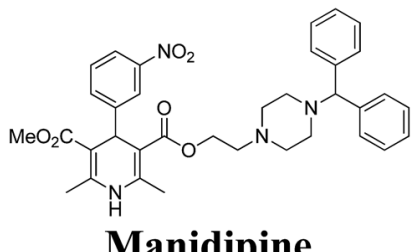

3- $\mathrm{NO}_{2}$

3- $\mathrm{NO}_{2}$

$3-\mathrm{NO}_{2}$

$-\mathrm{Me}$

$-\mathrm{Me}$

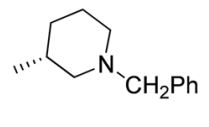

$-\mathrm{C}(\mathrm{Me})_{2} \mathrm{CH}_{2} \mathrm{~N}(\mathrm{Me})$ $\mathrm{CH}_{2} \mathrm{CH}_{2} \mathrm{CHPh}_{2}$

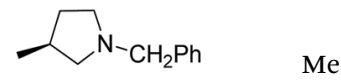

Manidipine 
Table 17 (Contd.)<smiles>[R20]OC(=O)C1=C(C)NC([Y])=C(O[R])C1c1ccccc1[X]</smiles>

DHP Drug<smiles>CC1=C(C(=O)OC(C)C)C(c2cccc([N+](=O)[O-])c2)C(C(=O)OC2CN(C(c3ccccc3)c3ccccc3)C2)=C(N)N1</smiles>

Azelnidipine<smiles>CC(=O)C1=C(C#N)NC(C)=C(C(=O)OC(C)C)C1c1cccc([N+](=O)[O-])c1</smiles>

Nilvadil

Nilvadipine<smiles>COCCOC(=O)C1=C(C)NC(C)=C(C(=O)OC/C=C/c2ccccc2)C1c1cccc([N+](=O)[O-])c1</smiles>

Atelec, Cinalong, Siscard $3-\mathrm{NO}_{2}$

\section{Cilnidipine}<smiles>CC1=C(C(=O)OCCN(Cc2ccccc2)c2ccccc2)C(c2cccc([N+](=O)[O-])c2)C(P2(=O)OCC(C)(C)CO2)=C(C)N1</smiles>

$3-\mathrm{NO}_{2}$

$-\mathrm{CHMe}_{2}$

$-\mathrm{Me}$<smiles>CC1CN(Cc2ccccc2)C1</smiles>

$-\mathrm{CHMe}_{2}$

$\mathrm{R}^{2}$

$\mathrm{NH}_{2}$

$3-\mathrm{NO}_{2}$

(

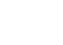

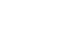

Efonidipine<smiles>CC(=O)COC(=O)C1=C(C)NC(C)=C(C(C)=O)C1c1ccccc1[N+](=O)[O-]</smiles>

Sapresta

2- $\mathrm{NO}_{2}$

$-\mathrm{Me}$

$-\mathrm{CH}_{2} \mathrm{COCH}_{3}$

Me

Aranidipine<smiles>CCOC(=O)C1=C(C)NC(C)=C(C(OCC)OCC)C1c1ccccc1/C=C/C(=O)OC</smiles>

Motens, Lacipil

Lacidipine<smiles>CCOC1=C(COCCN)NC(C)=C(C(C)=O)C1c1ccccc1Cl</smiles>

Norvasc, Amlodin

2-Cl

2- $\mathrm{CH}=$

$\mathrm{CHCOOCMe}_{3}$

- Et

- Et

$\mathrm{Me}$

Amlodipine 
<smiles></smiles>

DHP Drug Brand name $\mathrm{X}$ $\mathrm{R}^{1}$ $\mathrm{R}^{2}$ $\mathrm{Y}$<smiles>CCCC(=O)OCOC(=O)C1=C(C)NC(C)=C(C(C)=O)[C@H]1c1cccc(Cl)c1Cl</smiles>
2,3-Di-Cl $-\mathrm{Me}$ $-\mathrm{CH}_{2} \mathrm{OCO} n \mathrm{Pr}$ $\mathrm{Me}$ Clevidipine

The third generation drugs exhibit more stable pharmacokinetics than the second-generation. These are less cardioselective and, hence well tolerated in patients with heart failure. ${ }^{125}$ Now second and third generation 1,4-DHPs are being explored for the treatment of hypertension, angina, hypertrophic cardiomyopathy, ${ }^{126}$ post-hemorrhagic cerebral vasospasm $^{127}$ and pulmonary hypertension, Raynaud's phenomenon. ${ }^{128}$

\section{Conclusion}

Dihydropyridine (DHP) scaffold has certainly revolutionalised the pharmaceutical research with its unprecedented biological properties. We have reviewed various methods for the synthesis of 1,2- and 1,4-dihydropyridine including the strategies which can furnish enantiopure DHPs, either by asymmetric synthesis or by chiral resolution. DHPs accept wide range of reactions that has triggered the synthesis of different class of compounds of great medicinal value, including natural products. Alkaloids deplancheine, tangutorine, dihydroakummicine, olivacine, $( \pm)$-guatambuine, L-pipecolic acid, $( \pm)$-geissoschizine, $( \pm)$-akagerine, lyaline, lyadine, harman-dihydropyrimidine, camptothecin, 20-deoxycamptothecin, akuammiline alkaloids precursor, silicine-methuenine alkaloids, vinoxine, $( \pm)-2,7-$ dihydropleiocarpamine, tubifoline \& tubifolidine, ervitsine and several other alkaloids have been synthesized following two simple reaction methodologies of DHPs. First, both 1,2 and 1,4dihydropyridines give 1,3-dipolar addition reaction and readily undergo $[2+2]$ cycloaddition reactions with dienophiles. Second, reaction of enamine functional group in dihydropyridines with electrophile $\left(\mathrm{x}^{+}\right)$to form iminium salt, which undergoes $\alpha$-attack of nucleophiles in a regio- and stereoselective manner (non-biomimetic oxidation) to give substituted tetrahydropyridine derivatives.

We have collated vast amount of literature regarding the strategies for the synthesis of DHPs. However, the continuously growing field of DHPs demands more diversity, tethering/ merging of new moieties with DHP scaffold. Therefore this is still a vibrant and challenging area for medicinal chemists to explore new synthetic methodologies or sync different methodologies together to develop new DHP-drugs. Many DHPbased drugs have been blockbuster of their time; therefore, we have also highlighted commercial value of previously approved DHP-based drugs in brief.

\section{Acknowledgements}

One of the author SKS thank University Grants Commission (UGC), India for providing the UGC startup Grant, No. F.30-109/ 2015, FD Diary No. 7235.

\section{References}

1 Q. Huang, Y. Li, C. Sheng, Y. Dou, M. Zheng, Z. Zhu and J. Wang, J. Hypertens., 2015, 33(1), e94.

2 H. Nakano, K. Osone, M. Takeshita, E. Kwon, C. Seki, H. Matsuyama, N. Takano and Y. Kohari, Chem. Commun., 2010, 46, 4827-4829.

3 (a) S. K. Singh and V. K. Sharma, Curr. Org. Chem., 2014, 18, 1159-1207; (b) R. Lavilla, J. Chem. Soc., Perkin Trans. 1, 2002, 1141-1156; (c) U. Eisner and J. Kuthan, Chem. Rev., 1972, 72, 1-43; (d) D. M. Stout and A. I. Meyers, Chem. Rev., 1982, 82, 223-243; (e) E. M. P. Silva, P. A. M. M. Varandas and A. M. S. Silva, Synthesis, 2013, 45, 3053-3089.

4 F. W. Fowler, J. Org. Chem., 1972, 37, 1321-1323.

5 (a) C. A. Bear, W. R. Cullen, J. P. Kutney, V. E. Ridaura, J. Trotter and A. Zanarotti, J. Am. Chem. Soc., 1973, 95, 3058-3060; (b) J. P. Kutney, R. Greenhouse and V. E. Riduara, J. Am. Chem. Soc., 1974, 96, 7364-7365.

6 P. Beeken, J. N. Bonfiglio, I. Hasan, J. J. Piwinski, B. Weinstein, K. A. Zoo and F. W. Fowler, J. Am. Chem. Soc., 1979, 101, 6677-6682. 
7 (a) Y.-S. Cheng, A. Lupo and F. W. Fowler, J. Am. Chem. Soc., 1983, 105, 7696-7703; (b) M. J. Wyle and F. W. Fowler, J. Org. Chem., 1984, 49, 4025-4029.

8 D. L. Comins, H. Hong and J. M. Salvador, J. Org. Chem., 1991, 56, 7197-7199.

9 T. J. Donohoe, A. J. McRiner and P. Sheldrake, Org. Lett., 2000, 2, 3861-3863.

10 (a) F. Palacios, C. Alonso, G. Rubiales and J. M. Ezpeleta, Eur. J. Org. Chem., 2001, 2115-2122; (b) F. Palacios, E. Herrán and G. Rubiales, J. Org. Chem., 1999, 64, 62396246.

11 (a) H. M. Sklenicka, R. P. Hsung, L.-L. Wei, M. J. McLaughlin, A. I. Gerasyuto and S. J. Degen, Org. Lett., 2000, 2, 1161-1164; (b) L.-L. Wei, R. P. Hsung, H. M. Sklenicka and A. I. Gerasyuto, Angew. Chem., Int. Ed., 2001, 40, 1516-1518; (c) J. K. F. Geirsson and J. F. Johannesdottir, J. Org. Chem., 1996, 61, 7320-7325.

12 T.-P. Loh, P.-L. Lye, R.-B. Wang and K.-Y. Sim, Tetrahedron Lett., 2000, 41, 7779-7783.

13 B. Brunner, N. Stogaitis and M. Lautens, Org. Lett., 2006, 8, 3473-3476.

14 M. Motamed, E. M. Bunnelle, S. W. Singaram and R. Sarpong, Org. Lett., 2007, 9, 2167-2170.

15 D. M. Hodgson, M. L. Jones, C. R. Maxwell, A. R. Cowely, A. L. Thompson, O. Ichihara and I. R. Matthews, Tetrahedron, 2009, 65, 7825-7836.

16 J.-P. Wan, S.-F. Gan, G.-L. Sun and Y.-J. Pan, J. Org. Chem., 2009, 74, 2862-2865.

17 I. Yavari, M. J. Bayat, M. Sirouspour and S. Souri, Tetrahedron, 2010, 66, 7995-7999.

18 J. T. Binder and S. F. Kirsch, Org. Lett., 2006, 8, 2151-2153. 19 D. Tejedor, G. Méndez-Abt and F. García-Tellado, Chem.Eur. J., 2010, 16, 428-431.

20 H. Wei, Y. Wang, B. Yue and P.-F. Xu, Adv. Synth. Catal., 2010, 352, 2450-2454.

21 T. Harschneck and S. F. Kirsch, J. Org. Chem., 2011, 76, 2145-2156.

22 T. Shono, Y. Matsumara, O. Onomura and Y. Yamada, Tetrahedron Lett., 1987, 28, 4073-4074.

23 (a) D. Tejedor, L. Cotos, G. Méndez-Abt and F. GarcíaTellado, J. Org. Chem., 2014, 79, 10655-10661; (b) D. Tejedor, M. C. Prieto-Ramírez, M. Ingold, M. Chicón and F. García-Tellado, Org. Lett., 2016, 18, 2770-2773.

24 C. Challa, M. John and R. S. Lankalapalli, Tetrahedron Lett., 2013, 54, 3810-3812.

25 B. J. Fallon, J. B. Garsi, E. Derat, M. Amatore, C. Aubert and M. Petit, ACS Catal., 2015, 5, 7493-7497.

26 (a) A. Hantzsch, Ber. Dtsch. Chem. Ges., 1881, 14, 1637-1638; (b) A. Hantzsch, Justus Liebigs Ann. Chem., 1882, 1, 215-219.

27 M.-L. Bennasar, R. Lavilla, M. Alvarez and J. Bosch, Heterocycles, 1988, 27, 789-824.

28 F. Kröhnke, Angew. Chem., 1953, 65, 605-628.

29 F. Kröhnke, K. Ellgast and E. Bertram, Liebigs Ann. Chem., 1956, 600, 176-210.

30 H. Ahlbrecht and F. Kröhnke, Liebigs Ann. Chem., 1967, 704, 133-139.
31 D. Mauzerall and F. H. Westheimer, J. Am. Chem. Soc., 1955, 77, 2261-2264.

32 R. F. Hutton and F. H. Westheimer, Tetrahedron, 1958, 3, 73-77.

33 H. Minato, S. Fujie, K. Okuma and M. Kobayashi, Chem. Lett., 1977, 1091-1094.

34 (a) D. L. Comins and A. H. Abdullah, J. Org. Chem., 1982, 47, 4315-4319; (b) D. L. Comins and N. B. Mantlo, J. Heterocycl. Chem., 1983, 20, 1239-1243; (c) D. L. Comins, A. H. Abdullah and R. K. Smith, Tetrahedron Lett., 1983, 24, 2711-2714; (d) D. L. Comins, Tetrahedron Lett., 1983, 24, 2807-2810; (e) D. L. Comins and N. B. Mantlo, Tetrahedron Lett., 1983, 24, 3683-3686; (f) D. L. Comins, E. D. Stroud and J. J. Herrick, Heterocycles, 1984, 22, 151-157.

35 R. Yamaguchi, Y. Nakazono and M. Kawanisi, Tetrahedron Lett., 1983, 24, 1801-1804.

36 (a) E. Piers and M. Soucy, Can. J. Chem., 1974, 52, 35633564; (b) K. Akiba, Y. Iseki and M. Wada, Tetrahedron Lett., 1982, 23, 429-432; (c) D. D. Weller, G. R. Luellen and D. L. Weller, J. Org. Chem., 1983, 48, 3061-3067; (d) D. D. Weller, E. P. Stirchak and D. L. Weller, J. Org. Chem., 1983, 48, 4597-4605.

37 G. W. J. Fleet, C. J. Fuller and P. J. C. Harding, Tetrahedron Lett., 1978, 19, 1437-1440.

38 (a) J. C. Bommer and K. W. Morse, J. Chem. Soc., Chem. Commun., 1977, 137-138; (b) J. C. Bommer and K. W. Morse, Inorg. Chem., 1980, 19, 587-593.

39 M. F. Semmelhack, R. D. Stauffer and A. Yamashita, J. Org. Chem., 1977, 42, 3180-3188.

40 D. L. Comins and A. H. Abdullah, J. Org. Chem., 1984, 49, 3392-3394.

41 A. I. De Lucas, J. Fernández-Gadea, N. Martín and C. Seoane, Tetrahedron, 2001, 57, 5591-5595.

42 M.-L. Bennasar, T. Roca, M. Monerris, C. Juan and J. Bosch, Tetrahedron, 2002, 58, 8099-8106.

43 S. Ko, M. N. V. Sastry, C. Lin and C.-F. Yao, Tetrahedron Lett., 2005, 46, 5771-5774.

44 J.-C. Legeay, J. J. V. Eynde and J. P. Bazureaua, Tetrahedron, 2005, 61, 12386-12397.

45 J. H. Lee, Tetrahedron Lett., 2005, 46, 7329-7330.

46 M. Meheswara, V. Siddaiah, Y. K. Rao, Y.-M. Tzeng and C. Sridhar, J. Mol. Catal. A: Chem., 2006, 260, 179-180.

47 J. Bräckow and K. T. Wanner, Tetrahedron, 2006, 62, 23952404.

48 G. Babu and P. T. Perumal, Aldrichimica Acta, 2000, 33, 1622.

49 (a) R. Nagarajan, S. Chitra and P. T. Perumal, Tetrahedron, 2001, 57, 3419-3423; (b) M. Anniyappan, D. Muralidharan and P. T. Perumal, Tetrahedron Lett., 2003, 44, 3653-3657.

50 R. S. Kumar, R. Nagarajan and P. T. Perumal, Synthesis, 2004, 949-959.

51 V. Sridharan, P. T. Perumal, C. Avendano and J. C. Menendez, Tetrahedron, 2007, 63, 4407-4413.

52 J. Moreau, A. Duboc, C. Hubert, J.-P. Hurvois and J.-L. Renaud, Tetrahedron Lett., 2007, 48, 8647-8650.

53 F. Palacios, E. Herrán, C. Alonso and G. Rubiales, ARKIVOC, 2007, iv, 397-407. 
54 S. Kikuchi, M. Iwai, H. Murayama and S. Fukuzawa, Tetrahedron Lett., 2008, 49, 114-116.

55 S.-X. Wang, Z. Y. Li, J.-C. Zhang and J.-T. Li, Ultrason. Sonochem., 2008, 15, 677-680.

56 A. M. Zonouz and S. B. Hosseini, Synth. Commun., 2008, 38, 290-296.

57 M. Sharma, N. Aggarwal and D. S. Rawat, J. Heterocycl. Chem., 2008, 45, 737-739.

58 A. Heydari, S. Khaksar, M. Tajbakhsh and H. R. Bijanzadeh, J. Fluorine Chem., 2009, 130, 609-614.

59 C. A. Sperger and K. T. Wanner, Tetrahedron, 2009, 65, 5824-5833.

60 E. Rafiee, S. Eavani, S. Rashidzadeh and M. Joshaghani, Inorg. Chim. Acta, 2009, 362, 3555-3562.

61 A. Debache, W. Ghalem, R. Boulcina, A. Belfaitah, S. Rhouati and B. Carboni, Tetrahedron Lett., 2009, 50, 5248-5250.

62 G. Sabitha, K. Arundhathi, K. Sudhakar, B. S. Sastry and J. S. Yadav, Synth. Commun., 2009, 39, 2843-2851.

63 T. Sirijindalert, K. Hansuthirakul, P. Rashatasakhon, M. Sukwattanasinitt and A. Ajavakom, Tetrahedron, 2010, 66, 5161-5167.

64 J. Yang, C. Wang, X. Xie, H. Li and Y. Li, Eur. J. Org. Chem., 2010, 4189-4193.

65 F. Tamaddon, Z. Razmi and A. A. Jafari, Tetrahedron Lett., 2010, 51, 1187-1189.

66 S. Sueki, R. Takei, J. Abe and I. Shimizu, Tetrahedron Lett., 2011, 52, 4473-4477.

67 X. Wang, H. Gong, Z. Quan, L. Li and H. Ye, Synth. Commun., 2011, 41, 3251-3258.

68 T. Shibanuma, M. Iwanani, K. Okuda, T. Takenaka and M. Murakami, Chem. Pharm. Bull., 1980, 28, 2809-2812.

69 T. Tamazawa, H. Arima, T. Kojima, Y. Isomura, M. Okada, S. Fujita, T. Furuya, T. Takenaka, O. Inagaki and M. Terai, J. Med. Chem., 1986, 29, 2504-2511.

70 B.-L. Zhang, W. He, X. Shi, M.-L. Huan, Q.-J. Huang and S.-Y. Zhou, Bioorg. Med. Chem. Lett., 2010, 20, 805-808.

71 J. W. Young, US Pat., 2002, vol. 6, 448), pp. $275 \mathrm{~B} 2$.

72 S. Goldmann, J. Stolefuss and L. Born, J. Med. Chem., 1992, 35, 3341-3344.

73 (a) Z. Xitian, US Pat., 2003, vol. 6, 646), p. 131; (b) R. Joshi and M. Gurjar, US Pat., 2005, vol. 7, 148), p. 358; (c) P. Spargo, US Pat., 2000, vol. 6, 046), p. 338.

74 D. M. Gotrane, R. D. Deshmukh, P. V. Ranade, S. P. Sonawane, B. M. Bhawal, M. M. Gharpure and M. K. Gurjar, Org. Process Res. Dev., 2010, 14, 640-643.

75 M. D. Taylor, R. J. Himmelsbach, B. E. Kornberg, J. Quin, E. Lunney and A. Michel, J. Org. Chem., 1989, 54, 55855590.

76 J. E. Arrowsmith, S. F. Campbell, P. E. Cross, J. K. Stubbs, R. A. Burges, D. G. Gardiner and K. J. Blackburn, J. Med. Chem., 1986, 29, 1696-1702.

77 B. Lamm, R. Simonsson and S. Sundell, Tetrahedron Lett., 1989, 30, 6423-6426.

78 D. Vo, W. C. Matowe, M. Ramesh, N. Iqbal, M. W. Wolowyk, S. E. Howlett and E. E. Knaus, J. Med. Chem., 1995, 38, 28512859.
79 R. Shan, S. E. Howlett and E. E. Knaus, J. Med. Chem., 2002, 45, 955-961.

80 R. Shan and E. E. Knaus, Bioorg. Med. Chem. Lett., 1999, 9, 2613-2614.

81 J. Jiang, A.-H. Li, S.-Y. Jang, L. Chang, N. Melman, S. Moro, X. Ji, E. B. Lobkovsky, J. C. Clardy and K. A. Jacobson, J. Med. Chem., 1999, 42, 3055-3065.

82 N. Martín, A. Martinez-Grau, C. Seoane, J. L. Marco, A. Albert and F. H. Cano, Tetrahedron: Asymmetry, 1995, 6, $877-880$.

83 J. Jiang, J. Yu, X.-X. Sun, Q.-Q. Rao and L.-Z. Gong, Angew. Chem., Int. Ed., 2008, 47, 2458-2462.

84 T. Yamamoto, S. Ohno, S. Niwa, M. Tokumasu, M. Hagihara, H. Koganei, S. Fujita, T. Takeda, Y. Saitou, S. Iwayama, A. Takahara, S. Iwata and M. Shoji, Bioorg. Med. Chem. Lett., 2011, 21, 3317-3319.

85 J. P. Kutney, M. Noda, N. G. Lewis, B. Monteiro, D. Mostowicz and B. R. Worth, Can. J. Chem., 1982, 60, 2426-2430.

86 D. L. Comins and Y. C. Myoung, J. Org. Chem., 1990, 55, 292-298.

87 A. B. Charette, M. Grenon, A. Lemire, M. Pourashraf and J. Martel, J. Am. Chem. Soc., 2001, 123, 11829-11830.

88 A. Lemire, M. Grenon, M. Pourashraf and A. B. Charette, Org. Lett., 2004, 6, 3517-3520.

89 R. Abou-Jneid, S. Ghoulami, M.-T. Martin, E. T. H. Dau, N. Travert and A. Al-Mourabit, Org. Lett., 2004, 6, 39333936.

90 A. Lemire and A. B. Charette, Org. Lett., 2005, 7, 2747-2750. 91 C. Schroif-Gregoire, N. Travert, A. Zaparucha and A. AlMourabit, Org. Lett., 2006, 8, 2961-2964.

92 A. Lemire and A. B. Charette, J. Org. Chem., 2010, 75, 20772080.

93 E. Wenkert, T. D. J. Halls, G. Kunesch, K. Orito, R. L. Stephens, W. A. Temple and J. S. Yadav, J. Am. Chem. Soc., 1979, 101, 5370-5376.

94 R. Besselievre, B.-P. Cosson, B. C. Das and H.-P. Husson, Tetrahedron Lett., 1980, 21, 63-66.

95 J. Bosch, M.-L. Bennasar, E. Zulaica and M. Feliz, Tetrahedron Lett., 1984, 25, 3119-3122.

96 J. Bosch, M.-L. Bennasar and E. Zulaica, J. Org. Chem., 1986, 51, 2289-2297.

97 M. Alvarez, M. Salas, A. de Veciana, R. Lavilla and J. Bosch, Tetrahedron Lett., 1990, 31, 5089-5091.

98 M.-L. Bennasar, B. Vidal and J. Bosch, J. Am. Chem. Soc., 1993, 115, 5340-5341.

99 M.-L. Bennasar, B. Vidal and J. Bosch, J. Chem. Soc., Chem. Commun., 1995, 125-126.

100 M.-L. Bennasar, E. Zulaica, J.-M. Jiménez and J. Bosch, J. Org. Chem., 1993, 58, 7756-7767.

101 (a) M.-L. Bennasar, B. Vidal and J. Bosch, J. Org. Chem., 1996, 61, 1916-1917; (b) M.-L. Bennasar, B. Vidal and J. Bosch, J. Org. Chem., 1997, 62, 3597-3609.

102 M.-L. Bennasar, B. Vidal, A. Lázaro, R. Kumar and J. Bosch, Tetrahedron Lett., 1996, 37, 3541-3544.

103 M.-L. Bennasar, B. Vidal and J. Bosch, Chem. Commun., 1996, 2755-2756. 
104 D. Zhang, I. Llorente and L. S. Liebesking, J. Org. Chem., 1997, 62, 4330-4338.

105 W. Benson and E. Winterfeldt, Heterocycles, 1981, 15, 935-941. 106 M.-L. Bennasar, B. Vidal, B. A. Sufi and J. Bosch, Chem. Commun., 1998, 2639-2640.

107 M.-L. Bennasar, J.-M. Jimenez, B. Vidal, B. A. Sufi and J. Bosch, J. Org. Chem., 1999, 64, 9605-9612.

108 K. Yamada, K. Aoki, T. Kato, D. Uemura and T. E. E. Van, J. Chem. Soc., Chem. Commun., 1974, 908-909.

109 M.-L. Bennasar, E. Zulaica, C. Juan, Y. Alonso and J. Bosch, J. Org. Chem., 2002, 67, 7465-7474.

110 (a) R. T. Brown, L. Jianli and C. A. M. Santos, Tetrahedron Lett., 2000, 41, 859-862; (b) W. Shen, G. A. Coburn, W. G. Bornmann and S. J. Danishefsky, J. Org. Chem., 1993, 58, 611-617; (c) K. Tagami, N. Nakazawa, S. Sano and Y. Nagao, Heterocycles, 2000, 53, 771-775.

111 T. Putkonen, A. Tolvanen and R. Jokela, Tetrahedron Lett., 2001, 42, 6593-6594.

112 M. Berner, A. Tolvanen and R. Jokela, Tetrahedron Lett., 1999, 40, 7119-7122.

113 M.-L. Bennasar, T. Roca and M. Monernis, J. Org. Chem., 2004, 69, 752-756.

114 M. Amat, M.-D. Coll, N. Llor, C. Escolano, E. Molins, C. Miravitlles and J. Bosch, Tetrahedron: Asymmetry, 2003, 14, 1691-1699.

115 F. Bossert and W. Vater, Med. Res. Rev., 1989, 9, 291-324.
116 F. Bossert and W. Vater, Naturwissenschaften, 1971, 58, 578.

117 (a) H. Nakayama and Y. Kanaoka, Heterocycles, 1996, 42, 901-909; (b) F. Bossert, H. Meyer and E. Wehinger, Angew. Chem., Int. Ed., 1981, 20, 762-769.

118 H. Komoda, T. Inoue and K. Node, Clin. Exp. Hypertens., 2010, 32, 121-128.

119 R. Boer and R. Gekeler, Drugs Future, 1995, 20, 499-509.

120 (a) G. A. Wächter, M. C. Davis, A. R. Martin and S. G. Franzblau, J. Med. Chem., 1998, 41, 2436-2438; (b) B. Desai, D. Sureja, Y. Naliapara, A. Shah and A. K. Saxena, Bioorg. Med. Chem., 2001, 9, 1993-1998.

121 J. M. Tusell, S. Barrón and J. Serratosa, Brain Res., 1993, 622, 99-104.

122 P. Ioan, E. Carosati, M. Micucci, G. Cruciani, F. Broccatelli, B. S. Zhorov, A. Chiarini and R. Budriesi, Curr. Med. Chem., 2011, 18, 4901-4922.

123 F. H. Leenen, Am. J. Hypertens., 1996, 9, 97S-104S.

124 D. D. Freedman and D. D. Waters, Drugs, 1987, 34, 578-598.

125 T. F. Lüscher and F. Cosentino, Drugs, 1998, 55, 509-517.

126 T. Tokushima, T. Utsunomiya, T. Ogawa, K. Kidoh, Y. Ohtsubo, T. Ryu, K. Yoshida, T. Ogata, S. Tsuji and S. Matsuo, Basic Res. Cardiol., 1996, 91, 329-336.

127 D. Tomassoni, A. Lanari, G. Silvestrelli, E. Traini and F. Amenta, Clin. Exp. Hypertens., 2008, 30, 744-766.

128 A. Herrick, Curr. Treat. Options Cardiovasc. Med., 2008, 10, 146-155. 